National Toxicology Program

NTP DEVELOPMENTAL AND

REPRODUCTIVE TOXICITY

TECHNICAL REPORT ON THE

PRENATAL DEVELOPMENT

STUDIES OF

TRIS(CHLOROPROPYL)

PHOSPHATE

(CASRN 13674-84-5) IN

SPRAGUE DAWLEY

(HSD:Sprague Dawley ${ }^{\circledR}$ SD $^{\circledR}$ )

Rats (Gavage Studies)

NTP DART 01

JUNE 2020 


\title{
NTP Developmental and Reproductive Toxicity Technical Report on the Prenatal Development Studies of Tris(chloropropyl) Phosphate (CASRN 13674-84-5) in Sprague Dawley (Hsd:Sprague Dawley ${ }^{\circledR}$ SD $^{\circledR}$ ) Rats (Gavage Studies)
}

DART Report 01

June 2020

\author{
National Toxicology Program \\ Public Health Service \\ U.S. Department of Health and Human Services
}

ISSN: 2690-2052

Research Triangle Park, North Carolina, USA 


\section{Foreword}

The National Toxicology Program (NTP), established in 1978, is an interagency program within the Public Health Service of the U.S. Department of Health and Human Services. Its activities are executed through a partnership of the National Institute for Occupational Safety and Health (part of the Centers for Disease Control and Prevention), the Food and Drug Administration (primarily at the National Center for Toxicological Research), and the National Institute of Environmental Health Sciences (part of the National Institutes of Health), where the program is administratively located. NTP offers a unique venue for the testing, research, and analysis of agents of concern to identify toxic and biological effects, provide information that strengthens the science base, and inform decisions by health regulatory and research agencies to safeguard public health. NTP also works to develop and apply new and improved methods and approaches that advance toxicology and better assess health effects from environmental exposures.

The NTP Technical Report series for developmental and reproductive toxicity studies began in 2019. The studies described in this NTP Technical Report series (i.e., the NTP DART Report series) are designed and conducted to characterize and evaluate the developmental or reproductive toxicity of selected substances in laboratory animals. Substances (e.g., chemicals, physical agents, and mixtures) selected for NTP reproductive and developmental studies are chosen primarily on the basis of human exposure, level of commercial production, and chemical structure. The interpretive conclusions presented in NTP DART Reports are based only on the results of these NTP studies, and extrapolation of these results to other species, including characterization of hazards and risks to humans, requires analyses beyond the intent of these reports. Selection for study per se is not an indicator of a substance's developmental or reproductive toxicity potential.

NTP conducts its studies in compliance with its laboratory health and safety guidelines and the Food and Drug Administration Good Laboratory Practice Regulations and meets or exceeds all applicable federal, state, and local health and safety regulations. Animal care and use are in accordance with the Public Health Service Policy on Humane Care and Use of Laboratory Animals. Studies are subjected to retrospective quality assurance audits before they are presented for public review. Draft reports undergo external peer review before they are finalized and published.

The NTP DART Reports are available free of charge on the NTP website and cataloged in PubMed, a free resource developed and maintained by the National Library of Medicine (part of the National Institutes of Health). Data for these studies are included in NTP's Chemical Effects in Biological Systems database.

For questions about the reports and studies, please email NTP or call 984-287-3211. 


\section{Table of Contents}

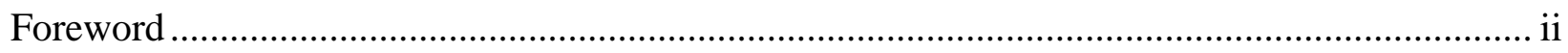

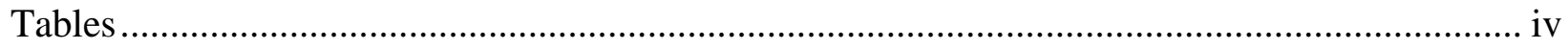

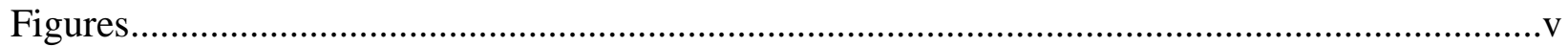

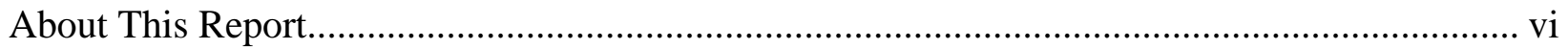

Explanation of Levels of Evidence for Developmental Toxicity ................................................ ix

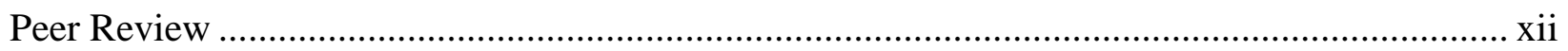

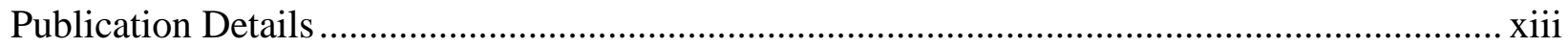

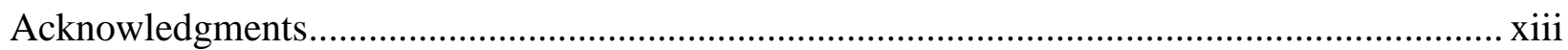

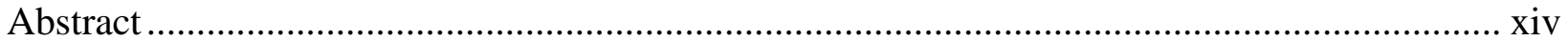

Dose Range-finding Prenatal Developmental Toxicity Study .............................................. xiv

Prenatal Developmental Toxicity Study .......................................................................... xiv

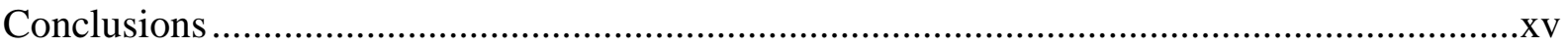

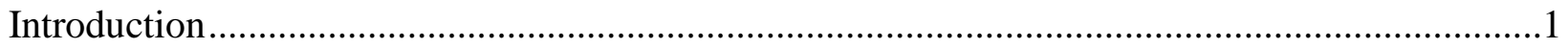

Tris(chloropropyl) Phosphate ............................................................................................1

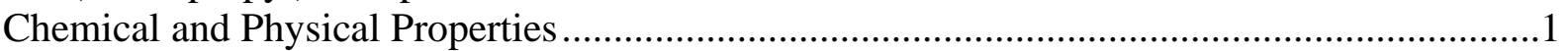

Production, Use, and Human Exposure .................................................................................

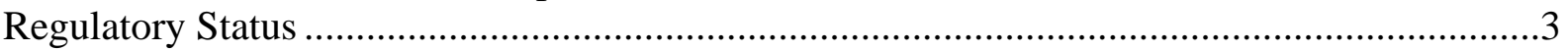

Absorption, Distribution, Metabolism, and Excretion .................................................................

Experimental Animals ………………......................................................................

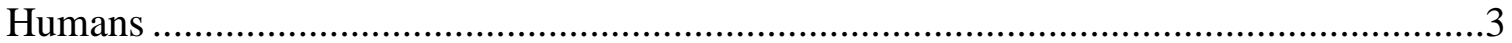

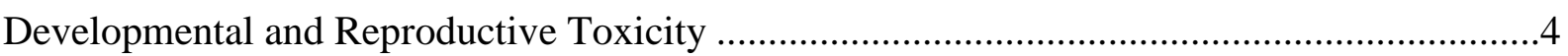

Experimental Animals ……………………………............................................

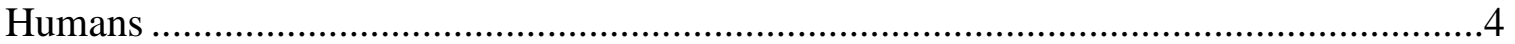

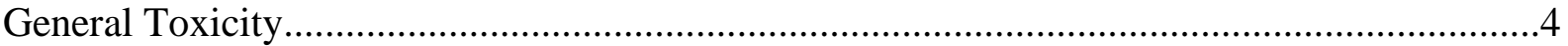

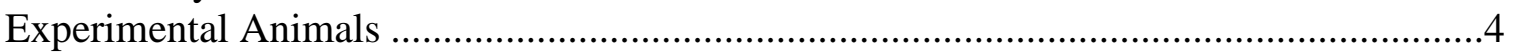

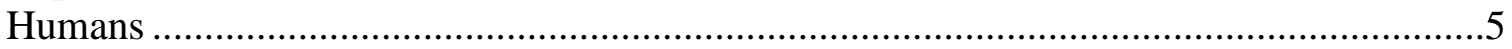

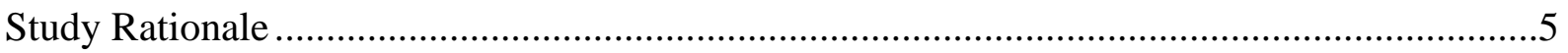

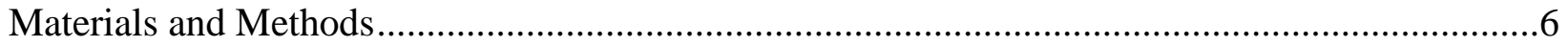

Overview of Prenatal Developmental Toxicity Study Designs ....................................................6

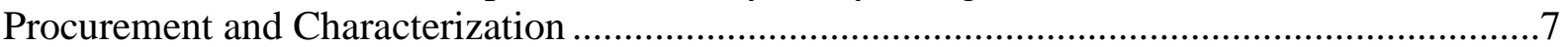

Tris(chloropropyl) Phosphate .......................................................................................

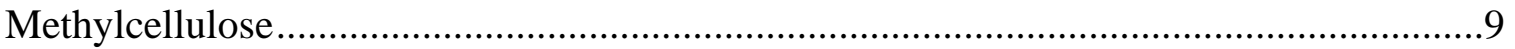

Preparation and Analysis of Dose Formulations................................................................

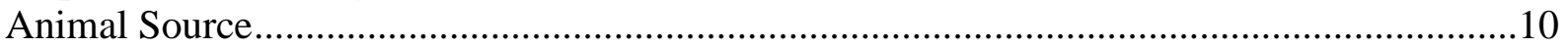

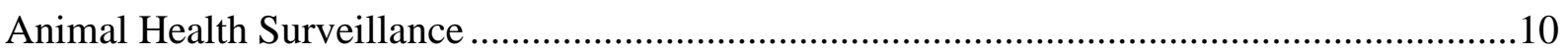

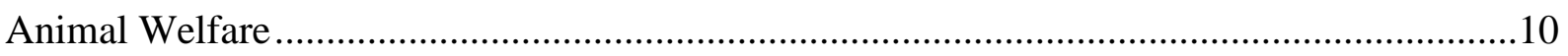

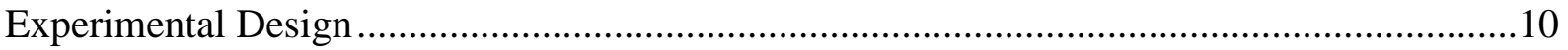

Dose Range-finding Study ............................................................................................11

Prenatal Developmental Toxicity Study ……………....................................................12

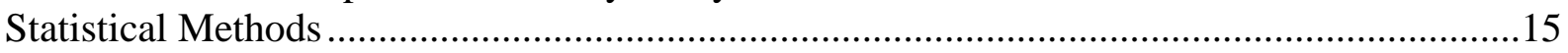




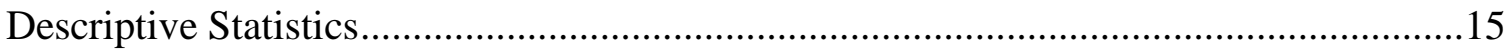

Analysis of Maternal Parameters and Uterine Contents ....................................................15

Analysis of Incidences of Gross Pathology and Morphology Findings .............................16

Historical Control Data .............................................................................................16

Quality Assurance Methods ...............................................................................................16

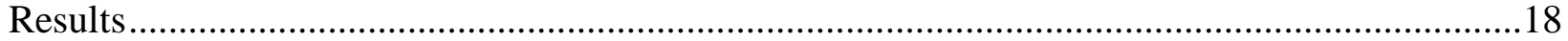

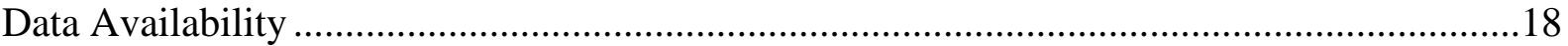

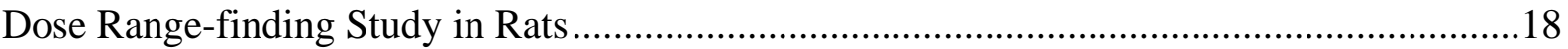

Maternal Findings ...................................................................................................

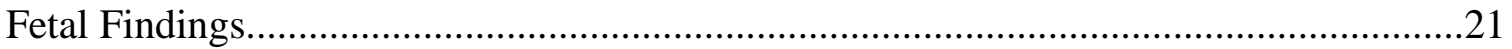

Dose Selection Rationale for the Prenatal Developmental Toxicity Study in Rats...........22

Prenatal Developmental Toxicity Study in Rats ...................................................................22

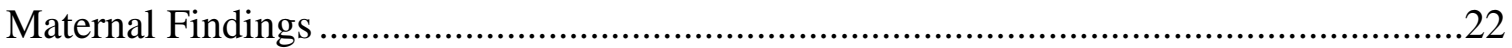

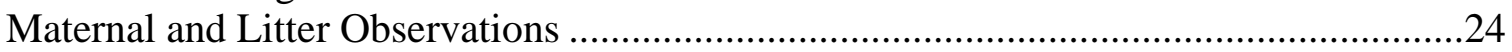

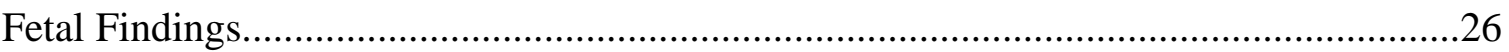

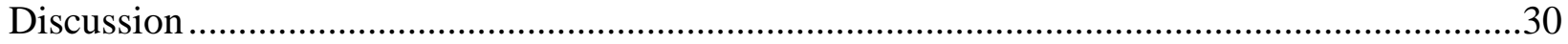

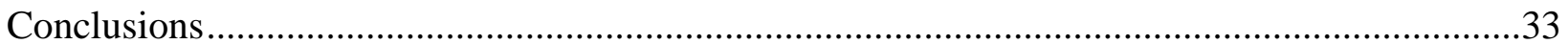

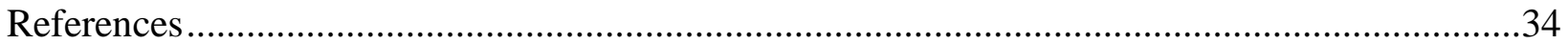

Appendix A. Chemical Characterization and Dose Formulation Studies................................... A-1

Appendix B. Ingredients, Nutrient Composition, and Contaminant Levels in NIH-07 Rat and Mouse Ration..........................................................................................

Appendix C. Sentinel Animal Program ....................................................................................

Appendix D. Summary of Peer Review Panel Comments ....................................................... D-1

Appendix E. Supplemental Files.............................................................................................

\section{Tables}

Summary of Exposure-related Findings in Rats in the Prenatal Developmental Toxicity Gavage Study of Tris(chloropropyl) Phosphate ............................................................. xvi

Table 1. Tris(chloropropyl) Phosphate Isomers in Commercial Products.......................................2

Table 2. Composition of Lots Used in the Prenatal Developmental Toxicity Studies of Tris(chloropropyl) Phosphate in Rats.............................................................................

Table 3. Experimental Design and Materials and Methods in the Dose Range-finding and Prenatal Developmental Toxicity Gavage Studies of Tris(chloropropyl) Phosphate

Table 4. Maternal Disposition of Rats in the Dose Range-finding Gavage Study of Tris(chloropropyl) Phosphate....................................................................................18

Table 5. Summary of Maternal Body Weight Gains of Rats in the Dose Range-finding Gavage Study of Tris(chloropropyl) Phosphate. 19

Table 6. Summary of Maternal Feed Consumption of Rats in the Dose Range-finding Gavage Study of Tris(chloropropyl) Phosphate..... 
Table 7. Summary of Uterine Content Data for Rats in the Dose Range-finding Gavage Study of Tris(chloropropyl) Phosphate.

Table 8. Maternal Disposition of Rats in the Prenatal Developmental Toxicity Gavage Study of Tris(chloropropyl) Phosphate

Table 9. Summary of Maternal Body Weight Gains of Rats in the Prenatal Developmental Toxicity Gavage Study of Tris(chloropropyl) Phosphate

Table 10. Summary of Maternal Feed Consumption of Rats in the Prenatal Developmental Toxicity Gavage Study of Tris(chloropropyl) Phosphate.

Table 11. Summary of Maternal Liver Weights and Liver Weight Ratios for Rats in the Prenatal Developmental Toxicity Gavage Study of Tris(chloropropyl) Phosphate .24

Table 12. Summary of Uterine Content Data for Rats in the Prenatal Developmental Toxicity Gavage Study of Tris(chloropropyl) Phosphate .25

Table 13. Summary of Selected Visceral Fetal Findings in Rats in the Prenatal Developmental Toxicity Gavage Study of Tris(chloropropyl) Phosphate.

Table 14. Summary of Selected Skeletal Fetal Findings in Rats in the Prenatal Developmental Toxicity Gavage Study of Tris(chloropropyl) Phosphate.

\section{Figures}

Figure 1. Design of a Dose Range-finding and Prenatal Developmental Toxicity Study in Rats

Figure 2. Maternal Growth Curves for Pregnant Rats Administered Tris(chloropropyl) Phosphate by Gavage in the Dose Range-finding Study....

Figure 3. Maternal Growth Curves for Pregnant Rats Administered Tris(chloropropyl) Phosphate by Gavage in the Prenatal Developmental Toxicity Study 


\section{About This Report}

National Toxicology Program ${ }^{1}$

${ }^{1}$ Division of the National Toxicology Program, National Institute of Environmental Health

Sciences, Research Triangle Park, North Carolina, USA

\section{Collaborators}

K.R. Ryan, L.J. Betz, C.R. Blystone, B.J. Collins, H.C. Cunny, J.M. Fostel, P.M. Foster, S.F. Harris, M.J. Hooth, A.P. King-Herbert, G.E. Kissling, B.S. McIntyre, C.J. Price, K.A.

Shipkowski, K.R. Shockley, M.V. Smith, M.D. Stout, V.L. Sutherland, K.J. Turner, M.K. Vallant, S. Waidyanatha, N.J. Walker

Division of the National Toxicology Program, National Institute of Environmental Health Sciences, Research Triangle Park, North Carolina, USA

Evaluated and interpreted results and reported findings

K.R. Ryan, Ph.D., Study Scientist

C.R. Blystone, Ph.D.

B.J. Collins, M.S.P.H.

H.C. Cunny, Ph.D.

J.M. Fostel, Ph.D.

P.M. Foster, Ph.D. (Retired)

M.J. Hooth, Ph.D.

A.P. King-Herbert, D.V.M.

G.E. Kissling, Ph.D. (Retired)

B.S. McIntyre, Ph.D.

K.A. Shipkowski, Ph.D.

K.R. Shockley, Ph.D.

M.D. Stout, Ph.D.

V.L. Sutherland, Ph.D.

M.K. Vallant, M.S., MT (Retired)

S. Waidyanatha, Ph.D.

N.J. Walker, Ph.D.

RTI International, Research Triangle Park, North Carolina, USA

Conducted studies and evaluated findings

C.J. Price, Ph.D., Principal Investigator

K.J. Turner, Ph.D., Study Director

Social \& Scientific Systems, Inc., Research Triangle Park, North Carolina, USA

Provided statistical analyses

M.V. Smith, Ph.D., Principal Investigator

L.J. Betz, M.S.

S.F. Harris, B.S. 


\section{Contributors}

Division of the National Toxicology Program, National Institute of Environmental Health Sciences, Research Triangle Park, North Carolina, USA

Provided oversight of report and audit preparation

G. K. Roberts, Ph.D.

M.K. Vallant, M.S., M.T.

Provided oversight of external peer review

E.A. Maull, Ph.D.

M.S. Wolfe, Ph.D.

Vistronix, Research Triangle Park, North Carolina, USA

Prepared data for report

P. Brown, B.S.

H. Gong, M.S.

C. Myers, M.S.

N. Sayers, B.S.

M. Shaw, B.S.

R. Whittlesey, M.S.

MRI Global, Kansas City, Missouri, USA

Conducted pretest chemistry activities and dose formulations

J. Algaier, Ph.D., Principal Investigator

K. Aillon, Ph.D.

L. Seimann, B.S.

CSS Corporation, Research Triangle Park, North Carolina, USA

Prepared quality assessment audits

S. Brecher, Ph.D., Principal Investigator

S. Iyer, B.S.

V.S. Tharakan, D.V.M.

Biotechnical Services, Inc., Little Rock, Arkansas, USA

Prepared draft report

S.R. Gunnels, M.A., Principal Investigator

K.K. Coker, Ph.D.

B.F. Hall, M.S.

L.M. Harper, B.S.

D.C. Serbus, Ph.D. 


\section{ICF, Durham, North Carolina, USA}

Provided contract oversight, edited and formatted report, and supported peer review D.F. Burch, M.E.M., Contract Manager

S.E. Blaine, B.A.

T.W. Cromer, M.P.S.

L.M. Green, M.P.H.

T. Hamilton, M.S.

P. E. Kellar, M.S.

W.K. Mitchell, B.S.

A.A. Murphy, B.S.

B.C. Riley, B.S. 


\section{Explanation of Levels of Evidence for Developmental Toxicity}

The National Toxicology Program (NTP) describes the results of individual studies of chemical agents and other test articles and notes the strength of the evidence for conclusions regarding each study. Generally, each study is confined to a single laboratory animal species, although in some instances, multiple species may be investigated under the purview of a single study report. Negative results, in which the study animals do not exhibit evidence of developmental toxicity, do not necessarily imply that a test article is not a developmental toxicant, but only that the test article is not a developmental toxicant under the specific conditions of the study. Positive results demonstrating that a test article causes developmental toxicity in laboratory animals under the conditions of the study are assumed to be relevant to humans, unless data are available that demonstrate otherwise. In addition, such positive effects should be assumed to be primary effects, unless there is clear evidence that they are secondary consequences of excessive maternal toxicity. Given that developmental events are intertwined in the reproductive process, effects on developmental toxicity may be detected in reproductive studies. Evaluation of such developmental effects should be based on the NTP Criteria for Levels of Evidence for Developmental Toxicity.

It is critical to recognize that the "levels of evidence" statements described herein describe only developmental hazard. The actual determination of risk to humans requires exposure data that are not considered in these summary statements.

Five categories of evidence of developmental toxicity are used to summarize the strength of the evidence observed in each experiment: two categories for positive results (clear evidence and some evidence); one category for uncertain findings (equivocal evidence); one category for no observable effects (no evidence); and one category for experiments that cannot be evaluated because of major design or performance flaws (inadequate study). Application of these criteria requires professional judgment by individuals with ample experience and an understanding of the animal models and study designs employed. For each study, conclusion statements are made using one of the following five categories to describe the findings. These categories refer to the strength of the evidence of the experimental results and not to potency or mechanism.

\section{Levels of Evidence for Evaluating Developmental System Toxicity}

- Clear evidence of developmental toxicity is demonstrated by data that indicate a dose-related effect on one or more of its four elements (embryo-fetal death, structural malformations, growth retardation, or functional deficits) that is not secondary to overt maternal toxicity.

- Some evidence of developmental toxicity is demonstrated by dose-related effects on one or more of its four elements (embryo-fetal death, structural malformations, growth retardation, or functional deficits), but where there are greater uncertainties or weaker relationships with regard to dose, severity, magnitude, incidence, persistence, and/or decreased concordance among affected endpoints.

- Equivocal evidence of developmental toxicity is demonstrated by marginal or discordant effects on developmental parameters that may or may not be related to the test article. 
- No evidence of developmental toxicity is demonstrated by data from a study with appropriate experimental design and conduct that are interpreted as showing no biologically relevant effects on developmental parameters that are related to the test article.

- Inadequate study of developmental toxicity is demonstrated by a study that, because of major design or performance flaws, cannot be used to determine the occurrence of developmental toxicity.

When a conclusion statement for a particular study is selected, consideration must be given to key factors that would support the selection of an individual category of evidence. Such consideration should allow for incorporation of scientific experience and current understanding of developmental toxicity studies in laboratory animals, particularly with respect to interrelationships between endpoints, impact of the change on development, relative sensitivity of endpoints, normal background incidence, and specificity of the effect. For those evaluations that may be on the borderline between two adjacent levels, some factors to consider in selecting the level of evidence of developmental toxicity are given below:

- Increases in severity and/or prevalence (more individuals and/or more affected litters) as a function of dose generally strengthen the level of evidence, keeping in mind that the specific manifestation may be different with increasing dose. For example, malformations may be observed at a lower dose level, but higher doses may produce embryo-fetal death.

- Effects seen in many litters may provide stronger evidence than effects confined to one or a few litters, even if the incidence within those litters is high.

- Because of the complex relationship between maternal physiology and development, evidence for developmental toxicity may be greater for a selective effect on the embryo-fetus or pup.

- Concordant effects (syndromic) may strengthen the evidence of developmental toxicity. Single endpoint changes by themselves may be weaker indicators of effect than concordant effects on multiple endpoints related by a common process or mechanism.

- In order to be assigned a level of "clear evidence” the endpoint(s) evaluated should normally show a statistical increase in the deficit, or syndrome, on a litter basis.

- In general, the more animals affected, the stronger the evidence; however, effects in a small number of animals across multiple, related endpoints should not be discounted, even in the absence of statistical significance for the individual endpoint(s). In addition, rare malformations with low incidence, when interpreted in the context of historical controls, may be biologically important.

- Consistency of effects across generations in a multigenerational study may strengthen the level of evidence. However, if effects are observed in the $\mathrm{F}_{1}$ generation but not in the $F_{2}$ generation (or the effects occur at a lesser frequency in the $F_{2}$ generation), this may be due to survivor selection for resistance to the effect (i.e., if the effect is incompatible with successful reproduction, then the affected individuals will not produce offspring). 
- Transient changes (e.g., pup weight decrements, reduced ossification in fetuses) by themselves may be weaker indicators of an effect than persistent changes.

- Uncertainty about the occurrence of developmental toxicity in one study may be lessened by effects (even if not identical) that are observed in a second species.

- Insights from supportive studies (e.g., toxicokinetics, ADME, computational models, structure-activity relationships) and developmental findings from other in vivo animal studies (NTP or otherwise) should be drawn upon when interpreting the biological plausibility of an effect.

- New assays and techniques need to be appropriately characterized to build confidence in their utility: their usefulness as indicators of effect is increased if they can be associated with changes in traditional endpoints.

For more information visit: http://ntp.niehs.nih.gov/go/10003. 


\section{Peer Review}

An external ad hoc panel was convened at the National Institute of Environmental Health Sciences, Research Triangle Park, NC on July 31, 2019, to peer review the draft NTP Developmental and Reproductive Toxicity Technical Report on the Prenatal Development Studies of Tris(chloropropyl) Phosphate (CASRN 13674-84-5) in Sprague Dawley (Hsd:Sprague Dawley ${ }^{\circledR} S D^{\circledR}$ ) Rats (Gavage Studies). The public could view the proceedings via webcast and there was opportunity for presentation of oral public comment. The selection of panel members and conduct of the peer review were in accordance with Federal policies and regulations. The panel was charged to:

1. Review and evaluate the scientific and technical elements of each study and its presentation.

2. Determine whether each study's experimental design, conduct, and findings support the NTP's conclusion regarding the prenatal developmental toxicity of the substance tested.

NTP carefully considered the panel's recommendations in finalizing the technical report. The peer review report is provided in Appendix D. Other meeting materials are available on the NTP website (https://ntp.niehs.nih.gov/go/meeting).

\section{Peer Reviewers}

George Daston, Ph.D., Chairperson

The Procter and Gamble Company

Cincinnati, Ohio, USA

\section{Cheryl Broussard, Ph.D.}

Centers for Disease Control and Prevention

Atlanta, Georgia, USA

Alan Hoberman, Ph.D.

Charles River Laboratories Preclinical Services

Horsham, Pennsylvania, USA

Linda Roberts, Ph.D.

NapaTox Consulting LLC

San Francisco, California, USA

Mary Alice Smith, Ph.D.

University of Georgia

Athens, Georgia, USA

Kimberley Treinen, Ph.D.

Sunovion Pharmaceuticals Inc.

Marlborough, Massachusetts, USA 


\section{Publication Details}

Publisher: National Toxicology Program

Publishing Location: Research Triangle Park, NC

ISSN: 2690-2052

DOI: https://doi.org/10.22427/NTP-DART-01

Report Series: NTP Developmental and Reproductive Toxicity Report Series

Report Series Number: 01

Official citation: National Toxicology Program (NTP). 2020. NTP developmental and reproductive toxicity technical report on the prenatal development studies of tris(chloropropyl) phosphate (CASRN 13674-84-5) in Sprague Dawley (Hsd:Sprague Dawley ${ }^{\circledR}$ SD $^{\circledR}$ ) rats (gavage studies). Research Triangle Park, NC: National Toxicology Program. DART Report 01.

\section{Acknowledgments}

This work was supported by the Intramural Research Program (ES103316, ES103318, and ES103319) at the National Institute of Environmental Health Sciences, National Institutes of Health and performed for the National Toxicology Program, Public Health Service, U.S. Department of Health and Human Services under contracts HHSN273201800006C, HHSN273201400020C, HHSN273201600020C, HHSN273201300009C, HHSN316201200054W, N01ES25500, HHSN273201100001C, HHSN291200555552, and HHSN273201300004C. 


\section{Abstract}

Tris(chloropropyl) phosphate (TCPP) is used as a flame retardant in textiles, furniture (flexible polyurethane foam), and other related products. In addition, it is manufactured for use in construction materials (rigid polyurethane foam), electronic products, paints, coatings, and adhesives. Several flame retardants have been removed from products in commerce because of toxicity concerns, and TCPP has been considered as a replacement flame retardant for use in these products. Because of concerns for increased use, and thus increased human exposure, the Consumer Product Safety Commission nominated TCPP for toxicological testing by the National Toxicology Program. Additional information on the evaluation of the potential toxicity of TCPP is available at the Program's website (http://ntp.niehs.nih.gov/testing/status/agents/tsm20263.html). The purpose of this report is to summarize and discuss TCPP effects on prenatal development. In these studies, time-mated female Sprague Dawley (Hsd:Sprague Dawley ${ }^{\circledR} \mathrm{SD}^{\circledR}$ ) rats received TCPP (95.7-97\% pure) in 0.5\% methylcellulose by gavage from implantation on gestation day (GD) 6 to the day before expected parturition (GD 20). Evidence of TCPP-related maternal and fetal toxicity was examined in the dose range-finding study followed by the standard prenatal developmental toxicity study.

\section{Dose Range-finding Prenatal Developmental Toxicity Study}

Groups of 11 time-mated female rats were administered 0, 300, 650, or 1,000 mg TCPP/kg body weight per day (mg/kg/day) in 0.5\% aqueous methylcellulose by gavage from GD 6 to GD 20 . Vehicle control $(0 \mathrm{mg} / \mathrm{kg}$ ) animals received aqueous methylcellulose.

Maternal toxicity was observed in the $1,000 \mathrm{mg} / \mathrm{kg}$ group as evidenced by 7 of 11 dams being either found dead or euthanized moribund. Associated clinical observations in the $1,000 \mathrm{mg} / \mathrm{kg}$ group included convulsion, tremors, prone, gasping, hypoactivity, hunched posture, nasal discharge, stained fur, piloerection, salivation, and rooting (pre- and postdosing), which occurred throughout gestation. One female in the $650 \mathrm{mg} / \mathrm{kg}$ group was euthanized moribund on GD 16 with associated clinical observations including cold to touch, hypoactivity, paleness, ataxia, and labored breathing, which may have been related to TCPP exposure. All vehicle control and $300 \mathrm{mg} / \mathrm{kg}$ animals survived to study termination. No TCPP-related effects were found on maternal body weights, body weight gain, or feed consumption from GD 6 to GD 20 . Additionally, there were no significant exposure-related effects on postimplantation loss, fetal body weights, or fetal sex ratio, although limited litters were available for assessment in the $1,000 \mathrm{mg} / \mathrm{kg}$ TCPP group because of maternal toxicity. Finally, there were no significant exposure-related external fetal findings (including examination of the palate).

\section{Prenatal Developmental Toxicity Study}

Because of the maternal toxicity observed at $1,000 \mathrm{mg} / \mathrm{kg}$ in the dose ranging-finding study, groups of 25 time-mated female rats were administered $0(n=50), 162.5,325$, or $650 \mathrm{mg}$ TCPP $/ \mathrm{kg} /$ body weight per day in $0.5 \%$ aqueous methylcellulose by gavage from GD 6 to GD 20 . Vehicle control $(0 \mathrm{~m} / \mathrm{kg})$ animals received aqueous methylcellulose. Animals were added to the vehicle control group to obtain historical control data for both maternal and fetal findings in this strain of rat. In this study, TCPP was well tolerated and no exposure-related effects occurred on mortality, maternal body weights, body weight gains, or feed consumption during gestation. Low incidences of clinical observations including nasal discharge, salivation, twitches, ataxia, piloerection, audible respiratory sounds, and hyperactivity were observed in the $650 \mathrm{mg} / \mathrm{kg}$ group. Adverse clinical observations were not observed in other groups exposed to TCPP. There 
were no notable placental or other maternal gross observations at necropsy except for doserelated increases in absolute (9\%, 16\%, and $26 \%$ at $162.5,325$, and $650 \mathrm{mg} / \mathrm{kg}$, respectively) and relative liver weights.

No significant effects of TCPP were observed on postimplantation loss, mean fetal body weights, or fetal sex ratio. Likewise, no biologically relevant exposure-related malformations were found in external, visceral, and skeletal fetal exams of groups exposed to TCPP.

\section{Conclusions}

Under the conditions of the prenatal study, no evidence of developmental toxicity ${ }^{\dagger}$ of TCPP was found in Hsd:Sprague Dawley ${ }^{\circledR} \mathrm{SD}^{\circledR}$ rats administered 162.5, 325, or $650 \mathrm{mg} / \mathrm{kg}$ in the absence of overt maternal toxicity.

Trade names: Amgard TMCP, Antiblaze 80, Antiblaze TMCP, Fyrol PCF

${ }^{\dagger}$ See Explanation of Levels of Evidence for Developmental Toxicity. 
Summary of Exposure-related Findings in Rats in the Prenatal Developmental Toxicity Gavage Study of Tris(chloropropyl) Phosphate

\begin{tabular}{|c|c|c|c|c|}
\hline & $0 \mathrm{mg} / \mathrm{kg}^{\mathrm{a}}$ & $162.5 \mathrm{mg} / \mathrm{kg}$ & $325 \mathrm{mg} / \mathrm{kg}$ & $650 \mathrm{mg} / \mathrm{kg}$ \\
\hline \multicolumn{5}{|l|}{ Maternal Parameters } \\
\hline Animals on Study & 50 & 25 & 25 & 25 \\
\hline Number Pregnant & 44 & 21 & 21 & 20 \\
\hline Number Died or Euthanized Moribund & 0 & 0 & 0 & 0 \\
\hline Clinical Observations & None & None & None & $\begin{array}{l}\text { Ataxia, audible } \\
\text { respiratory sounds, } \\
\text { hyperactivity, nasal } \\
\text { discharge, piloerection, } \\
\text { salivation, and twitches }\end{array}$ \\
\hline
\end{tabular}

\section{Body Weight and Feed Consumption ${ }^{\mathrm{b}}$}

Necropsy Body Weight

Body Weight Change GD 6 to 21

Feed Consumption GD 6 to 21

\section{Necropsy Observations}

Organ Weights

\section{Developmental/Fetal Parameters}

Number of Litters Examined

Number of Live Fetuses Evaluated

Number of Live Fetuses per Litter ${ }^{\mathrm{C}}$

Number of Early Resorptions ${ }^{\mathrm{d}}$

Number of Late Resorptions ${ }^{\mathrm{d}}$

Number of Dead Fetuses ${ }^{\mathrm{d}}$

Number of Whole Litter Resorptions

Percent Postimplantation Loss ${ }^{\mathrm{c}}$

Fetal Body Weight per Litter ${ }^{\mathrm{b}}$

Male Fetal Weight per Litter

Female Fetal Weight per Litter

Gravid Uterine Weight ${ }^{\mathrm{b}}$

External Findings

Visceral Findings

Skeletal Findings

$\begin{array}{lll}382.3 \pm 3.1 & 386.3 \pm 4.2 & 384.3 \pm 5.1 \\ 139.6 \pm 2.5 & 143.6 \pm 3.0 & 139.9 \pm 3.8 \\ 22.8 \pm 0.23 & 22.5 \pm 0.33 & 22.9 \pm 0.33\end{array}$

None

44

599

$13.61 \pm 0.30$

22

2

1

0

$\begin{array}{cc}3.81 \pm 1.13 & 3.42 \pm 0.99 \\ 5.29 \pm 0.04 & 5.22 \pm 0.06 \\ 5.42 \pm 0.05 & 5.35 \pm 0.06 \\ 5.17 \pm 0.04 & 5.08 \pm 0.06 \\ 98.89 \pm 1.93 & 101.98 \pm 2.23 \\ \text { None } & \text { None } \\ \text { None } & \text { None } \\ \text { None } & \text { None }\end{array}$

$16 \% \uparrow$ in absolute liver weight absolute live weight

$$
21
$$

300

$14.29 \pm 0.37$

11

0

0

0

$$
21
$$

270

$12.86 \pm 0.62$

11

0

2

0

$4.33 \pm 1.19$

$5.42 \pm 0.08$

$5.47 \pm 0.06$

$5.30 \pm 0.09$

$95.76 \pm 4.06$

None

None

None

$$
\begin{aligned}
& 379.4 \pm 8.2 \\
& 137.6 \pm 6.3 \\
& 22.2 \pm 0.42
\end{aligned}
$$

$26 \% \uparrow$ in absolute liver weight
20

259

$12.95 \pm 0.91$

15

0

0

0

$7.17 \pm 4.50$

$5.22 \pm 0.07$

$5.34 \pm 0.06$

$5.09 \pm 0.07$

$91.78 \pm 5.91$

None

None

None

Level of Evidence of Developmental Toxicity: No evidence

GD = gestation day.

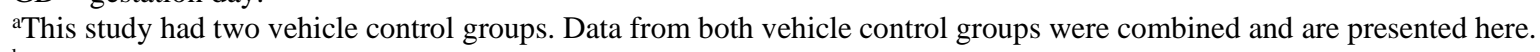

besults given in grams. Data are displayed as mean \pm standard error.

cData are displayed as mean \pm standard error.

${ }^{\mathrm{d}}$ No statistical analyses were performed on number of early resorptions, number of late resorptions, or number of dead fetuses. 


\section{Introduction}

\section{Tris(chloropropyl) Phosphate}

Tris(chloropropyl) phosphate (TCPP) is a flame retardant commonly used in consumer products. Its chemical formula is $\mathrm{C}_{9} \mathrm{H}_{18} \mathrm{Cl}_{3} \mathrm{O}_{4} \mathrm{P}$ and its molecular weight is 327.57 . The test article name represents the mixture. Its trade names are Amgard TMCP, Antiblaze 80, Antiblaze TMCP, and Fyrol PCF.

It was nominated to the National Toxicology Program (NTP) by the Consumer Product Safety Commission for toxicological testing. NTP is evaluating TCPP toxicity on various cellular or molecular targets in vitro (e.g., high throughput screening) and in vivo following subchronic and chronic exposure to rats and mice. Genotoxicity and immunotoxicity assessments also are under evaluation following TCPP exposure. Further information on NTP's evaluation of the potential toxicity of TCPP is available at the Program's website. ${ }^{1}$ The purpose of this report is to summarize and discuss TCPP effects on prenatal development in rats.

\section{Chemical and Physical Properties}

TCPP is a clear colorless liquid mixture. ${ }^{2-6}$ TCPP has a molar mass of $327.59 \mathrm{~g} / \mathrm{mol}$ and a relative density of $1.29 \mathrm{~g} / \mathrm{cm}^{3}$ at $25^{\circ} \mathrm{C}$. It has an estimated boiling point greater than $200^{\circ} \mathrm{C}$, vapor pressure less than $2 \mathrm{~mm} \mathrm{Hg}$ at $25^{\circ} \mathrm{C}$, water solubility $1.6 \mathrm{~g} / \mathrm{L}$ at $20^{\circ} \mathrm{C}$, and $\log \mathrm{Kow}$ (octanol:water partition coefficient) 2.59.

\section{Production, Use, and Human Exposure}

TCPP is produced as an isomeric mixture in a closed system by the reaction of phosphorus oxychloride and propylene oxide to generate a mixture of four isomers. ${ }^{4}$ The most abundant isomer in commercial products is tris(1-chloro-2-propyl) phosphate (50-85\%) (Table 1). Additional isomers include bis(2-chloro-1-methylethyl)-2-chloropropyl phosphate (15-40\%), bis(2-chloropropyl) 2-chloroisopropyl phosphate (<15\%), and tris(2-chloropropyl) phosphate $(<1 \%)$. Variations in manufacturing methods result in commercial formulations that contain different ratios of the four isomers. The TCPP mixture and commercial products are commonly referenced by the major isomer, tris(1-chloro-2-propyl) phosphate, and by CASRN 13674-84-5. ${ }^{3}$

The U.S. production volume of TCPP was approximately 54 million pounds in $2012 .^{7}$ TCPP is used as a flame retardant within textiles, furniture (flexible polyurethane foam), and other related products. In addition, it is manufactured for use in construction materials (rigid polyurethane foam), electronic products, paints, coatings, and adhesives. ${ }^{2}$ TCPP has been proposed as a substitute for brominated flame retardants and as a replacement for other chlorinated flame retardants such as tris(2-chloroethyl) phosphate. 8 ; 9 


\begin{tabular}{|c|c|c|c|}
\hline Isomer & CASRN & Chemical Structure & $\begin{array}{l}\text { Percentage } \\
\text { (w/w) in } \\
\text { Commercia } \\
1 \text { Products }\end{array}$ \\
\hline $\begin{array}{l}\text { Tris(1-chloro-2-propyl) Phosphate } \\
\text { 2-Propanol, 1-chloro-, 2,2',2"-phosphate } \\
\text { Tris(2-chloro-1-methylethyl) phosphate } \\
\text { Tris(2-chloro isopropyl)phosphate }\end{array}$ & $13674-84-5$ & & $50-85 \%$ \\
\hline $\begin{array}{l}\text { Bis(2-chloro-1-methylethyl) 2-Chloropropyl Phosphate } \\
\text { Bis(1-chloro-2-propyl) 2-chloro-1-propyl phosphate } \\
\text { Bis(2-chloro isopropyl) 2-chloropropyl phosphate }\end{array}$ & $76025-08-6$ & & $15-40 \%$ \\
\hline $\begin{array}{l}\text { Bis(2-chloropropyl) 2-Chloroisopropyl Phosphate } \\
\text { 2-Chloro-1-methylethyl bis(2-chloropropyl) phosphate } \\
\text { Bis(2-chloropropyl) 2-chloro-1-methylethyl phosphate } \\
\text { Bis(2-chloro-1-propyl) 1-chloro-2-propyl phosphate }\end{array}$ & 76649-15-5 & & $<15 \%$ \\
\hline $\begin{array}{l}\text { Tris(2-chloropropyl) Phosphate } \\
\text { 1-Propanol, 2-chloro-, phosphate (3:1) } \\
\text { Tris(2-chloro-1-propyl) phosphate }\end{array}$ & $6145-73-9$ & & $<1 \%$ \\
\hline
\end{tabular}

TCPP isomers (in bold, noted by the U.S. Environmental Protection Agency [EPA] Registry Name) and common synonyms listed in the EPA Substance Registry Services database ${ }^{10}$.

${ }^{a}$ Test article name represents the mixture.

Fate and transport of TCPP were recently summarized by the U.S. Environmental Protection Agency's (EPA) Design for the Environment Branch. ${ }^{3}$ Available data suggest that TCPP is routinely found in drinking, ground, and surface waters. TCPP is expected to be highly mobile in soil because of its carbon-water partition values. It is also anticipated to be persistent in the environment based on the results of 28-day biodegradation studies, which suggest the half-life is greater than 60 days. ${ }^{11}$ TCPP has been detected in sediment, surface water, household dust, indoor air, and ambient air. ${ }^{3}$

Human exposure to TCPP can occur through inhalation, oral, or dermal contact. The EPA Office of Pollution Prevention and Toxics suggests that potential occupational exposure to TCPP is likely to occur through inhalation of vapors and dermal exposures during the manufacturing of consumer products containing $\mathrm{TCPP}^{2}$ or when working with consumer products containing TCPP. Because TCPP is considered ubiquitous in the environment, consumers could be exposed by inhalation of vapor, direct skin contact, and incidental ingestion. Exposures can occur in offices, homes, and other indoor environments as a result of using consumer products such as upholstered furniture containing TCPP. Children may be more susceptible to ingestion because of increased object-to-mouth behaviors. 9; 12 


\section{Regulatory Status}

TCPP is listed on the Toxic Substances Control Act (TSCA) Inventory. TCPP is one of several flame retardants included in that Inventory's Work Plan, and EPA released a problem formulation and initial assessment document for the chlorinated phosphate ester cluster that includes TCPP in August 2015. ${ }^{2}$ The conclusion of that problem formulation is that EPA will assess risks to consumers, the general population, and aquatic organisms following exposure to TCPP and similar chemicals. Currently, no regulations restrict production or use of TCPP in the United States.

The European Union Risk Assessment Report for TCPP indicates no unacceptable risks for workers, consumers, or the general population, with the exception of effects on fertility and developmental toxicity related to dermal exposure to workers manufacturing TCPP. ${ }^{5}$ TCPP is currently not registered under the REACH (Registration, Evaluation, Authorisation, and Restriction of Chemicals) Regulation; therefore, the European Chemicals Agency (ECHA) has no usable data available for this substance from registered dossiers. ${ }^{13}$

\section{Absorption, Distribution, Metabolism, and Excretion}

\section{Experimental Animals}

TCPP is readily absorbed and excreted in rats following gavage administration of $50 \mu \mathrm{mol}$ $\left[{ }^{14} \mathrm{C}\right] \mathrm{TCPP} / \mathrm{kg}$ body weight. ${ }^{14}$ In this study, approximately $98 \%$ of the administered dose was recovered during 168 hours after dosing. Of the administered dose, 67\%, 22\%, and $7.7 \%$ were recovered in urine, feces, and expired air, respectively, within 48 hours. TCPP was rapidly distributed to tissues, with tissue-to-blood ratios highest in liver and kidney followed by lung, spleen, and adipose during the first 12 hours after administration. Elimination half-life in blood was estimated to be approximately 59 hours. Biliary excretion studies showed that approximately $45 \%$ of the administered dose was excreted in bile within 48 hours and that TCPP excreted in feces is likely from biliary excretion.

Additional absorption, disposition, metabolism, excretion, and toxicokinetic data are summarized in the European Union Risk Assessment Report ${ }^{5}$ and the EPA Design for the Environment Report, Flame Retardants Used in Flexible Polyurethane Foam: An Alternatives Assessment Update. ${ }^{3}$ These reports indicate that TCPP is readily absorbed and excreted, whose findings were based on animal studies.

\section{Humans}

The literature contains no studies on the absorption, distribution, metabolism, or excretion of TCPP in humans. TCPP metabolism was investigated in vitro with human liver microsomes by Van den Eede et al. ${ }^{15}$ Incubation of microsomes with TCPP resulted in several Phase I metabolites including bis(1-chloro-2-propyl) phosphate, a major metabolite; bis(1-chloro-2-propyl) 1-hydroxy-2-propyl phosphate; bis(1-chloro-2-propyl) 1-carboxy-2-propyl phosphate; and 1-chloro-2-propyl,1-hydroxy-2-propyl phosphate. No Phase II metabolites were detected. 


\section{Developmental and Reproductive Toxicity}

\section{Experimental Animals}

A prenatal developmental toxicity study conducted by Kawasaki et al. ${ }^{16}$ is reported in the literature. ${ }^{16}$ Wistar rats were fed a diet containing $0 \%, 0.01 \%, 0.1 \%$, or $1 \%$ TCPP during gestation days (GD) 0 through GD $20(\mathrm{n}=11$ to 14). Daily TCPP intake for the exposed groups was estimated to be 6,70 , or $625 \mathrm{mg} / \mathrm{kg}$ body weight per day, respectively. Following exposure, no significant effects on dam survival, feed consumption, or body weight gain during gestation occurred. No effects on the number of implants, resorptions, or live or dead fetuses were found. An exam of fetal morphology demonstrated no significant external or visceral test article-related effects. Although no statistically significant increases in the incidences of skeletal abnormalities were found, dose-related increases in the incidences of cervical ribs and absent 13th ribs were reported, which suggest developmental toxicity.

Summaries of the results of a two-generation reproduction study in Wistar rats exposed to TCPP are presented in various hazard and risk assessment reports. ${ }^{3 ;}$ Rats (28 per sex per group) received $0,100,333$, or $1,000 \mathrm{mg} T C P P / \mathrm{kg} /$ day in the diet over two generations. Animals were fed TCPP 10 weeks prior to mating, during mating, and throughout gestation and lactation until study end. No treatment-related clinical observations or mortality in either parental generation were reported. TCPP exposure did not affect precoital time, mating index, fecundity index, fertility index, duration of gestation, or postimplantation loss. The mean number of pups delivered was lower in the $\mathrm{F}_{0}$ and $\mathrm{F}_{1}$ generations in the mid- and high-dose groups compared to the control.

\section{Humans}

The literature contains no studies on the reproductive or developmental toxicity of TCPP in humans.

\section{General Toxicity}

\section{Experimental Animals}

The toxicity database, which includes published and unpublished data for TCPP, has been summarized in the National Industrial Chemicals Notification and Assessment Scheme, ${ }^{17}$ EPA's Design for the Environment Branch, ${ }^{3}$ Environmental Health Criteria for Flame Retardants by the World Health Organization, ${ }^{9}$ SIDS (Screening Information Dataset) Initial Assessment Profile, ${ }^{11}$ European Union Risk Assessment Report, ${ }^{5}$ and the Agency for Toxic Substances and Disease Registry Toxicological Profile for Phosphate Ester Flame Retardants. ${ }^{6}$

Reported acute oral LD $\mathrm{LD}_{50}$ (lethal dose for $50 \%$ of exposed animals) values for TCPP range from 1,000 to $4,000 \mathrm{mg} / \mathrm{kg}$ body weight in male rats and 2,000 mg/kg in female rats. ${ }^{4 ;}$; 11 Common clinical observations observed in acute studies included ataxia, hunched posture, lethargy, labored respiration, increased salivation, body tremors, and piloerection. Macroscopic signs of toxicity included hemorrhagic lungs and dark liver and kidneys. The acute dermal $L_{50}$ in rats and rabbits is reported to be greater than $5,000 \mathrm{mg} / \mathrm{kg}$ and the inhalation $\mathrm{LC}_{50}$ (lethal concentration for $50 \%$ of exposed animals) in rats is greater than $4.6 \mathrm{mg} / \mathrm{L}$. ${ }^{4 ;}$; 11 The EPA Design for the Environment Branch assigned a low hazard to TCPP for acute toxicity. ${ }^{3}$ 
In a 13-week toxicity study, Fyrol PCF ${ }^{\circledR}$ (i.e., TCPP) administered in feed to Sprague Dawley rats (20 per sex per concentration) at exposure concentrations from 800 to 20,000 ppm had no effect on mortality, clinical observations, changes in hematology, clinical chemistry, or urinalysis parameters in the study animals. ${ }^{18}$ Body weights were decreased $(<12 \%$ compared to controls) at the highest exposure concentration in males and females. Significantly increased liver weights were noted in all treated males and in the two highest exposure groups of females (7,500 and 20,000 ppm). Kidney weights were increased in males in the 7,500 and 20,000 ppm groups. Histopathological evaluation revealed minor changes in the liver, kidney, and thyroid gland, which were most prevalent in the two highest exposure concentration groups. The EPA Design for the Environment Branch assigned a moderate hazard to TCPP for repeat dose toxicity on the basis of these data. ${ }^{3}$

Subsequently, NTP conducted 13-week studies in rats and mice; the data are available in NTP's Chemical Effects in Biological Systems database. ${ }^{19}$ TCPP was administered in feed at dietary concentrations of $0,2,500,5,000,10,000,20,000$, or 40,000 ppm in rats and 0,1,250, 2,500, $5,000,10,000$, or 20,000 ppm in mice (10 per sex per group). Rat exposures included a perinatal exposure from GD 6 to postnatal day 21 prior to the 13-week exposure. All rat dams exposed to 40,000 ppm (gestation) and all male pups (first week postweaning) in the 20,000 ppm group were removed because of overt toxicity. Body weights in all exposed rats at weaning were 13\% to $30 \%$ lower than controls. In mice, no treatment-related mortality or clinical observations of toxicity were found. Terminal body weights were 12\% (rats) and 29\% (mice) lower than controls in the 20,000 ppm groups. Treatment-related increases occurred in relative liver (rats, mice) and thymus (rats) weights. In rats, treatment-related increases were found in the incidences of biliary hyperplasia and increased cellularity of the thymic cortex. In mice, the incidences of hepatocellular hypertrophy and male renal tubule epithelium cytoplasmic alterations were observed to be treatment related. In summary, subchronic exposure to TCPP in feed resulted in reduced dam and pup survival (rats); the liver, thymus, and kidney were considered primary targets of toxicity.

\section{Humans}

No direct studies of tris(chloropropyl) phosphate exposure on human health have been conducted.

\section{Study Rationale}

The Consumer Product Safety Commission nominated TCPP in 2005 because of its expected increased use as a flame retardant for flexible polyurethane foam used in home furnishings and construction materials. ${ }^{20}$ TCPP exposure to consumers via oral, dermal, and inhalation routes was also expected to increase, and the publicly available toxicity data at the time were considered limited. One report in the literature suggested that TCPP exposure might affect development ${ }^{16}$; therefore, NTP determined further studies were warranted to characterize the effects of oral TCPP administration in pregnant rats and on fetal development. 


\section{Materials and Methods}

\section{Overview of Prenatal Developmental Toxicity Study Designs}

Prenatal developmental toxicity studies are conducted to ascertain if in utero exposure to a test agent results in embryo-fetal death, structural malformations/variations, growth retardation, or functional deficits not secondary to overt maternal toxicity. Overt maternal toxicity has been shown to affect normal embryo-fetal growth and development (e.g., excessively lower maternal body weight gains and lower fetal weights, increased maternal stress in mice, and cleft palate). ${ }^{21-}$ 23 The presence of maternal toxicity, however, should not negate a priori an apparent fetal response. Rather, given the maternal/embryo-fetal interrelationship, maternal responses should be considered when interpreting fetal findings. Pregnant animals should be administered the highest feasible dose levels of test agent (or the limit dose) to achieve maximal dam and fetal exposure and sufficiently challenge the test system to identify potential developmental hazards. ${ }^{24}$

The conduct of a dose range-finding study helps determine dose selection when the potential for test agent-induced maternal toxicity is unknown and can provide preliminary information on embryo-fetal outcomes (e.g., postimplantation loss, changes in fetal weight, external defects) and informs the design for a prenatal developmental toxicity study. In the prenatal developmental toxicity study, fetal examination is expanded to include examination of the fetal viscera, head (soft tissue and skeletal components), and the skeleton for osseous and cartilaginous defects. Abnormalities are categorized in one of two groups: (1) malformations that are permanent structural changes that could adversely affect survival, development, or function; and (2) variations that are a divergence beyond the usual range of structural constitution but might not adversely affect survival or health, ${ }^{22}$ consistent with the descriptions by Makris et al. ${ }^{25}$ The study design for the dose range-finding and prenatal developmental toxicity studies is presented in Figure 1. 


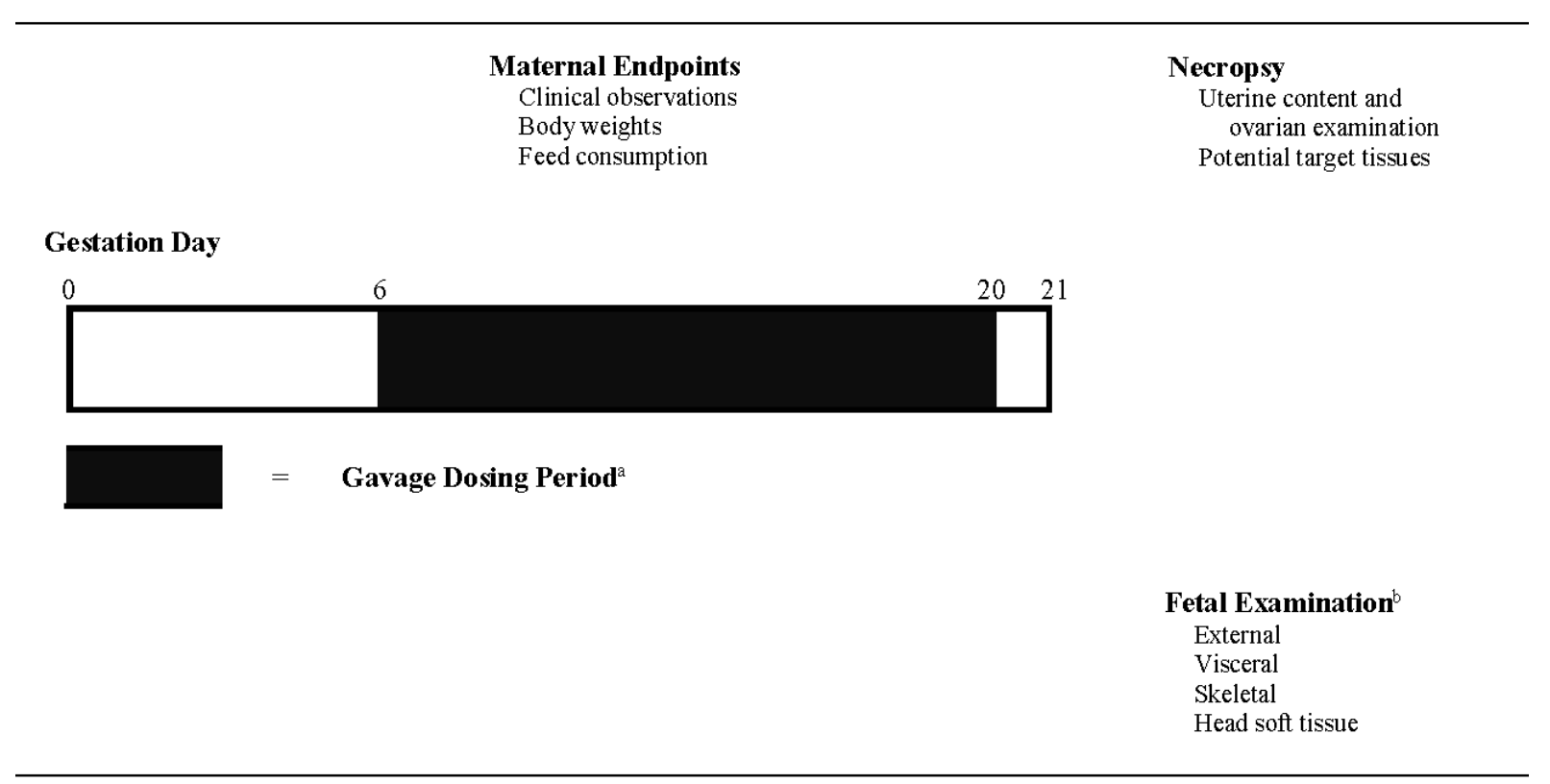

Figure 1. Design of a Dose Range-finding and Prenatal Developmental Toxicity Study in Rats

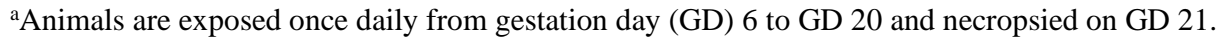

${ }^{b}$ All fetuses are examined externally (including inspection of the oral cavity). Fetuses in the prenatal developmental toxicity study also are examined for visceral and skeletal effects with approximately $50 \%$ of the heads examined for soft tissue alterations.

\section{Procurement and Characterization}

\section{Tris(chloropropyl) Phosphate}

Tris(chloropropyl) phosphate (TCPP) was obtained from Albemarle Corporation (Orangeburg, SC) in two lots (101 and 134). Lot 101 was used in the dose range-finding study, and lots 101 and 134 were blended to form lot M072911NP, which was stored in two drums and used during the prenatal developmental toxicity study. Identity and purity of lots 101 and 134 were confirmed prior to blending (Table 2). Homogeneity of the blended lot M072911NP was confirmed both within the individual drums and between the two drums. Identity, purity, and stability analyses were conducted by the analytical chemistry laboratory at MRI Global (Kansas City, MO) (Appendix A).

Lots 101, 134, and M072911NP of the test chemical (clear oily liquids) were identified using proton and carbon-13 Fourier transform nuclear magnetic resonance (FT-NMR) spectroscopy. Because of the isomeric complexity of the test article, two-dimensional FT-NMR was performed on lot M072911NP including homonuclear correlation spectroscopy (COSY) and heteronuclear correlation (HETCOR) spectroscopy to confirm the data from the proton and carbon-13 NMR spectra. In addition, lots 101 and M072911NP were analyzed using Fourier transform infrared (FT-IR) and ultraviolet/visible (UV-Vis) spectroscopy and gas chromatography (GC) with mass spectrometry (MS) detection. GC/MS using electron ionization of lots 101 and M072911NP identified one major peak and three other peaks with similar molecular weights, indicating the presence of isomeric compounds (Table 2). The major peak (Isomer 1), identified as tris(1-chloro-2-propyl) phosphate, CASRN 13674-84-5, matched a literature spectrum. ${ }^{26}$ The three other isomers were identified as bis(2-chloro-1-methylethyl) 2-chloropropyl phosphate 
(Isomer 2, CASRN 76025-08-6); bis(2-chloropropyl) 2-chloroisopropyl phosphate (Isomer 3, CASRN 76649-15-5); and tris(2-chloropropyl) phosphate (Isomer 4, CASRN 6145-73-9).

The percentages of individual and combined isomers estimated for each lot using GC with flame ionization detection (FID) using two systems are shown in Table 2 and align with the range of percentages reported in commercial products (Table 1). For lots 101 and M072911NP, the following additional analyses were conducted: moisture content by Karl Fischer titration; elemental analyses for carbon, hydrogen, nitrogen, and chlorine (ICON Development Solutions (Whitesboro, NY); octanol:water partition coefficients (log P) of the major peak; density; and acid number and ester value. Acid number and ester value were determined using titration with standardized $\sim 0.001 \mathrm{~N}$ sodium hydroxide and $\sim 0.5 \mathrm{~N}$ hydrochloric acid, respectively, and are also shown for each isomer (Table 2). Results for elemental analyses for carbon, hydrogen, nitrogen, and chlorine for all lots were consistent with the theoretical values for TCPP. The purity of the lots, estimated based on the combined percentages of four isomers, was equal to or greater than $96 \%$ (Table 2 ).

Table 2. Composition of Lots Used in the Prenatal Developmental Toxicity Studies of Tris(chloropropyl) Phosphate in Rats

\begin{tabular}{|c|c|c|c|c|}
\hline Analysis & Lot $101^{a}$ & Lot 134 & $\begin{array}{c}\text { Lot } \\
\text { M072911NP } \\
\text { Drum } 1^{b}\end{array}$ & $\begin{array}{c}\text { Lot } \\
\text { M072911NP } \\
\text { Drum } 2\end{array}$ \\
\hline \multicolumn{5}{|l|}{ Elemental (\%) } \\
\hline Carbon & 33.02 & ND & 33.06 & 32.93 \\
\hline Hydrogen & 5.64 & ND & 5.62 & 5.55 \\
\hline Nitrogen & 0.14 & ND & 0.09 & 0.10 \\
\hline Chlorine & 31.92 & ND & 32.00 & 32.19 \\
\hline Water: Karl Fischer (\%) & 0.093 & ND & 0.038 & 0.039 \\
\hline Acid Number (mg KOH/g) & 0.011 & ND & 0.067 & ND \\
\hline Ester Value (mg KOH/g) & 104.7 & ND & 105.85 & ND \\
\hline Relative Density (g/mL) & 1.294 & ND & 1.296 & 1.296 \\
\hline \multicolumn{5}{|l|}{$\log P$} \\
\hline TCPP Peak 1 & 2.69 & ND & 2.59 & ND \\
\hline TCPP Peak 2 & 2.74 & ND & 2.65 & ND \\
\hline \multicolumn{5}{|l|}{ Purity: GC/FID (\%) ${ }^{\mathrm{c}}$} \\
\hline \multicolumn{5}{|l|}{ System 1: DB-5 } \\
\hline Sum of TCPP isomers & 96.04 & 98.79 & 97.04 & 97.43 \\
\hline Isomer 1 & 65.22 & 71.33 & 67.57 & 68.54 \\
\hline Isomer 2 & 26.80 & 24.29 & 25.65 & 25.21 \\
\hline Isomer 3 & 3.86 & 3.07 & 3.61 & 3.48 \\
\hline Isomer 4 & 0.16 & 0.14 & 0.21 & 0.20 \\
\hline Reportable impurities \% (number) ${ }^{\mathrm{d}}$ & $3.76(7)$ & $1.14(3)$ & $2.74(8)$ & $2.35(8)$ \\
\hline
\end{tabular}




\begin{tabular}{|c|c|c|c|c|}
\hline Analysis & Lot 101 & Lot 134 & $\begin{array}{c}\text { Lot } \\
\text { M072911NP } \\
\text { Drum } 1^{b}\end{array}$ & $\begin{array}{c}\text { Lot } \\
\text { M072911NP } \\
\text { Drum } 2\end{array}$ \\
\hline \multicolumn{5}{|l|}{ System 2: DB-WAX } \\
\hline Sum of TCPP isomers & ND & ND & 97.50 & 97.91 \\
\hline Isomer 1 & ND & ND & 67.84 & 68.85 \\
\hline Isomer 2 & ND & ND & 25.87 & 25.42 \\
\hline Isomer 3 & ND & ND & 3.61 & 3.47 \\
\hline Isomer 4 & ND & ND & 0.18 & 0.17 \\
\hline Reportable impurities \% (number) ${ }^{\mathrm{d}}$ & ND & ND & $2.49(6)$ & $2.09(6)$ \\
\hline
\end{tabular}

ND = not determined; TCPP = tris(chloropropyl) phosphate; GC/FID = gas chromatography/flame ionization detection. aused in the dose range-finding study.

bLots 101 and 134 were blended to generate lot M072911NP, used in the prenatal developmental toxicity study.

'Isomers 1 through 4 were identified as tris(1-chloro-2-propyl) phosphate, bis(2-chloro-1-methylethyl) 2-chloropropyl phosphate, bis(2 chloropropyl) 2-chloroisopropyl phosphate, and tris(2-chloropropyl) phosphate, respectively (Appendix A).

${ }^{\mathrm{d} I m p u r i t i e s} \geq 0.05 \%$ are listed.

To ensure stability, the test chemical was stored under inert gas at $\sim 25^{\circ} \mathrm{C}$, in sealed drums. Periodic analyses of lots 101 and M072911NP of the test chemical were performed prior to and during the animal studies by the analytical chemistry laboratory using FT-NMR and GC/FID; no degradation of the test chemical was detected.

\section{Methylcellulose}

Methylcellulose was obtained from Spectrum Quality Products (Gardena, CA) in two lots (YX0540 and 2AJ0439). Lot YX0540 was used as the vehicle in the dose range-finding study and lot 2AJ0439 was used in the prenatal developmental toxicity study. The identity of both lots was confirmed by the analytical chemistry laboratory using FT-IR spectroscopy. Methoxy group content was determined by Galbraith Laboratories (Knoxville, TN) using titration with standardized sodium thiosulfate solution. Methoxy group content was $30.4 \%$ and $31.0 \%$ for lots YX0540 and 2AJ0439, respectively, both within the accepted range of 27.5-31.5\%.

\section{Preparation and Analysis of Dose Formulations}

Prior to conducting the dose range-finding study, formulation homogeneity studies at $1.56 \mathrm{mg} / \mathrm{mL}$ and $200 \mathrm{mg} / \mathrm{mL}$ and stability studies at $1.56 \mathrm{mg} / \mathrm{mL}$ were performed by the analytical chemistry laboratory using GC/FID. Homogeneity was confirmed, with the stipulation that high-dose formulations be stirred constantly during use to maintain homogeneity. Stability was confirmed for at least 7 days for dose formulations stored in sealed glass containers at $\sim 5^{\circ} \mathrm{C}$ and for 3 hours under simulated animal room conditions at $5^{\circ} \mathrm{C}$. The $1.56 \mathrm{mg} / \mathrm{mL}$ formulation was $93.8 \%, 88 \%$, and $86.6 \%$ of the day 0 value at 7,14 , and 42 days, respectively, suggesting some loss over time. Additional stability studies were conducted at 32.5 and $130 \mathrm{mg} / \mathrm{mL}$ prior to the prenatal developmental toxicity study; stability of the $130 \mathrm{mg} / \mathrm{mL}$ formulation for up to 42 days was confirmed, whereas that of the $32.5 \mathrm{mg} / \mathrm{mL}$ formulation for up to 35 days was confirmed for formulations stored in sealed glass containers at $\sim 5^{\circ} \mathrm{C}$.

The dose formulations were prepared by the analytical chemistry laboratory once (dose rangefinding study) or three times (prenatal developmental toxicity study) by mixing TCPP with a 
$0.5 \%$ methylcellulose solution to give the required concentrations with a dosing volume of $5 \mathrm{~mL} / \mathrm{kg}$. The dose formulations were stored at $\sim 5^{\circ} \mathrm{C}$ in sealed glass jars for up to 30 days (dose range-finding study) or 15 days (prenatal developmental toxicity study).

Dose formulations of TCPP were analyzed by the analytical chemistry laboratory using GC/FID. During the dose range-finding study, the formulations were analyzed twice; all 10 dose formulations were within $10 \%$ of the target concentrations (Table A-3). Animal room samples received on day 36 were also analyzed; two of six were within $10 \%$ of the target concentrations and the other four were within 11-31\%. During the prenatal developmental toxicity study, the dose formulations were prepared three times and analyzed once; all nine dose formulation samples were within $10 \%$ of the target concentrations (Table A-4). During the preparation of formulations, homogeneity was confirmed using the 32.5 and $130 \mathrm{mg} / \mathrm{mL}$ concentrations (Table A-4.). Animal room samples of each dose formulation were also analyzed; six were within $10 \%$ of the target concentrations and three were within $12-15 \%$.

\section{Animal Source}

Female Sprague Dawley (Hsd:Sprague Dawley ${ }^{\circledR} \mathrm{SD}^{\circledR}$ ) rats for use in the dose range-finding and prenatal developmental toxicity studies were obtained from Envigo (formerly Harlan Laboratories, Inc., Dublin, VA or Indianapolis, IN) (Table 3). This stock is routinely used in NTP studies for toxicity evaluation. Sexually mature (12 to 13 weeks old) females were timemated overnight at the vendor and were received on gestation day (GD) 2 for the dose rangefinding study and on GD 1 or GD 2 for the prenatal developmental toxicity study. GD 0 was defined as the day positive evidence of mating was observed. In addition, 10 non-mated females were received for use as sentinels during the prenatal developmental toxicity study.

\section{Animal Health Surveillance}

In accordance with the NTP Sentinel Animal Program (Appendix C), female sentinels were evaluated in the prenatal developmental toxicity study on January 31 and February 15, 2012. All test results were negative.

\section{Animal Welfare}

Animal care and use were in accordance with the Public Health Service Policy on Humane Care and Use of Animals. All animal studies were conducted in an animal facility accredited by AAALAC International. Studies were approved by the RTI International Animal Care and Use Committee and conducted in accordance with all relevant NIH and NTP animal care and use policies and applicable federal, state, and local regulations and guidelines.

\section{Experimental Design}

In the dose range-finding and prenatal developmental toxicity studies, time-mated rats were housed individually, provided $\mathrm{NIH}-07$ feed and water ad libitum, and observed at least twice daily for viability (morning and afternoon). Clinical observations were performed from GD 3 through GD 21 until removal, typically twice daily (at the time of dose administration and cageside post dose). Females were weighed daily from GD 3 through GD 21. Feed consumption was recorded for GD 3 to 6, GD 6 to 9, GD 9 to 12, GD 12 to 15, GD 15 to 18, and GD 18 to 21. Details of the study design including animal source and identification, diet, water, husbandry, 
environmental conditions, euthanasia, necropsy, and fetal evaluations are summarized in Table 3. Information on feed composition and contaminants is provided in Appendix B.

On GD 21, rats were weighed, euthanized with $\mathrm{CO}_{2}$ inhalation, and examined for gross lesions of the thoracic and abdominal cavities. The gravid uterus, ovary, liver, and adrenal glands were excised and weighed (organs for prenatal developmental toxicology study only), and any placental findings were recorded. The numbers of implantation sites and corpora lutea visible on the surface of each ovary were recorded. Uterine contents were examined for pregnancy status and the number and location of all live and dead fetuses (a live fetus is defined as one that responds to stimuli; a dead fetus is defined as a term fetus that does not respond to stimuli and is not markedly autolyzed), and resorptions were recorded.

Resorptions were classified as early or late. Early resorptions included a conceptus characterized by a grossly necrotic mass that had no recognizable fetal form or presence of nidation sites ("pregnant by stain”). Late resorptions were characterized by grossly necrotic but recognizable fetal form with placental remnants visible. ${ }^{27 ;} 28$ Postimplantation loss was calculated as the number of dead plus resorbed conceptuses divided by the total number of implantations (multiplied by 100). For each uterus with no macroscopic evidence of implantation, the uterus was stained with $10 \%(\mathrm{v} / \mathrm{v})$ ammonium sulfide to visualize any possible early implantation sites. $^{29}$

Adult females that were euthanized moribund, delivered early, or found dead received a gross necropsy that included an examination of the thoracic and abdominal viscera for evidence of dosing trauma or toxicity. The uterus of each female was examined and stained, if necessary, to determine pregnancy status. Females were not retained for further examination.

\section{Dose Range-finding Study}

Time-mated rats were individually identified by ear tag and randomized by GD 3 body weight stratification into four groups using RTI International's Instem ${ }^{\mathrm{TM}}$ Provantis $^{\circledR}$ (version 8.2.0) electronic data collection system.

Groups of 11 time-mated female rats were administered 0 (vehicle control), 300, 650, or $1,000 \mathrm{mg}$ TCPP/kg body weight per day (mg/kg/day), based on the most recent weight, in $0.5 \%$ aqueous methylcellulose by gavage from GD 6 to GD 20. Vehicle control animals received aqueous methylcellulose alone; the dosing volume was $5 \mathrm{~mL} / \mathrm{kg}$. One thousand $\mathrm{mg} / \mathrm{kg}$ was considered the limit dose for a prenatal development study in rats and was chosen as the high dose in the dose range-finding study. Dose selection was supported by developmental and twogeneration reproduction studies reported in the literature. ${ }^{3 ;}$;; 16

On GD 21, live fetuses of surviving females were counted, sexed, weighed, and examined for external morphological abnormalities, including inspection of the oral cavity for cleft palate. Fetuses were euthanized by intraperitoneal injection of a commercially available solution containing sodium pentobarbital. Fetuses were not retained following completion of the external examination. 


\section{Prenatal Developmental Toxicity Study}

On receipt (GD 1 or GD 2), time-mated rats were individually identified by tail tattoo and randomized, based on GD 3 body weight stratification, into five groups using RTI's Instem ${ }^{\mathrm{TM}}$ Provantis $^{\circledR}$ (version 8.2.0) electronic data collection system. Dams were delivered 2 days apart to allow for a staggered study start.

Groups of 25 time-mated female rats were administered 0 (2 concurrent vehicle control groups), 162.5, 325, or $650 \mathrm{mg}$ TCPP/kg body weight (based on the most recent weight) per day in $0.5 \%$ aqueous methylcellulose by gavage from GD 6 to GD 20 (15 days). The additional vehicle control group was included to generate additional control data for both maternal and fetal findings in this strain of rat. At the end of the study, the vehicle control groups were evaluated for reproducibility and combined for assessment of treatment-related effects because they were run concurrently. Vehicle control animals received aqueous methylcellulose alone; the dosing volume was $5 \mathrm{~mL} / \mathrm{kg}$.

On GD 21, fetuses were removed from the uterus, and live fetuses individually weighed. The uteri of animals that did not appear pregnant were examined for nidations (implantation sites) by staining with $0.5 \%$ ammonium sulfide. ${ }^{29}$ All fetuses were examined externally for alterations, including inspection of the oral cavity for cleft palate. Live fetuses were subsequently euthanized by intraperitoneal injection of sodium pentobarbital. Fetal sex was confirmed by inspection of gonads in situ. All fetuses were examined for soft tissue alterations under a stereomicroscope. ${ }^{30}$; 31 The heads were removed from approximately half the fetuses in each litter and fixed in Bouin's solution and subsequently examined by free-hand sectioning. ${ }^{32}$ This technique precludes skeletal evaluations of the skull; therefore, remaining heads and all fetuses were eviscerated, fixed in ethanol, macerated in potassium hydroxide, stained with alcian blue and alizarin red, and examined for subsequent cartilage and osseous alterations. ${ }^{33 ;} 34$ External, visceral, and skeletal fetal alterations were recorded as developmental variations or malformations.

Table 3. Experimental Design and Materials and Methods in the Dose Range-finding and Prenatal Developmental Toxicity Gavage Studies of Tris(chloropropyl) Phosphate

\begin{tabular}{|c|c|}
\hline Dose Range-finding Study & Prenatal Developmental Toxicity Study \\
\hline \multicolumn{2}{|l|}{ Study Laboratory } \\
\hline RTI International (Research Triangle Park, NC) & RTI International (Research Triangle Park, NC) \\
\hline \multicolumn{2}{|l|}{ Strain and Species } \\
\hline Sprague Dawley (Hsd:Sprague Dawley ${ }^{\circledR} \mathrm{SD}^{\circledR}$ ) rats & Sprague Dawley (Hsd:Sprague Dawley ${ }^{\circledR} \mathrm{SD}^{\circledR}$ ) rats \\
\hline \multicolumn{2}{|l|}{ Animal Source } \\
\hline $\begin{array}{l}\text { Envigo (formerly Harlan Laboratories, Inc., Dublin, } \\
\text { VA) }\end{array}$ & $\begin{array}{l}\text { Envigo (formerly Harlan Laboratories, Inc., Dublin, } \\
\text { VA) }\end{array}$ \\
\hline \multicolumn{2}{|l|}{ Day of Arrival } \\
\hline Gestation day (GD) 2 & GD 1 or GD 2 \\
\hline \multicolumn{2}{|l|}{ Average Age on Arrival } \\
\hline 12 weeks & 12 to 13 weeks \\
\hline \multicolumn{2}{|l|}{ Weight Range at Randomization } \\
\hline 195.8 to 246.6 g on GD 3 & 203.5 to $256.0 \mathrm{~g}$ on GD 3 \\
\hline
\end{tabular}




\section{Calendar Day of First Dose (GD 6) and Last Dose (GD 20)}

GD 6 (August 2, 2010) and GD 20 (August 16, 2010)

\section{Duration of Dosing}

GD 6 to GD 20, once daily

\section{Size of Study Groups}

11 time-mated females

\section{Method of Randomization and Identification}

Time-mated animals were uniquely identified on day of receipt by ear tag and assigned to dose group by body weight stratified randomization of GD 3 body weights using Instem Provantis ${ }^{\circledR}$ (version 8) electronic data collection system.

Each animal was assigned a unique animal number in Provantis. This number was linked to the respective marking and all data collected during the study were associated with the Provantis animal number.

\section{Animals per Cage}

1

Diet

Irradiated NIH-07 Certified Rodent Diet wafer diet (Zeigler Brothers, Inc., Gardners, PA), available ad libitum

\section{Water}

Tap water (Durham, NC, municipal supply) via automatic watering system (Edstrom Industries, Inc., Waterford, WI), available ad libitum

\section{Cages}

Solid-bottom polycarbonate cages (Ancare, Bellmore, $\mathrm{NY}$ ), changed and rotated weekly

\section{Bedding}

Certified irradiated Sani-Chips ${ }^{\circledR}$ hardwood cage bedding (P.J. Murphy Forest Products Corporation, Montville, NJ), changed weekly

\section{Cage Filters}

Filter paper (Ancare, Bellmore, NY), changed weekly

\section{Racks}

Stainless steel (Lab Products, Inc., Seaford, DE), changed every 2 weeks, rotated once during the study
GD 6 (January 29, 2012) and GD 20 (February 15, 2012); staggered start

GD 6 to GD 20, once daily

50 time-mated females (2 vehicle control groups with 25 each), 25 time-mated females (treated groups)

Time-mated animals were uniquely identified on day of receipt by tail tattoo and assigned to dose group by body weight stratified randomization of GD 3 body weights using Instem Provantis (version 8) electronic data collection system.

Each animal was assigned a unique animal number in Provantis. This number was linked to the respective marking and all data collected during the study were associated with the Provantis animal number.

1

Same as dose range-finding study

Same as dose range-finding study

Solid-bottom polycarbonate cages (Lab Products, Inc., Seaford, DE), changed and rotated weekly

Same as dose range-finding study

Filter paper (Granville Milling Co., Creedmoor, NC), changed weekly

Same as dose range-finding study

\section{Animal Room Environment}


Dose Range-finding Study

Temperature: $72^{\circ} \mathrm{F} \pm 3^{\circ} \mathrm{F}$

Relative humidity: $50 \% \pm 15 \%$

Room fluorescent light: 12 hours/day

Room air changes: at least 10/hour

Doses

$0,300,650$, or $1,000 \mathrm{mg} / \mathrm{kg}$ in $0.5 \%$ methylcellulose (dosing volume $5 \mathrm{~mL} / \mathrm{kg}$ )

\section{Type and Frequency of Observation of Dams}

Observed for viability twice daily from GD 3 through GD 20. Clinical observations were recorded twice daily from GD 3 until necropsy; (prior to dosing [out of cage] and at 1 to 3 hours post dose [cage side]) beginning on GD 6. Animals were weighed daily beginning on GD 3. Feed consumption was recorded at 3-day intervals from GD 3 through GD 21.

\section{Primary Method of Euthanasia}

$100 \% \mathrm{CO}_{2}$ (adults) or intraperitoneal injection of a solution containing sodium pentobarbital (fetuses)

\section{Necropsy and Postmortem Evaluation of Females}

On GD 21, terminal body and gravid uterine weights were recorded and the uterine contents examined. The number of corpora lutea on each ovary was recorded. The number and location of all fetuses (live or dead) and resorptions (early or late) and the total number of implantation sites were recorded; if no macroscopic evidence of pregnancy, the uterus was stained to visualize potential evidence of implantation sites.

For animals removed early, gross necropsy including an examination of the thoracic and abdominal viscera was performed. The uterus of each female was examined to determine pregnancy status or, if no evidence of pregnancy, stained to visualize possible early implantation sites.

\section{Fetal Evaluation}

Live fetuses were counted, sexed, weighed, and examined for external morphological abnormalities that included inspection of the oral cavity for cleft palate.

\section{Prenatal Developmental Toxicity Study}

Same as dose range-finding study

$0,162.5,325$, or $650 \mathrm{mg} / \mathrm{kg}$ in $0.5 \%$ methylcellulose (dosing volume $5 \mathrm{~mL} / \mathrm{kg}$ )

Observed for viability twice daily from GD 3 through GD 20. Clinical observations were recorded once daily from GD 3 until necropsy; (prior to dosing [out of cage], and at 1 to 3 hours post dose [cage side]) from GD 6 through GD 20. Feed consumption was recorded at 3-day intervals from GD 3 through GD 21.

$100 \% \mathrm{CO}_{2}$ (adults) or oral administration of a solution containing sodium pentobarbital (fetuses)

On GD 21, terminal body, adrenal glands, liver, ovary, and gravid uterine weights were recorded and the uterine contents examined. The number of corpora lutea on each ovary was recorded. The number and location of all fetuses (live or dead) and resorptions (early or late) and the total number of implantation sites were recorded; if no macroscopic evidence of pregnancy, the uterus was stained to visualize potential evidence of implantation sites.

There were no early removals.

Live fetuses were counted, sexed, weighed, and examined for external morphological abnormalities that included inspection of the oral cavity for cleft palate. Placental morphology was also evaluated.

Live fetuses were euthanized and then examined for visceral morphological abnormalities by fresh dissection. The sex of each fetus was confirmed by internal examination. The heads from approximately half the fetuses in each litter were fixed, sectioned, and examined. All fetuses were eviscerated, fixed, stained, and examined for skeletal developmental variations, malformations, or other morphological findings.

$\mathrm{GD}=$ gestation day. 


\section{Statistical Methods}

In both the dose range-finding study and the main study, statistical analyses were performed on data from pregnant females that survived until the end of the study and were examined on GD 21 and from live fetuses. Statistical analyses were performed using SAS 9.3 (SAS Institute, Cary NC) software.

\section{Descriptive Statistics}

Maternal Parameters: Maternal body weights were measured daily starting at GD 3 and reported as means. Terminal maternal body weights at GD 21 were adjusted for gravid uterine weight by subtracting the gravid uterine weight from the dam's body weight. Body weight gains were calculated over each 3-day interval and from GD 6 to GD 21. Daily feed consumption was averaged over each 3-day interval and from GD 6 to GD 21. These continuous variables, in addition to gravid uterine weights, other organ weights, hematology, and clinical chemistry were summarized with means and standard errors.

Placental and Fetal Parameters: Data on uterine contents are reported as means and standard errors of counts per dam/litter (corpora lutea, implants, resorptions, dead fetuses) and as total numbers of occurrences (resorptions, dead fetuses). Data from females that were not pregnant or that did not survive to the end of the study were not included. Postimplantation loss is calculated as a percentage of the number of implants per dam. Fetal findings are reported as means and standard errors of counts per litter (numbers of live fetuses, male fetuses, female fetuses), means and standard errors of litter means (fetal weight, male fetal weight, female fetal weight), and total numbers of occurrences (total number of live fetuses). In addition, several calculated variables are reported, including the percentage of live male fetuses per litter.

Incidences of morphological findings from the gross, external, visceral, skeletal, and head examinations of pathology of placentae and fetuses are presented as number and percentage of affected fetuses and as number and percentage of affected litters.

\section{Analysis of Maternal Parameters and Uterine Contents}

Maternal organ and body weight data, which historically have approximately normal distributions, were analyzed with the parametric multiple comparison procedures of Dunnett ${ }^{35}$ and Williams. ${ }^{36 ;} 37$ Non-normally distributed variables, such as food consumption and uterine content endpoints, were analyzed using the nonparametric multiple comparison methods of Shirley $^{38}$ (as modified by Williams ${ }^{39}$ ) and Dunn. ${ }^{40}$ For normally distributed and non-normally distributed variables, the Jonckheere test ${ }^{41}$ was used to assess the significance of dose-related trends at $\mathrm{p}<0.01$ to determine whether a trend-sensitive test (the Williams or Shirley test) was more appropriate than a test that does not assume a monotonic dose-related trend (the Dunnett or Dunn test). Prior to statistical analysis, extreme values identified by the outlier test of Dixon and Massey $^{42}$ were examined by NTP personnel, and implausible values were eliminated from the analysis.

Fetal body weights were analyzed using mixed-effects linear models, with litter as a random effect to account for potential within-litter correlations. To test for a linear trend, the numerical value of the dose was entered into the model and its significance was evaluated. For pairwise comparisons with the control group, a second mixed-effects model with dose entered into the 
model as a categorical variable was estimated, followed by the Dunnett ${ }^{35}$ and $\mathrm{Hsu}^{43}$ multiple comparison tests.

\section{Analysis of Incidences of Gross Pathology and Morphology Findings}

Incidences of gross findings, malformations, and variations in the fetuses were summarized and analyzed as number of litters affected and as number of fetuses affected. Incidences of gross findings, malformations and numbers of litters affected were analyzed using the CochranArmitage trend test ${ }^{44}$ and the Fisher exact test. ${ }^{45}$ Incidences of numbers of fetuses affected were analyzed using mixed-effects logistic regression in which the litter was a random effect to account for potential litter effects. ${ }^{46-48}$ For each fetal finding, an initial mixed-effects logistic regression model used the numerical value of the dose to assess the significance of a dose-related trend; a subsequent logistic regression model incorporated dose as a categorical variable to compare each dose group with the control group. To conduct the mixed-effects logistic regression analyses, at least one finding was required per dose group and the correlation matrix describing the relationship between litters was required to be "positive definite.” If the mixedeffects logistic regression failed to converge or did not meet the specified criteria, two separate analyses were used to bracket the true $\mathrm{p}$ value. The Cochran-Armitage trend test and the Fisher exact test were used with the litter as the experimental unit to calculate the upper limit for the true $\mathrm{p}$ value and with the fetus as the experimental unit to calculate the lower limit for the true $\mathrm{p}$ value.

\section{Historical Control Data}

The concurrent control group represents the most valid comparison to the treated groups and is the only control group analyzed statistically in NTP developmental and reproductive toxicity studies. However, historical control data are often helpful in interpreting potential exposurerelated effects, particularly for uncommon fetal findings that occur at a very low incidence. For meaningful comparisons, the conditions for studies in the historical control database must be generally similar. Significant factors that might affect the background incidences of fetal findings at a variety of anatomical sites are diet, sex, strain/stock, route of exposure, study type, or laboratory that conducted the study. The NTP historical control database for teratology studies contains all fetal evaluations (e.g., teratology studies or modified one-generation studies) for each laboratory. In general, the historical control database for a given study includes studies using the same route of administration and study design. Historical control data for rats in this NTP Developmental and Reproductive Toxicity Technical Report, however, contain all studies conducted by the laboratory because of the limited number of studies available. The concurrent controls are included in the historical control data set. NTP historical controls are available online at https://ntp.niehs.nih.gov/go/historical_controls.

\section{Quality Assurance Methods}

The dose range-finding and prenatal developmental toxicity studies were conducted in compliance with Food and Drug Administration Good Laboratory Practice Regulations (21 CFR, Part 58). Records from these studies were submitted to the NTP Archives. The prenatal developmental toxicity study was audited retrospectively by an independent quality assessment contractor. Separate audits covered completeness and accuracy of the final study data tables for the dose range-finding and prenatal developmental toxicity studies and a draft of this NTP 
Developmental and Reproductive Toxicity Technical Report. Audit procedures and findings are presented in the reports and are on file at NIEHS. The audit findings were reviewed and assessed by NTP staff, and all comments were resolved or otherwise addressed during the preparation of this report. 


\section{Results}

\section{Data Availability}

NTP evaluated all study data. Data relevant for evaluating toxicological findings are presented here. All study data are available in the NTP Chemical Effects in Biological Systems (CEBS) database: http://dx.doi.org/10.22427/NTP-DATA-DART-01. ${ }^{49}$

\section{Dose Range-finding Study in Rats}

\section{Maternal Findings}

\section{Viability and Clinical Observations}

Seven of 11 dams in the $1,000 \mathrm{mg} / \mathrm{kg}$ group were either found dead or euthanized moribund (Table 4). Associated adverse neurological clinical observations in the 1,000 mg/kg group included convulsions, tremors, and hypoactivity. Additional observations included gasping, hunched posture, nasal discharge, stained fur, piloerection, prone, salivation, and rooting (preand postdosing), which occurred throughout the gestational period (Appendix $\mathrm{E}^{49}$ ). One female was euthanized moribund in the $650 \mathrm{mg} / \mathrm{kg}$ group on gestation day (GD) 16 with clinical observations including cold to touch, hypoactivity, paleness, ataxia, and labored breathing. All vehicle control ( $0 \mathrm{mg} / \mathrm{kg}$ ) and $300 \mathrm{mg} / \mathrm{kg}$ animals survived to study termination and showed no treatment-related clinical observations.

Table 4. Maternal Disposition of Rats in the Dose Range-finding Gavage Study of Tris(chloropropyl) Phosphate

\begin{tabular}{lcccc}
\hline & $\mathbf{0 ~} \mathbf{~ g} / \mathbf{k g}$ & $\mathbf{3 0 0} \mathbf{~} \mathbf{g} / \mathbf{k g}$ & $\mathbf{6 5 0} \mathbf{~ m g} / \mathbf{k g}$ & $\mathbf{1 , 0 0 0 ~} \mathbf{~} \mathbf{g} / \mathbf{k g}$ \\
\hline Time-mated Females & 11 & 11 & 11 & 11 \\
Pregnant (on GD 21) & 10 & 11 & 7 & 4 \\
Euthanasia Moribund - Pregnant & 0 & 0 & $1^{\mathrm{a}}$ & $5^{\mathrm{b}}$ \\
Found Dead - Pregnant & 0 & 0 & 0 & $1^{\mathrm{c}}$ \\
Nonpregnant (on GD 21) & 1 & 0 & 3 & 0 \\
Found Dead - Nonpregnant & 0 & 0 & 0 & $1^{\mathrm{d}}$ \\
\hline
\end{tabular}

GD = gestation day.

aDam removed on GD 16.

bDams removed on GD 6, GD 13, and GD 20 (3).

${ }^{\mathrm{C}}$ Dam found dead on GD 13.

${ }^{\mathrm{d}}$ Dam found dead on GD 6.

\section{Body Weights and Feed Consumption}

Maternal body weight gain from GD 9 to GD 12 was 26\% lower in the 1,000 mg/kg group relative to the vehicle control group (Table 5). Maternal body weight gain from GD 6 to GD 21 in the $1,000 \mathrm{mg} / \mathrm{kg}$ group, however, was similar to that in the vehicle control group. Overall, no dose-related effects on maternal body weight gain during gestation were found (Figure 2; Table 5 and Appendix $\mathrm{E}^{49}$ ). 
In association with transient body weight changes, maternal feed consumption was 19\% (GD 6 to GD 9) and 12\% (GD 9 to GD 12) lower in the 1,000 mg/kg group relative to vehicle controls for those time periods (Table 6). Feed consumption from GD 6 to GD 21 by the 1,000 mg/kg group, however, was similar to that in the vehicle control group. Feed consumption in the 300 and $650 \mathrm{mg} / \mathrm{kg}$ groups was similar to that in the vehicle control group (Table 6).

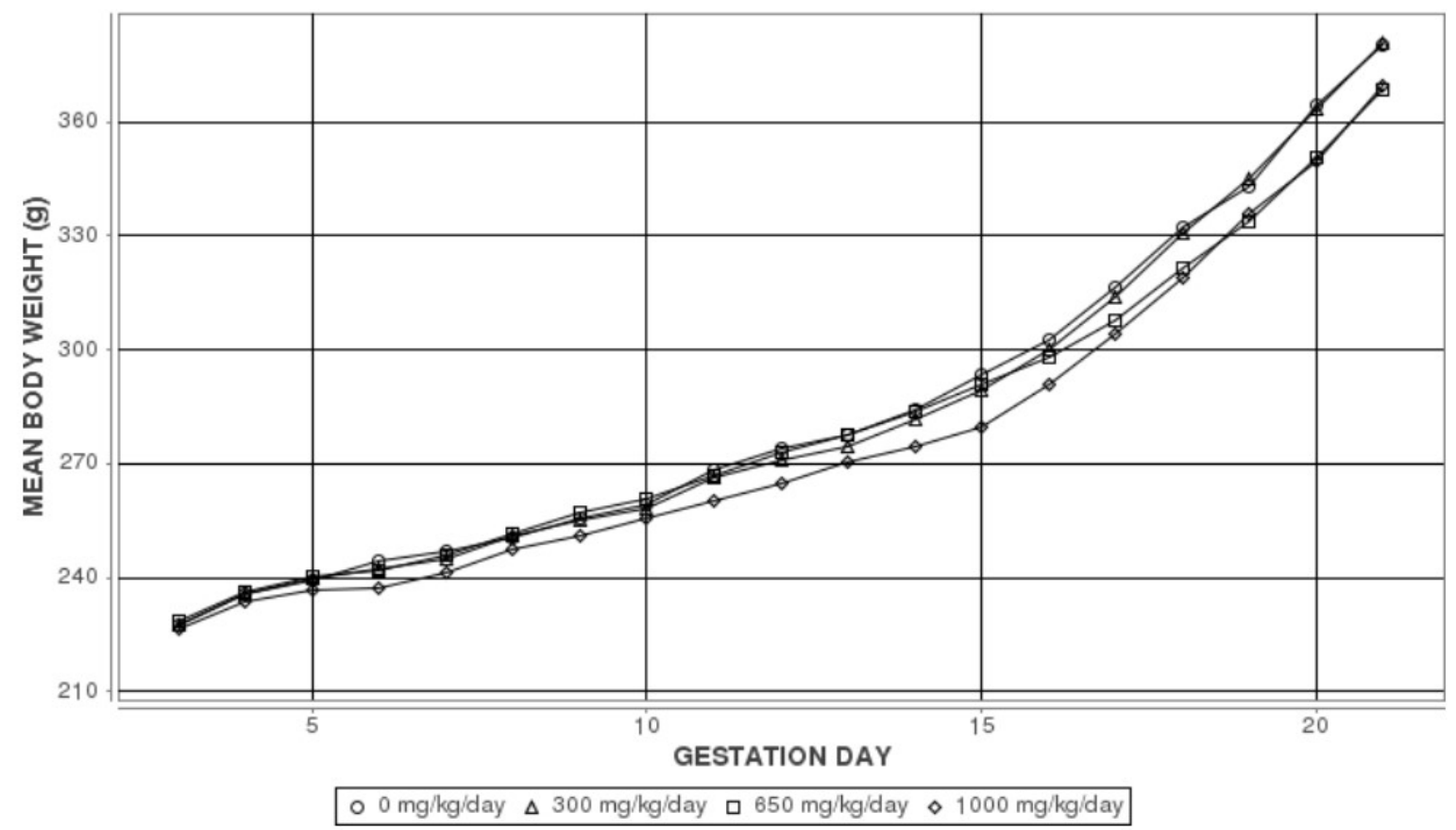

Figure 2. Maternal Growth Curves for Pregnant Rats Administered Tris(chloropropyl) Phosphate by Gavage in the Dose Range-finding Study

Information for statistical significance in maternal weights is provided in Table 5 and Appendix E. ${ }^{49}$

Table 5. Summary of Maternal Body Weight Gains of Rats in the Dose Range-finding Gavage Study of Tris(chloropropyl) Phosphate

\begin{tabular}{|c|c|c|c|c|}
\hline $\begin{array}{c}\text { Gestation Day } \\
\text { Interval }\end{array}$ & $0 \mathrm{mg} / \mathrm{kg}$ & $300 \mathrm{mg} / \mathrm{kg}$ & $650 \mathrm{mg} / \mathrm{kg}$ & $1,000 \mathrm{mg} / \mathrm{kg}$ \\
\hline $6-21$ & $136.1 \pm 2.6^{\mathrm{a}}(10)$ & $138.4 \pm 4.3(11)$ & $127.5 \pm 17.1(7)$ & $130.2 \pm 12.7$ \\
\hline $3-6$ & $16.5 \pm 2.5(10)$ & $14.8 \pm 2.3(11)$ & $13.0 \pm 1.1(8)$ & $10.8 \pm 1.2(10)$ \\
\hline $6-9$ & $11.4 \pm 0.4(10)$ & $12.8 \pm 1.1(11)$ & $15.1 \pm 1.3(8)$ & $12.1 \pm 1.8(9)$ \\
\hline $9-12$ & $18.5 \pm 1.1^{*}(10)$ & $15.8 \pm 0.8(11)$ & $16.1 \pm 0.9(8)$ & $13.8 \pm 1.5 *(9)$ \\
\hline $12-15$ & $19.3 \pm 0.9(10)$ & $18.1 \pm 0.9(11)$ & $17.7 \pm 1.9(8)$ & $17.4 \pm 2.5(7)$ \\
\hline $15-18$ & $38.9 \pm 1.7(10)$ & $41.6 \pm 1.9(11)$ & $30.5 \pm 9.8(7)$ & $39.3 \pm 3.4(7)$ \\
\hline $18-21$ & $48.1 \pm 0.8(10)$ & $50.1 \pm 2.0(11)$ & $46.8 \pm 4.4(7)$ & $47.0 \pm 7.4(4)$ \\
\hline
\end{tabular}

*Statistically significant $(\mathrm{p} \leq 0.05)$ trend (by the Jonckheere test) or pairwise comparison (by the Williams or Dunnett test). A significant trend test is indicated in the vehicle control column. A significant pairwise comparison with the vehicle control group is indicated in the dose group column.

${ }^{a}$ Body weight gains for pregnant females are given in grams. Data are displayed as mean \pm standard error. Number of dams weighed is given in parentheses. 
Table 6. Summary of Maternal Feed Consumption of Rats in the Dose Range-finding Gavage Study of Tris(chloropropyl) Phosphate

\begin{tabular}{|c|c|c|c|c|}
\hline $\begin{array}{l}\text { Gestation Day } \\
\text { Interval }\end{array}$ & $0 \mathrm{mg} / \mathrm{kg}$ & $300 \mathrm{mg} / \mathrm{kg}$ & $650 \mathrm{mg} / \mathrm{kg}$ & $1,000 \mathrm{mg} / \mathrm{kg}$ \\
\hline $6-21$ & $21.8 \pm 0.46^{\mathrm{a}}(10)$ & $21.4 \pm 0.44(11)$ & $21.8 \pm 1.21(7)$ & $21.4 \pm 0.76$ \\
\hline $3-6$ & $19.8 \pm 0.54(10)$ & $19.5 \pm 0.42(11)$ & $19.6 \pm 0.55(8)$ & $19.0 \pm 0.55(10)$ \\
\hline $6-9$ & $19.5 \pm 0.53^{* *}(10)$ & $17.8 \pm 0.51(11)$ & $17.9 \pm 0.86(8)$ & $15.9 \pm 0.71^{* *}(9)$ \\
\hline $9-12$ & $20.6 \pm 0.43^{* *}(10)$ & $19.6 \pm 0.48(11)$ & $19.6 \pm 0.47(8)$ & $18.2 \pm 0.69^{* *}(9)$ \\
\hline $12-15$ & $20.9 \pm 0.52(10)$ & $20.9 \pm 0.34(11)$ & $21.9 \pm 0.57(8)$ & $21.0 \pm 0.79(7)$ \\
\hline $15-18$ & $24.1 \pm 0.63(10)$ & $23.6 \pm 0.62(11)$ & $24.7 \pm 1.71(7)$ & $24.9 \pm 0.62(7)$ \\
\hline $18-21$ & $23.9 \pm 0.54 *(10)$ & $25.1 \pm 0.62(11)$ & $24.5 \pm 2.79(7)$ & $26.5 \pm 1.07(4)$ \\
\hline
\end{tabular}

*Statistically significant ( $\leq 0.05)$ trend (by the Jonckheere test) or pairwise comparison (by the Shirley or Dunn test). A significant trend test is indicated in the vehicle control column. A significant pairwise comparison with the vehicle control group is indicated in the dose group column.

** $\mathrm{p} \leq 0.01$.

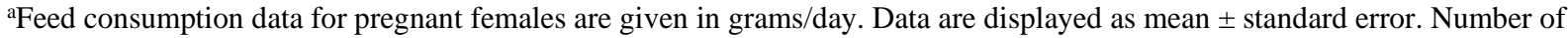
dams with feed consumption measured is given in parentheses.

\section{Maternal and Litter Observations}

The maternal toxicity observed in the $1,000 \mathrm{mg} / \mathrm{kg}$ TCPP dose group resulted in only 4 litters available for assessments, as compared to 7 to 11 litters in the other groups (Table 7). This dose group had fewer implants per female; however, this is a variable endpoint in this strain and because TCPP dosing began on GD 6, this finding is not considered related to treatment. Also, the number of live male fetuses per litter in the $1,000 \mathrm{mg} / \mathrm{kg}$ group was significantly lower (by 53\%) compared to vehicle controls. Additional observations included nonsignificant decreases in the number of live fetuses per litter and mean gravid uterine weight in the 650 and 1,000 mg/kg groups. These findings were considered to have an uncertain relationship to TCPP exposure because of the small sample size and number of litters available for evaluation. Overall, TCPP exposure had no significant effects on embryo-fetal survival (i.e., postimplantation loss) or growth retardation (i.e., fetal weight).

Table 7. Summary of Uterine Content Data for Rats in the Dose Range-finding Gavage Study of Tris(chloropropyl) Phosphate

\begin{tabular}{|c|c|c|c|c|}
\hline & $0 \mathrm{mg} / \mathrm{kg}$ & $300 \mathrm{mg} / \mathrm{kg}$ & $650 \mathrm{mg} / \mathrm{kg}$ & $1,000 \mathrm{mg} / \mathrm{kg}$ \\
\hline \multicolumn{5}{|l|}{ Pregnancy Summary } \\
\hline Mated females & 11 & 11 & 11 & 11 \\
\hline Pregnant females & 10 & 11 & 8 & 10 \\
\hline $\begin{array}{l}\text { Pregnant females examined on } \\
\text { GD } 21^{\text {a }}\end{array}$ & $10^{* *}$ & 11 & 7 & $4^{*}$ \\
\hline Corpora lutea per female ${ }^{b}$ & $16.90 \pm 0.66(10)$ & $15.55 \pm 0.77(11)$ & $16.14 \pm 1.37(7)$ & $16.25 \pm 0.48(4)$ \\
\hline Implantations per female ${ }^{\mathrm{b}}$ & $13.90 \pm 0.62(10)$ & $13.45 \pm 0.53(11)$ & $12.43 \pm 1.21(7)$ & $10.75 \pm 2.59(4)$ \\
\hline Percent postimplantation loss ${ }^{\mathrm{b}}$ & $2.14 \pm 2.14(10)$ & $0.83 \pm 0.83(11)$ & $6.46 \pm 3.99(7)$ & $1.92 \pm 1.92(4)$ \\
\hline Total resorptions per litter ${ }^{\mathrm{b}}$ & $0.30 \pm 0.30(10)$ & $0.09 \pm 0.09(11)$ & $0.29 \pm 0.18(7)$ & $0.25 \pm 0.25$ \\
\hline
\end{tabular}




\begin{tabular}{|c|c|c|c|c|}
\hline & $0 \mathrm{mg} / \mathrm{kg}$ & $300 \mathrm{mg} / \mathrm{kg}$ & $650 \mathrm{mg} / \mathrm{kg}$ & $1,000 \mathrm{mg} / \mathrm{kg}$ \\
\hline Early resorptions per litter ${ }^{b}$ & $0.30 \pm 0.30(10)$ & $0.09 \pm 0.09(11)$ & $0.29 \pm 0.18(7)$ & $0.25 \pm 0.25(4)$ \\
\hline Late resorptions per litter ${ }^{\mathrm{b}}$ & $0.00 \pm 0.00(10)$ & $0.00 \pm 0.00(11)$ & $0.00 \pm 0.00(7)$ & $0.00 \pm 0.00$ \\
\hline Dead fetuses per litter ${ }^{\mathrm{b}}$ & $0.00 \pm 0.00(10)$ & $0.00 \pm 0.00$ & $0.00 \pm 0.00(7)$ & $0.00 \pm 0.00$ \\
\hline Number of early resorptions ${ }^{\mathrm{C}}$ & 3 & 1 & 2 & 1 \\
\hline Number of late resorptions & 0 & 0 & 0 & 0 \\
\hline $\begin{array}{l}\text { Number of whole litter } \\
\text { resorptions }^{\mathrm{a}}\end{array}$ & 0 & 0 & 0 & 0 \\
\hline Number of dead fetuses & 0 & 0 & 0 & 0 \\
\hline \multicolumn{5}{|l|}{ Live Fetuses $^{\mathrm{b}}$} \\
\hline Number of live fetuses & 136 & 147 & 83 & 42 \\
\hline Live fetuses per litter & $13.60 \pm 0.69(10)$ & $13.36 \pm 0.58(11)$ & $11.86 \pm 1.44(7)$ & $10.50 \pm 2.53(4)$ \\
\hline Live male fetuses per litter & $7.44 \pm 0.56^{*}(9)^{\mathrm{d}}$ & $6.64 \pm 0.59(11)$ & $5.57 \pm 1.02(7)$ & $3.50 \pm 0.87^{* *}(4)$ \\
\hline Live female fetuses per litter & $6.11 \pm 0.48(9)^{\mathrm{d}}$ & $6.73 \pm 0.66(11)$ & $6.29 \pm 0.87(7)$ & $7.00 \pm 2.16(4)$ \\
\hline $\begin{array}{l}\text { Percent live male fetuses per } \\
\text { litter }\end{array}$ & $54.95 \pm 2.48(9)^{\mathrm{d}}$ & $49.91 \pm 4.20(11)$ & $46.53 \pm 6.43(7)$ & $39.81 \pm 10.48(4)$ \\
\hline \multicolumn{5}{|l|}{ Fetal Weight $(\mathrm{g})^{\mathrm{d}}$} \\
\hline Fetal weight per litter & $5.13 \pm 0.06(9)^{\mathrm{e}}$ & $5.24 \pm 0.09(11)$ & $5.20 \pm 0.10(7)$ & $5.23 \pm 0.22(4)$ \\
\hline Male weight per litter & $5.23 \pm 0.07(9)^{\mathrm{e}}$ & $5.42 \pm 0.07(11)$ & $5.33 \pm 0.15(7)$ & $5.44 \pm 0.21$ \\
\hline Female weight per litter & $5.01 \pm 0.07(9)^{\mathrm{e}}$ & $5.07 \pm 0.09(11)$ & $5.15 \pm 0.09(7)$ & $5.06 \pm 0.14$ \\
\hline \multicolumn{5}{|l|}{$\begin{array}{l}\text { Gravid Uterine Weight }(\mathrm{g})^{\mathrm{f}} \\
\mathrm{f}\end{array}$} \\
\hline Gravid uterine weight & $98.11 \pm 4.01(10)$ & $96.62 \pm 3.35(11)$ & $86.37 \pm 9.78(7)$ & $74.65 \pm 15.90(4)$ \\
\hline Terminal body weight & $378.7 \pm 5.7(10)$ & $376.4 \pm 6.3(11)$ & $363.9 \pm 20.4(7)$ & $365.0 \pm 10.1(4)$ \\
\hline Adjusted body weight & $280.62 \pm 4.86(10)$ & $279.76 \pm 4.06(11)$ & $277.54 \pm 11.58(7)$ & $290.35 \pm 11.08$ \\
\hline
\end{tabular}

Values are reported per litter as mean \pm standard error (n) and do not include nonpregnant females or those that did not survive to end of study.

$\mathrm{GD}=$ gestation day.

*Statistically significant $(\mathrm{p} \leq 0.05)$ trend (denoted in vehicle control column) or pairwise comparison (denoted in dose group column).

${ }^{* *} \mathrm{p} \leq 0.01$.

aStatistical analysis performed by the Cochran-Armitage (trend) and Fisher exact (pairwise) tests.

bStatistical analysis performed by the Jonckheere (trend) and Shirley or Dunn (pairwise) tests.

${ }^{\mathrm{c} N o}$ statistical analyses were performed on the number of early resorptions.

${ }^{d}$ Statistical analysis performed using a mixed-effects linear model with litter as a random effect (trend and pairwise).

$e_{n}=9$ litters: Individual sex and fetal body weight data for 14 fetuses were inadvertently not collected for one litter.

fStatistical analysis performed by the Jonckheere (trend) and Williams or Dunnett (pairwise) tests; adjusted body

weight $=$ terminal body weight minus gravid uterine weight.

\section{Fetal Findings}

\section{External}

No exposure-related external malformations or variations were attributed to TCPP administration at 300,650 , or $1,000 \mathrm{mg} / \mathrm{kg}$ (Appendix $\mathrm{E}^{49}$ ). 


\section{Dose Selection Rationale for the Prenatal Developmental Toxicity Study in Rats}

Excessive maternal toxicity (animals were euthanized moribund or found dead) in the dose range-finding study was observed at $1,000 \mathrm{mg} / \mathrm{kg}$. At $650 \mathrm{mg} / \mathrm{kg}$, an uncertain relationship between TCPP administration and toxicity was found because of the presence of a single moribund dam with adverse clinical observations. No toxicity was observed at lower doses. Thus, dose concentrations of $0,162.5$, 325, or $650 \mathrm{mg} / \mathrm{kg}$ were chosen for the subsequent prenatal developmental toxicity gavage study.

\section{Prenatal Developmental Toxicity Study in Rats}

\section{Maternal Findings}

\section{Viability and Clinical Observations}

No animals were removed from the study prior to scheduled necropsy (Table 8). Dose-related clinical observations were observed in six females in the $650 \mathrm{mg} / \mathrm{kg}$ group and included nasal discharge, salivation, twitches, ataxia, piloerection, audible respiratory sounds, and hyperactivity (Appendix $\mathrm{E}^{49}$ ). The duration for most of the clinical observations was limited to 1 day of gestation aside from hyperactivity in one female, which was observed over a 7-day period starting on GD 7. No dose-related clinical effects were observed in the other TCPP groups or in the vehicle control $(0 \mathrm{mg} / \mathrm{kg})$ animals.

Table 8. Maternal Disposition of Rats in the Prenatal Developmental Toxicity Gavage Study of Tris(chloropropyl) Phosphate

\begin{tabular}{lcccc}
\hline & $\mathbf{0 ~} \mathbf{~ m g / k g}$ & $\mathbf{1 6 2 . 5} \mathbf{~ m g / k g}$ & $\mathbf{3 2 5} \mathbf{~ m g / k g}$ & $\mathbf{6 5 0} \mathbf{~ m g / k g}$ \\
\hline Time-mated Females & 50 & 25 & 25 & 25 \\
Pregnant (on GD 21) & 44 & 21 & 21 & 20 \\
Nonpregnant (on GD 21) & 6 & 4 & 4 & 5 \\
\hline
\end{tabular}

GD = gestation day.

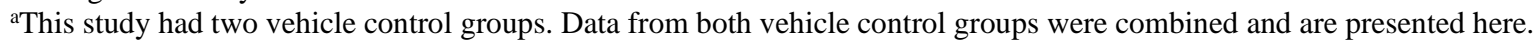

\section{Body Weights and Feed Consumption}

No dose-related effects on maternal body weight gain during gestation were found in any dose group (Figure 3 and Table 9). Daily mean body weights for dams in each dose group are available in Appendix E. ${ }^{49}$ Compared to the vehicle control group, maternal feed consumption was 8-16\% lower over GD 6 to GD 9 and GD 9 to GD 12 for dams in the $650 \mathrm{mg} / \mathrm{kg}$ group (Table 10). The feed consumption differences were transient, and, overall, TCPP administration had no effect on maternal feed consumption during gestation (Table 10). 


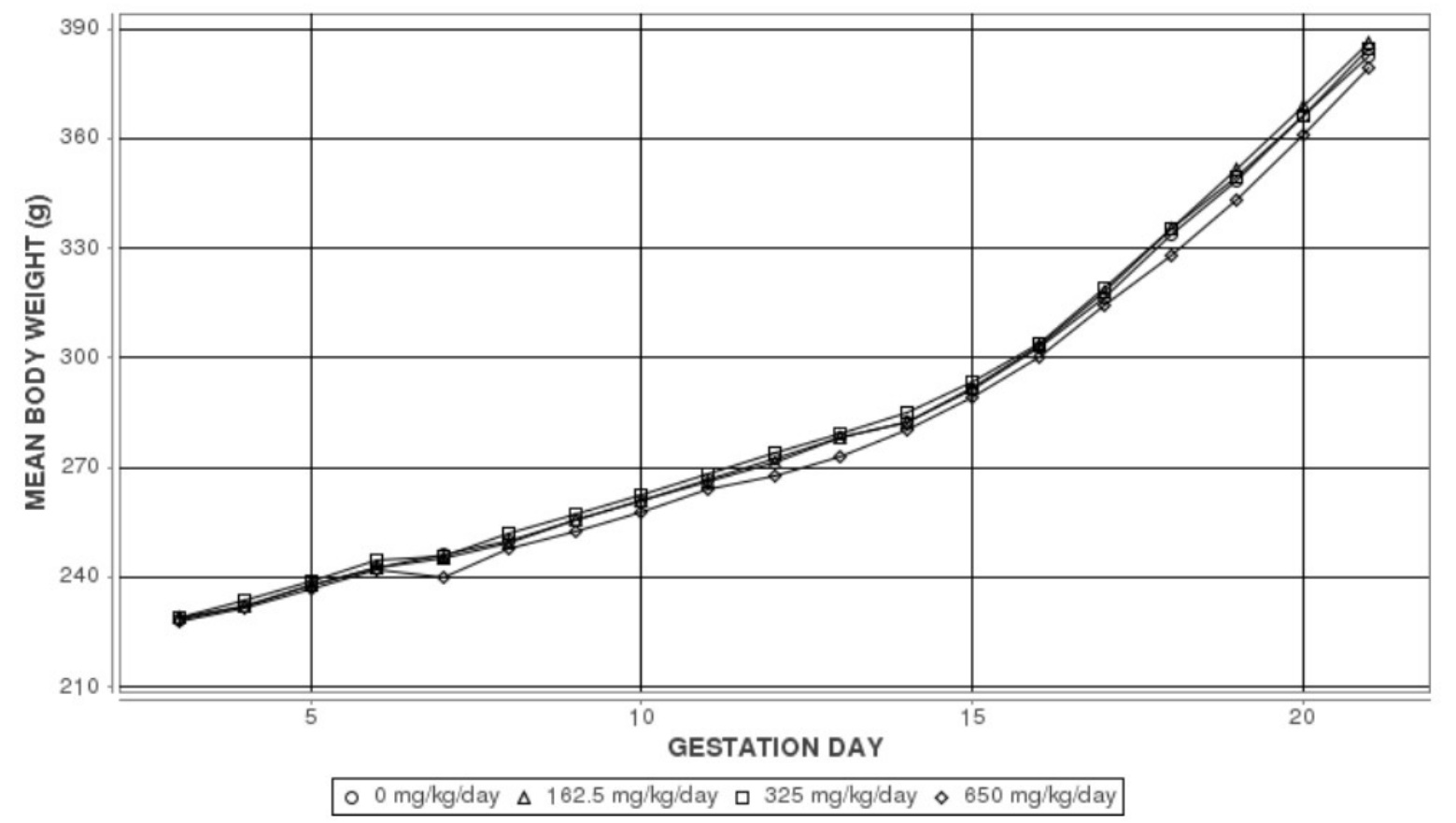

Figure 3. Maternal Growth Curves for Pregnant Rats Administered Tris(chloropropyl) Phosphate by Gavage in the Prenatal Developmental Toxicity Study

Information for statistical significance in maternal weights is provided in Table 9 and Appendix E. ${ }^{49}$

Table 9. Summary of Maternal Body Weight Gains of Rats in the Prenatal Developmental Toxicity Gavage Study of Tris(chloropropyl) Phosphate

\begin{tabular}{|c|c|c|c|c|}
\hline $\begin{array}{c}\text { Gestation Day } \\
\text { Interval }\end{array}$ & $0 \mathrm{mg} / \mathrm{kg}$ & $162.5 \mathrm{mg} / \mathrm{kg}$ & $325 \mathrm{mg} / \mathrm{kg}$ & $650 \mathrm{mg} / \mathrm{kg}$ \\
\hline $6-21$ & $139.6 \pm 2.5^{\mathrm{a}}(44)$ & $143.6 \pm 3.0(21)$ & $139.9 \pm 3.8(21)$ & $137.6 \pm 6.3(20)$ \\
\hline $3-6$ & $14.4 \pm 0.8(44)$ & $14.1 \pm 0.7(21)$ & $15.7 \pm 1.0(21)$ & $14.1 \pm 1.0(20)$ \\
\hline $6-9$ & $12.9 \pm 0.6(44)$ & $13.0 \pm 0.6(21)$ & $12.5 \pm 0.8(21)$ & $10.6 \pm 0.8(20)$ \\
\hline $9-12$ & $16.8 \pm 0.6(44)$ & $15.5 \pm 1.1(21)$ & $16.8 \pm 0.8(21)$ & $15.4 \pm 1.2(20)$ \\
\hline $12-15$ & $18.9 \pm 0.9(44)$ & $20.5 \pm 0.9(21)$ & $19.6 \pm 1.4(21)$ & $21.2 \pm 1.3(20)$ \\
\hline $15-18$ & $42.4 \pm 1.0(44)$ & $43.7 \pm 1.0(21)$ & $41.9 \pm 1.6(21)$ & $39.0 \pm 2.2(20)$ \\
\hline $18-21$ & $48.8 \pm 1.4(44)$ & $50.8 \pm 1.5(21)$ & $49.0 \pm 1.8(21)$ & $51.4 \pm 3.1(20)$ \\
\hline
\end{tabular}

Statistical analysis performed by the Jonckheere test (trend) or the Williams or Dunnett test (pairwise comparison) found no statistically significant trend or pairwise comparison.

${ }^{a}$ Body weight gains for pregnant females are given in grams. Data are displayed as mean \pm standard error. Number of dams weighed is given in parentheses. 
Table 10. Summary of Maternal Feed Consumption of Rats in the Prenatal Developmental Toxicity Gavage Study of Tris(chloropropyl) Phosphate

\begin{tabular}{|c|c|c|c|c|}
\hline $\begin{array}{l}\text { Gestation Day } \\
\text { Interval }\end{array}$ & $0 \mathrm{mg} / \mathrm{kg}$ & $162.5 \mathrm{mg} / \mathrm{kg}$ & $325 \mathrm{mg} / \mathrm{kg}$ & $650 \mathrm{mg} / \mathrm{kg}$ \\
\hline $6-21$ & $22.8 \pm 0.23^{\mathrm{a}}(44)$ & $22.5 \pm 0.33(21)$ & $22.9 \pm 0.33(21)$ & $22.2 \pm 0.42(20)$ \\
\hline $3-6$ & $20.2 \pm 0.42(44)$ & $18.7 \pm 0.24(21)$ & $19.7 \pm 0.50(21)$ & $19.4 \pm 0.55(20)$ \\
\hline $6-9$ & $20.4 \pm 0.32 * *$ & $19.4 \pm 0.37(21)$ & $18.8 \pm 0.41^{* *}(21)$ & $17.0 \pm 0.46^{* *}(20)$ \\
\hline $9-12$ & $21.6 \pm 0.34 * *(44)$ & $20.7 \pm 0.41(21)$ & $21.0 \pm 0.38(21)$ & $19.8 \pm 0.54^{* *}(20)$ \\
\hline $12-15$ & $21.6 \pm 0.22(44)$ & $21.1 \pm 0.37(21)$ & $22.4 \pm 0.55(21)$ & $21.4 \pm 0.29(20)$ \\
\hline $15-18$ & $24.8 \pm 0.34$ (44) & $25.0 \pm 0.42(21)$ & $25.5 \pm 0.53(21)$ & $25.2 \pm 0.74(20)$ \\
\hline $18-21$ & $25.5 \pm 0.36 * *$ & $26.3 \pm 0.51(21)$ & $27.0 \pm 0.38 *(21)$ & $27.8 \pm 0.66 * *(20)$ \\
\hline
\end{tabular}

*Statistically significant ( $\leq 0.05$ ) trend (by the Jonckheere test) or pairwise comparison (by the Shirley or Dunn test). A significant trend test is indicated in the vehicle control column. A significant pairwise comparison with the vehicle control group is indicated in the dose group column.

$* * \mathrm{p} \leq 0.01$.

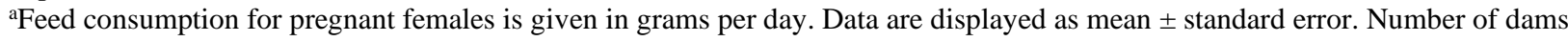
with feed consumption measured is given in parentheses.

\section{Maternal and Litter Observations}

There were no maternal gross observations at necropsy (Appendix $\mathrm{E}^{49}$ ). However, there were dose-related increases in absolute (9\%, 16\%, and 26\% at 162.5, 325, and $650 \mathrm{mg} / \mathrm{kg}$, respectively) and relative liver weights (Table 11).

Table 11. Summary of Maternal Liver Weights and Liver Weight Ratios for Rats in the Prenatal Developmental Toxicity Gavage Study of Tris(chloropropyl) Phosphate ${ }^{a}$

\begin{tabular}{|c|c|c|c|c|}
\hline & 0 mg/kg & $162.5 \mathrm{mg} / \mathrm{kg}$ & $325 \mathrm{mg} / \mathrm{kg}$ & $650 \mathrm{mg} / \mathrm{kg}$ \\
\hline n & 44 & 21 & 21 & 20 \\
\hline Necropsy Body Wt. & $378.5 \pm 3.0$ & $382.7 \pm 4.0$ & $383.1 \pm 5.2$ & $375.2 \pm 8.3$ \\
\hline \multicolumn{5}{|l|}{ Liver } \\
\hline Absolute & $14.35 \pm 0.19 * *$ & $15.62 \pm 0.32 * *$ & $16.58 \pm 0.27^{* *}$ & $18.02 \pm 0.56^{* *}$ \\
\hline Relative & $37.93 \pm 0.41^{* *}$ & $40.78 \pm 0.67^{* *}$ & $43.39 \pm 0.78^{* *}$ & $48.09 \pm 1.09 * *$ \\
\hline
\end{tabular}

**Statistically significant ( $\leq 0.01$ ) trend (by the Jonckheere test) or pairwise comparison (by the Williams or Dunnett test). A significant trend test is indicated in the vehicle control column. A significant pairwise comparison with the vehicle control group is indicated in the dose group column.

aLiver weights (absolute weights) and body weights are given in grams; liver weight-to-body weight ratios (relative weights) are given as mg organ weight/g body weight. Data are displayed as mean \pm standard error.

There were no effects on pregnancy status or litter size following TCPP administration (Table 12). Although a twofold increase in mean percent postimplantation loss in the $650 \mathrm{mg} / \mathrm{kg}$ group as compared to the vehicle controls was found, this increase is the result of one dam that had nine early resorptions. Given the singular litter incidence, this finding in the $650 \mathrm{mg} / \mathrm{kg}$ group was not considered related to TCPP administration. The number of live fetuses per litter was $5 \%$ lower in the 325 and $650 \mathrm{mg} / \mathrm{kg}$ groups and was accompanied by lower gravid uterine weights $(<7 \%)$ at these doses; however, these differences were not statistically significant. No exposure-related effects on absolute fetal body weights (male or female) were evident. 
Table 12. Summary of Uterine Content Data for Rats in the Prenatal Developmental Toxicity Gavage Study of Tris(chloropropyl) Phosphate

\begin{tabular}{|c|c|c|c|c|}
\hline & $0 \mathrm{mg} / \mathrm{kg}$ & $162.5 \mathrm{mg} / \mathrm{kg}$ & $325 \mathrm{mg} / \mathrm{kg}$ & $650 \mathrm{mg} / \mathrm{kg}$ \\
\hline \multicolumn{5}{|l|}{ Pregnancy Summary } \\
\hline Mated females & 50 & 25 & 25 & 25 \\
\hline Pregnant females & 44 & 21 & 21 & 20 \\
\hline $\begin{array}{l}\text { Pregnant females examined on } \\
\text { GD } 21^{\mathrm{a}}\end{array}$ & 44 & 21 & 21 & 20 \\
\hline Corpora lutea per female & $16.64 \pm 0.37(44)$ & $18.05 \pm 0.55(21)$ & $16.62 \pm 0.72(21)$ & $17.55 \pm 0.85(20)$ \\
\hline Implantations per female & $14.18 \pm 0.29(44)$ & $14.81 \pm 0.38(21)$ & $13.48 \pm 0.65(21)$ & $13.70 \pm 0.67(20)$ \\
\hline Percent postimplantation loss ${ }^{\mathrm{b}}$ & $3.81 \pm 1.13(44)$ & $3.42 \pm 0.99(21)$ & $4.33 \pm 1.19(21)$ & $7.17 \pm 4.50(20)$ \\
\hline Total resorptions per litter ${ }^{\mathrm{b}}$ & $0.55 \pm 0.16(44)$ & $0.52 \pm 0.15(21)$ & $0.52 \pm 0.15(21)$ & $0.75 \pm 0.45(20)$ \\
\hline Early resorptions per litter ${ }^{\mathrm{b}}$ & $0.50 \pm 0.16(44)$ & $0.52 \pm 0.15(21)$ & $0.52 \pm 0.15(21)$ & $0.75 \pm 0.45(20)$ \\
\hline Late resorptions per litter ${ }^{\mathrm{b}}$ & $0.05 \pm 0.03(44)$ & $0.00 \pm 0.00(21)$ & $0.00 \pm 0.00(21)$ & $0.00 \pm 0.00(20)$ \\
\hline Dead fetuses per litter ${ }^{\mathrm{b}}$ & $0.02 \pm 0.02(44)$ & $0.00 \pm 0.00(21)$ & $0.10 \pm 0.07(21)$ & $0.00 \pm 0.00(20)$ \\
\hline Number of early resorptions ${ }^{c}$ & 22 & 11 & 11 & 15 \\
\hline Number of late resorptions ${ }^{c}$ & 2 & 0 & 0 & 0 \\
\hline $\begin{array}{l}\text { Number of whole litter } \\
\text { resorptions }^{\mathrm{a}}\end{array}$ & 0 & 0 & 0 & 0 \\
\hline Number of dead fetuses ${ }^{c}$ & 1 & 0 & 2 & 0 \\
\hline \multicolumn{5}{|l|}{ Live Fetuses $^{\mathrm{b}}$} \\
\hline Number of live fetuses & 599 & 300 & 270 & 259 \\
\hline Live fetuses per litter & $13.61 \pm 0.30(44)$ & $14.29 \pm 0.37(21)$ & $12.86 \pm 0.62(21)$ & $12.95 \pm 0.91(20)$ \\
\hline Live male fetuses per litter & $6.48 \pm 0.28(44)$ & $7.57 \pm 0.41(21)$ & $6.71 \pm 0.54(21)$ & $6.60 \pm 0.54(20)$ \\
\hline Live female fetuses per litter & $7.14 \pm 0.30(44)$ & $6.71 \pm 0.52(21)$ & $6.10 \pm 0.46(21)$ & $6.35 \pm 0.66(20)$ \\
\hline $\begin{array}{l}\text { Percent live male fetuses } \\
\text { per litter }\end{array}$ & $47.71 \pm 1.88(44)$ & $53.48 \pm 3.05(21)$ & $50.51 \pm 3.79(21)$ & $50.04 \pm 3.96(20)$ \\
\hline \multicolumn{5}{|l|}{ Fetal Weight $(g)^{d}$} \\
\hline Fetal weight per litter & $5.29 \pm 0.04(44)$ & $5.22 \pm 0.06(21)$ & $5.42 \pm 0.08(21)$ & $5.22 \pm 0.07(20)$ \\
\hline Male fetal weight per litter & $5.42 \pm 0.05(44)$ & $5.35 \pm 0.06(21)$ & $5.47 \pm 0.06(20)$ & $5.34 \pm 0.06(19)$ \\
\hline Female fetal weight per litter & $5.17 \pm 0.04(44)$ & $5.08 \pm 0.06(21)$ & $5.30 \pm 0.09(21)$ & $5.09 \pm 0.07(20)$ \\
\hline \multicolumn{5}{|l|}{ Gravid Uterine Weight (g) ${ }^{\mathrm{e}}$} \\
\hline Gravid uterine weight & $98.89 \pm 1.93(44)$ & $101.98 \pm 2.23(21)$ & $95.76 \pm 4.06(21)$ & $91.78 \pm 5.91(20)$ \\
\hline Terminal body weight & $378.5 \pm 3.0(44)$ & $382.7 \pm 4.0(21)$ & $383.1 \pm 5.2(21)$ & $375.2 \pm 8.3(20)$ \\
\hline Adjusted body weight & $279.56 \pm 1.81(44)$ & $280.75 \pm 2.23(21)$ & $287.30 \pm 2.38(21)$ & $283.45 \pm 3.85(20)$ \\
\hline \multicolumn{5}{|c|}{$\begin{array}{l}\text { Values are reported per litter as mean } \pm \text { standard error (n) and do not include nonpregnant females or those that did not survive to } \\
\text { end of study. } \\
\text { GD = gestation day. } \\
\text { aStatistical analysis performed by the Cochran-Armitage (trend) and Fisher exact (pairwise) tests. } \\
\text { bStatistical analysis performed by the Jonckheere (trend) and Shirley or Dunn (pairwise) tests. } \\
\text { cNo statistical analyses were performed on the number of early resorptions, number of late resorptions, or number of dead } \\
\text { fetuses. } \\
\text { dStatistical analysis performed using a mixed-effects linear model with litter as a random effect (trend and pairwise). } \\
\text { eStatistical analysis performed by the Jonckheere (trend) and Williams or Dunnett (pairwise) tests; adjusted body } \\
\text { weight = terminal body weight minus gravid uterine weight. }\end{array}$} \\
\hline
\end{tabular}




\section{Fetal Findings}

\section{External}

In the external exam, various low or single-incidence findings were observed in the head and placenta that were considered unrelated to exposure. The only malformation, a meningoencephalocele in the $162.5 \mathrm{mg} / \mathrm{kg}$ group, was also considered unrelated to TCPP exposure because of the single incidence and lack of a dose response (Appendix $\mathrm{E}^{49}$ ).

\section{Visceral}

Malformations and associated variations were observed in the ureter, which included hydroureter malformations (bilateral and unilateral) in the vehicle control and $325 \mathrm{mg} / \mathrm{kg}$ groups and distention of the ureter (bilateral and unilateral) across all groups. Although associated, these findings were not considered exposure related because the incidences of findings in groups exposed to TCPP were either similar to or lower than the incidences in vehicle control animals. Various other single-incidence malformations and variations were observed in the abdomen, heart, and thorax following the visceral exam; these findings were either not considered exposure related or observed only in vehicle control animals. Overall, there were no effects of TCPP exposure on the incidences of fetal visceral abnormalities (Table 13; Appendix $\mathrm{E}^{49}$ ).

Table 13. Summary of Selected Fetal Visceral Findings in Rats in the Prenatal Developmental Toxicity Gavage Study of Tris(chloropropyl) Phosphate

\begin{tabular}{lcccc}
\hline & $\mathbf{0 ~} \mathbf{~ m g} / \mathbf{k g}$ & $\mathbf{1 6 2 . 5} \mathbf{~} \mathbf{g} / \mathbf{k g}$ & $\mathbf{3 2 5} \mathbf{~ m g / k g}$ & $\mathbf{6 5 0} \mathbf{~ m g} / \mathbf{k g}$ \\
\hline Total Number of Fetuses & 599 & 300 & 270 & 259 \\
\hline Number of Fetuses Examined & 599 & 299 & 270 & 259 \\
Number of Litters Examined & 44 & 21 & 21 & 20 \\
\hline
\end{tabular}

Pelvis

Ureter

Total, hydroureter - [M]

Fetuses

$1(0.17)$

$0(0.00)$

$1(0.37)$

$0(0.00)$

Litters

$1(2.27)$

$0(0.00)$

$1(4.76)$

$0(0.00)$

Bilateral, hydroureter - $[\mathrm{M}]$

Fetuses

$1(0.17)$

$0(0.00)$

$0(0.00)$

$0(0.00)$

Litters

1 (2.27)

$0(0.00)$

$0(0.00)$

$0(0.00)$

Left, hydroureter - [M]

Fetuses

$0(0.00)$

$0(0.00)$

$1(0.37)$

$0(0.00)$

Litters

$0(0.00)$

$0(0.00)$

$1(4.76)$

$0(0.00)$

Total, distended - [V]

Fetuses

$92(15.36)^{* * \#}$

35 (11.71)

$14(5.19)^{* * \# \#}$

$24(9.27)^{* *}$

Litters

30 (68.18)

15 (71.43)

$5(23.81)^{* *}$

$12(60.00)$

Bilateral, distended - [V]

Fetuses

$47(7.85)^{* * \#}$

$14(4.68)^{*}$

$7(2.59)^{* * \#}$

10 (3.86)* 


\begin{tabular}{|c|c|c|c|c|}
\hline & $0 \mathrm{mg} / \mathrm{kg}$ & $162.5 \mathrm{mg} / \mathrm{kg}$ & 325 mg/kg & $650 \mathrm{mg} / \mathrm{kg}$ \\
\hline Litters & $19(43.18)$ & $10(47.62)$ & 3 (14.29)* & $6(30.00)$ \\
\hline \multicolumn{5}{|c|}{ Left, distended - [V] } \\
\hline Fetuses & $22(3.67)$ & $9(3.01)$ & $4(1.48)$ & $9(3.47)$ \\
\hline Litters & $16(36.36)$ & $8(38.10)$ & $3(14.29)$ & $7(35.00)$ \\
\hline \multicolumn{5}{|c|}{ Right, distended - [V] } \\
\hline Fetuses & $23(3.84)^{*}$ & $12(4.01)$ & $3(1.11)^{* \#}$ & $5(1.93)$ \\
\hline Litters & 15 (34.09) & $4(19.05)$ & $1(4.76)^{* *}$ & $4(20.00)$ \\
\hline
\end{tabular}

Upper row denotes number of affected fetuses and (\%) and lower row the number of affected litters and (\%).

Statistical analysis for litter data and for fetal data (without the litter effects) performed by the Cochran-Armitage (trend) and Fisher exact (pairwise) tests.

*Statistically significant $(\mathrm{p} \leq 0.05)$ trend (denoted in vehicle control column) or pairwise comparison (denoted in dose group column).

${ }^{* *} \mathrm{p} \leq 0.01$.

Statistical analysis of fetuses with litter-based adjustments performed by mixed-effects logistic regression.

"Statistically significant $(\mathrm{p} \leq 0.05)$ trend (denoted in vehicle control column) or pairwise comparison (denoted in dose group column) in litter-based analysis of fetuses.

${ }^{\#} \mathrm{p} \leq 0.01$.

$[\mathrm{M}]=$ malformation; $[\mathrm{V}]=$ variation .

\section{Head}

Single incidences of malformations occurred in the head soft tissue including enlarged nasal sinus, anophthalmia, and folded retina that were noted in vehicle control animals and groups exposed to TCPP (Appendix $\mathrm{E}^{49}$ ). The only variation, enlarged lateral ventricle of the brain, was observed in the same fetus with anophthalmia and meningoencephalocele in the $162.5 \mathrm{mg} / \mathrm{kg}$ group. Overall, there were no effects of TCPP exposure on the incidences of fetal head abnormalities (Appendix $\mathrm{E}^{49}$ ).

\section{Skeletal}

Skeletal malformations including discontinuous rib cartilage and full lumbar ribs were observed in TCPP-exposed animals. The incidences of these findings were low, however, and considered not exposure related (Table 14, Appendix $\mathrm{E}^{49}$ ). Associated skeletal variations observed in TCPPtreated groups included incomplete ossification of the sternebrae (II and V), floating extra rib, rudimentary ribs (lumbar I), and bipartite or dumbbell ossification of the thoracic centrum. A statistically significant increase (trend and pairwise comparison) was found for the percentage of fetuses with rudimentary ribs in all TCPP groups (22\%, 23\%, 22\%) compared to the concurrent controls (14\%). Although this finding appears to be exposure related, it is not dose dependent. This lack of dose response, a variation of limited biological significance, and lack of any other related effect suggests that the finding is not toxicologically relevant. Overall, examination of the fetal skeleton for osseous and cartilaginous defects of the skull ( $\sim 50 \%$ of fetuses) and body only ( $100 \%$ of the fetuses) was not suggestive of an effect related to TCPP (Appendix $\mathrm{E}^{49}$ ). 
Table 14. Summary of Selected Fetal Skeletal Findings in Rats in the Prenatal Developmental Toxicity Gavage Study of Tris(chloropropyl) Phosphate

\begin{tabular}{|c|c|c|c|c|}
\hline & $0 \mathrm{mg} / \mathrm{kg}$ & $162.5 \mathrm{mg} / \mathrm{kg}$ & $325 \mathrm{mg} / \mathrm{kg}$ & $650 \mathrm{mg} / \mathrm{kg}$ \\
\hline Total Number of Fetuses & 599 & 300 & 270 & 259 \\
\hline Number of Fetuses Examined & 599 & 300 & 270 & 259 \\
\hline Number of Litters Examined & 44 & 21 & 21 & 20 \\
\hline \multicolumn{5}{|c|}{ Thoracic Vertebrae - Thoracic Centrum } \\
\hline \multicolumn{5}{|l|}{ Fused - [M] } \\
\hline Fetuses & $1(0.17)$ & $0(0.00)$ & $0(0.00)$ & $0(0.00)$ \\
\hline Litters & $1(2.27)$ & $0(0.00)$ & $0(0.00)$ & $0(0.00)$ \\
\hline \multicolumn{5}{|c|}{ Bipartite ossification, bipartite cartilage $-[\mathrm{M}]$} \\
\hline Fetuses & $1(0.17)$ & $0(0.00)$ & $0(0.00)$ & $0(0.00)$ \\
\hline Litters & $1(2.27)$ & $0(0.00)$ & $0(0.00)$ & $0(0.00)$ \\
\hline \multicolumn{5}{|c|}{ Unilateral ossification, bipartite cartilage - [M] } \\
\hline Fetuses & $1(0.17)$ & $0(0.00)$ & $0(0.00)$ & $0(0.00)$ \\
\hline Litters & $1(2.27)$ & $0(0.00)$ & $0(0.00)$ & $0(0.00)$ \\
\hline \multicolumn{5}{|c|}{ Unossified, bipartite cartilage - $[\mathrm{M}]$} \\
\hline Fetuses & $1(0.17)$ & $0(0.00)$ & $0(0.00)$ & $0(0.00)$ \\
\hline Litters & $1(2.27)$ & $0(0.00)$ & $0(0.00)$ & $0(0.00)$ \\
\hline \multicolumn{5}{|c|}{ Bipartite ossification, normal cartilage $-[\mathrm{V}]$} \\
\hline Fetuses & $2(0.33)$ & $3(1.00)$ & $1(0.37)$ & $1(0.39)$ \\
\hline Litters & $2(4.55)$ & $2(9.52)$ & $1(4.76)$ & $1(5.00)$ \\
\hline \multicolumn{5}{|c|}{ Bipartite ossification, dumbbell cartilage - [V] } \\
\hline Fetuses & $1(0.17)$ & $0(0.00)$ & $2(0.74)$ & $1(0.39)$ \\
\hline Litters & $1(2.27)$ & $0(0.00)$ & $2(9.52)$ & $1(5.00)$ \\
\hline \multicolumn{5}{|c|}{ Bipartite ossification, normal or dumbbell cartilage - [V] } \\
\hline Fetuses & $3(0.50)$ & $3(1.00)$ & $3(1.11)$ & $2(0.77)$ \\
\hline Litters & $3(6.82)$ & $2(9.52)$ & $3(14.29)$ & $1(5.00)$ \\
\hline \multicolumn{5}{|c|}{ Dumbbell ossification, normal cartilage - [V] } \\
\hline Fetuses & $7(1.17)$ & $4(1.33)$ & $4(1.48)$ & $7(2.70)$ \\
\hline Litters & $6(13.64)$ & $3(14.29)$ & $4(19.05)$ & $3(15.00)$ \\
\hline \multicolumn{5}{|c|}{ Dumbbell ossification, dumbbell cartilage - [V] } \\
\hline Fetuses & $3(0.50)$ & $1(0.33)$ & $2(0.74)$ & $2(0.77)$ \\
\hline Litters & $2(4.55)$ & $1(4.76)$ & $2(9.52)$ & $2(10.00)$ \\
\hline \multicolumn{5}{|c|}{ Dumbbell ossification, normal or dumbbell cartilage - [V] } \\
\hline Fetuses & $10(1.67)$ & $5(1.67)$ & $6(2.22)$ & $9(3.47)$ \\
\hline Litters & $8(18.18)$ & $4(19.05)$ & $5(23.81)$ & $4(20.00)$ \\
\hline \multicolumn{5}{|c|}{ Cartilage, normal ossification, dumbbell cartilage - [V] } \\
\hline Fetuses & $0(0.00)$ & $1(0.33)$ & $0(0.00)$ & $0(0.00)$ \\
\hline Litters & $0(0.00)$ & $1(4.76)$ & $0(0.00)$ & $0(0.00)$ \\
\hline \multicolumn{5}{|l|}{ Ribs } \\
\hline \multicolumn{5}{|l|}{ Cartilage, discontinuous - [M] } \\
\hline Fetuses & $0(0.00)$ & $1(0.33)$ & $0(0.00)$ & $0(0.00)$ \\
\hline Litters & $0(0.00)$ & $1(4.76)$ & $0(0.00)$ & $0(0.00)$ \\
\hline
\end{tabular}




\begin{tabular}{|c|c|c|c|c|}
\hline & $0 \mathrm{mg} / \mathrm{kg}$ & $162.5 \mathrm{mg} / \mathrm{kg}$ & $325 \mathrm{mg} / \mathrm{kg}$ & $650 \mathrm{mg} / \mathrm{kg}$ \\
\hline \multicolumn{5}{|c|}{ Cartilage, VIII attached to sternum - [M] } \\
\hline Fetuses & $1(0.17)$ & $0(0.00)$ & $0(0.00)$ & $0(0.00)$ \\
\hline Litters & $1(2.27)$ & $0(0.00)$ & $0(0.00)$ & $0(0.00)$ \\
\hline \multicolumn{5}{|c|}{ Discontinuous - $[\mathrm{M}]$} \\
\hline Fetuses & $1(0.17)$ & $0(0.00)$ & $0(0.00)$ & $0(0.00)$ \\
\hline Litters & $1(2.27)$ & $0(0.00)$ & $0(0.00)$ & $0(0.00)$ \\
\hline \multicolumn{5}{|c|}{ Floating extra $-[\mathrm{V}]$} \\
\hline Fetuses & $0(0.00)$ & $0(0.00)$ & $1(0.37)$ & $0(0.00)$ \\
\hline Litters & $0(0.00)$ & $0(0.00)$ & $1(4.76)$ & $0(0.00)$ \\
\hline \multicolumn{5}{|c|}{ Left, intercostal rib - [M] } \\
\hline Fetuses & $1(0.17)$ & $0(0.00)$ & $0(0.00)$ & $0(0.00)$ \\
\hline Litters & $1(2.27)$ & $0(0.00)$ & $0(0.00)$ & $0(0.00)$ \\
\hline \multicolumn{5}{|c|}{ Lumbar I full $-[\mathrm{M}]$} \\
\hline Fetuses & $4(0.67)$ & $4(1.33)$ & $2(0.74)$ & $3(1.16)$ \\
\hline Litters & $4(9.09)$ & $3(14.29)$ & $1(4.76)$ & $2(10.00)$ \\
\hline \multicolumn{5}{|c|}{ Lumbar I rudimentary $^{\mathrm{a}}-[\mathrm{V}]$} \\
\hline Fetuses & $82(13.69) * * \#$ & $65(21.67)^{* *}$ & $61(22.59)^{* * \#}$ & $56(21.62)^{* *}$ \\
\hline Litters & $29(65.91)$ & $17(80.95)$ & 17 (80.95) & $15(75.00)$ \\
\hline \multicolumn{5}{|l|}{ Sternebrae } \\
\hline \multicolumn{5}{|c|}{ Sternebra II, incomplete ossification - [V] } \\
\hline Fetuses & $1(0.17)$ & $0(0.00)$ & $0(0.00)$ & $0(0.00)$ \\
\hline Litters & $1(2.27)$ & $0(0.00)$ & $0(0.00)$ & $0(0.00)$ \\
\hline \multicolumn{5}{|c|}{ Sternebra V, incomplete ossification - $[\mathrm{V}]$} \\
\hline Fetuses & $2(0.33)$ & $1(0.33)$ & $4(1.48)$ & $0(0.00)$ \\
\hline Litters & $2(4.55)$ & $1(4.76)$ & $3(14.29)$ & $0(0.00)$ \\
\hline \multicolumn{5}{|c|}{ Sternebra(e), extra ossification site between sternebrae - [V] } \\
\hline Fetuses & $3(0.50)$ & $1(0.33)$ & $0(0.00)$ & $0(0.00)$ \\
\hline Litters & $2(4.55)$ & $1(4.76)$ & $0(0.00)$ & $0(0.00)$ \\
\hline \multicolumn{5}{|c|}{ Sternebra(e), Total, Incomplete Ossification - [V] } \\
\hline Fetuses & $3(0.50)$ & $1(0.33)$ & $4(1.48)$ & $0(0.00)$ \\
\hline Litters & $3(6.82)$ & $1(4.76)$ & $3(14.29)$ & $0(0.00)$ \\
\hline \multicolumn{5}{|c|}{ Sternebra(e), misaligned (>2, not V) - [V] } \\
\hline Fetuses & $1(0.17)$ & $0(0.00)$ & $0(0.00)$ & $0(0.00)$ \\
\hline Litters & $1(2.27)$ & $0(0.00)$ & $0(0.00)$ & $0(0.00)$ \\
\hline
\end{tabular}

Upper row denotes number of affected fetuses and (\%) and lower row the number of affected litters and (\%).

Statistical analysis for litter data and for fetal data (without the litter effects) performed by the Cochran-Armitage (trend) and Fisher exact (pairwise) tests.

**Statistically significant ( $\mathrm{p} \leq 0.01$ ) trend (denoted in vehicle control column) or pairwise comparison (denoted in dose group column) in litter-based analysis of fetuses.

Statistical analysis of fetuses with litter-based adjustments performed by mixed-effects logistic regression.

\#Statistically significant $(\mathrm{p} \leq 0.05)$ trend (denoted in vehicle control column) or pairwise comparison (denoted in dose group column) in litter-based analysis of fetuses.

$[\mathrm{M}]=$ malformation; $[\mathrm{V}]$ = variation.

${ }^{a}$ Historical incidence for all routes: Fetuses 114/1,385 (8.23\%), range 3.35-13.69\%; Litters 53/97 (54.64\%), range 26.32$65.91 \%$. 


\section{Discussion}

Tris(chloropropyl) phosphate (TCPP) is a high production flame retardant mixture for use in textiles, furniture (flexible polyurethane foam), construction materials (rigid polyurethane foam), electronic products, paints, coatings, and adhesives. ${ }^{2 ;} 50$ TCPP has been proposed as a substitute for brominated flame retardants and as a replacement for other chlorinated flame retardants such as tris(2-chloroethyl) phosphate that have been identified to be toxic. ${ }^{8 ;}$ Based on the potential for increased use and exposure, the Consumer Product Safety Commission nominated TCPP for toxicological testing by NTP. NTP is in the process of evaluating TCPP toxicity on various cellular or molecular targets in vitro and is testing for subchronic toxicity, chronic toxicity, carcinogenicity, genotoxicity, and immunotoxicity in rodent models. Further information on NTP's evaluation of the potential toxicity of TCPP is available at the Program's website. ${ }^{1}$ The purpose of this report is to summarize and discuss TCPP effects on prenatal development in rats because of concerns for exposure to women of childbearing potential and the lack of robust evaluations for developmental toxicity. This DART Technical Report presents the findings of the dose range-finding and prenatal developmental toxicity studies of TCPP in Hsd:Sprague Dawley ${ }^{\circledR} \mathrm{SD}^{\circledR}$ rats.

TCPP doses selected for the range-finding study were $0,300,650,1,000 \mathrm{mg} / \mathrm{kg}$. Maternal toxicity was observed, as evidenced by mortality and morbidity in 7 of 11 dams in the $1,000 \mathrm{mg} / \mathrm{kg}$ group. In previously conducted studies, TCPP did not affect survival of Wistar Han rats exposed to as much as $1,000 \mathrm{mg}$ TCPP/kg body weight per day in the diet over two generations.; 5 TCPP also did not affect survival in a developmental toxicity study of Wistar rats given TCPP in their diet (up to $893 \mathrm{mg} / \mathrm{kg}$ per day). ${ }^{3 ; 16}$ These data suggest the route of administration of TCPP could have contributed to maternal toxicity observed in the current range-finding study. Other differences in the exposure paradigms such as exposure duration and strain differences may also have contributed to toxicity.

In this dose range-finding study, treatment-related clinical observations are reported in dams exposed to $1,000 \mathrm{mg} / \mathrm{kg}$ TCPP. These included convulsions, tremors, prone, gasping, hypoactivity, hunched posture, nasal discharge, stained fur, piloerection, salivation, and rooting (pre- and postdosing), which occurred throughout gestation. One dam in the $650 \mathrm{mg} / \mathrm{kg}$ dose range-finding study was euthanized moribund following adverse clinical observations including ataxia, hypoactivity, piloerection, labored respiration, pale and cold to touch. Because of the singular incidence of overt toxicity and adverse clinical observations in the $650 \mathrm{mg} / \mathrm{kg}$ group, the relationship between TCPP exposure and maternal toxicity at this dose was considered uncertain. These findings are consistent with reported clinical observations from acute oral (gavage) toxicity studies, which are summarized in the European Union Risk Assessment Report of TCPP. ${ }^{5}$

Several clinical observations (e.g., convulsions, tremors) observed in the dose range-finding study indicate that high doses of TCPP may be neurotoxic in rats. TCPP belongs to the flame retardant class of organophosphate flame retardants, which are structurally similar to organophosphate pesticides, many of which have previously been shown to affect the nervous system. ${ }^{51-54}$ In vitro studies in neuronal cells suggest that flame retardants with an organophosphate backbone (i.e., organophosphate flame retardants) may be toxic to adult and developing nervous systems, ${ }^{55 ; 56}$ developing zebrafish, ${ }^{57 ;} 58$ and Caenorhabditis elegans. ${ }^{59 ; 60}$ 
However, the clinical observations of neurotoxicity observed in the range-finding study were not observed in a rodent developmental toxicity study in the published literature, ${ }^{16}$ possibly due to TCPP administration through feed. Likewise, clinical signs of neurotoxicity were not observed in several repeat dose or reproduction feed studies summarized by risk assessment documents or reported in the literature. 1; 3; 5; 11 These data suggest that neurological clinical observations are limited to instances of high bolus doses of TCPP.

The dose range-finding study results demonstrating overt maternal toxicity (i.e., mortality) at $1,000 \mathrm{mg} / \mathrm{kg}$ informed the selection of the TCPP doses for this prenatal developmental toxicity study, which were $0,162.5,325$, or $650 \mathrm{mg} / \mathrm{kg} /$ day As predicted, TCPP was well tolerated at all administered doses during the study, which allowed for definitive evaluation of TCPP effects on embryo-fetal development. No significant effects were observed on maternal survival, body weights, or feed consumption in the prenatal developmental toxicity study of TCPP. Also as anticipated, hyperactivity was observed in one $650 \mathrm{mg} / \mathrm{kg}$ dam, but not in dams exposed to lower doses. This clinical observation occurred from GD 7 to GD 13 and was considered treatment related. The clinical observations were also similar to those made in the range-finding study, which supports a dose-related effect of TCPP exposure. At necropsy, several organ weights were evaluated and dose-related increases in absolute and relative liver weights were found. Multiple studies have shown that TCPP exposure can increase liver weights and alter liver histopathology in rats and mice following repeat exposures. ${ }^{3-5 ; 19}$ Therefore, these results are concordant with previous research and confirm that the liver is a target following TCPP exposure in vivo. Whether chemical-induced changes in liver weights are adverse or adaptive has been debated in the literature and typically includes review of liver histopathology and enzyme induction (ref). ${ }^{61}$; ${ }^{62}$ In this study, all information required to determine if a $26 \%$ increase in dam relative liver weight is toxicologically relevant is not available; however, some studies suggest that a $50 \%$ increase in liver weight is correlated with adverse changes such as tumor induction (ref). ${ }^{63}$ The information available suggested that the dose-related increase in liver weight was deemed an adaptive change rather than representative of overt toxicity in the dams in this study.

Because of excess maternal toxicity in the $1,000 \mathrm{mg} / \mathrm{kg}$ group of the dose range-finding study, assessment of developmental toxicity was not possible at this dose. There were some indications of TCPP-related fetal effects in the $650 \mathrm{mg} / \mathrm{kg}$ group, but these findings were either not statistically significant (increased mean percent postimplantation loss, decreased number of live fetuses per litter, and decreased gravid uterine weight) or of no biological significance due to the magnitude of the effect (i.e., decreased mean fetal body weight per litter). Increasing the number of animals examined from 11 to 25 for the prenatal developmental toxicity study confirmed that TCPP exposure during gestation has no significant effect on embryo-fetal toxicity. Overall, there was no evidence of growth retardation following TCPP exposure.

Examination of fetuses for malformations or variations in the prenatal developmental toxicity study demonstrated that TCPP exposure does not cause toxicologically significant external, visceral, or skeletal defects. The only statistically significant exposure-related finding was an increase in the percentage of fetuses with lumbar rudimentary ribs. In NTP's experience, this skeletal variation is variable among this strain of rat. Rudimentary ribs have been reported to be common in laboratory rodents and are considered reversible and of limited toxicological relevance. ${ }^{64 ; 65}$ 
In the previously published developmental toxicity study in rats, ${ }^{16}$ dose-related increases in the incidences of cervical ribs and absent 13th rib malformations were reported. TCPP exposure in the study by Kawasaki et al. ${ }^{16}$ occurred in feed from GD 0 to GD 20 and was conducted in Wistar rats. These experimental variables (exposure window, route of administration, and rodent strain) may account for the differences in skeletal malformations observed between the Kawasaki et al. ${ }^{16}$ report and the prenatal developmental toxicity study described here. 


\section{Conclusions}

Under the conditions of this prenatal study, no evidence of developmental toxicity of TCPP was found in Hsd:Sprague Dawley ${ }^{\circledR} \mathrm{SD}^{\circledR}$ rats administered 162.5, 325, or $650 \mathrm{mg} / \mathrm{kg} / \mathrm{day}$ in the absence of overt maternal toxicity. 


\section{References}

1. National Toxicology Program (NTP). Tris(chloropropyl)phosphate - M20263. Research Triangle Park, NC: U.S. Department of Health and Human Services, Public Health Service, National Toxicology Program; 2016. http://ntp.niehs.nih.gov/testing/status/agents/tsm20263.html [Accessed: November 16, 2016]

2. U.S. Environmental Protection Agency (USEPA). TSCA work plan chemical problem formulation and initial assessment: Chlorinated phosphate ester cluster flame retardants. Washington, DC: U.S. Environmental Protection Agency, Office of Chemical Safety and Pollution Prevention, Office of Pollution Prevention and Toxics; 2015. EPA Document No. EPA/740/R-15/001.

3. U.S. Environmental Protection Agency (USEPA). Flame retardants used in flexible polyurethane foam: An alternatives assessment update. Washington, DC: U.S. Environmental Protection Agency; 2015. EPA Document No. EPA/744/R-15/002.

4. National Research Council (NRC). Toxicological risks of selected flame-retardant chemicals. Washington, DC: National Academies Press; 2000.

5. European Union (EU). Tris(2 chloro-1 methylethyl) Phosphate (TCPP), (CAS No. 13674-845, EINECS No. 237-158-7) risk assessment. Luxembourg: Office for Official Publications of the European Communities; 2008.

6. Agency for Toxic Substances and Disease Registry (ATSDR). Toxicological profile for phosphate ester flame retardants. Atlanta, GA: U.S. Department of Health and Human Services, Public Health Service, Agency for Toxic Substances and Disease Registry; 2012.

7. U.S. Environmental Protection Agency (USEPA). 2012 Chemical Data Reporting (CDR): 2propanol, 1-chloro, 2,2'2"-phosphate. Washington, DC: U.S. Environmental Protection Agency, Office of Chemical Safety and Pollution Prevention, Office of Pollution Prevention and Toxics; 2012.

8. Wilczynski SL, Killinger JM, Zwicker GM, Freudenthal RI. Fyrol FR-2 fertility study in male rabbits. Toxicologist. 1983; 3:22.

9. World Health Organization (WHO). Flame retardants: Tris(chloropropyl) phosphate and tris(2-chloroethyl) phosphate. Geneva, Switzerland: World Health Organization; 1998. Environmental Health Criteria 209.

10. U.S. Environmental Protection Agency (USEPA). Substance Registry Service (SRS): Chemical and substance resources. Washington, DC: U.S. Environmental Protection Agency; 2016.

https://iaspub.epa.gov/sor_internet/registry/substreg/searchandretrieve/substancesearch/search.do [Accessed: November 16, 2016]

11. Organisation for Economic Co-operation and Development (OECD). Screening Information Dataset (SIDS) initial assessment profile: Tris(1-chloro-2-propyl)phosphate, CAS No: 13674-845. Geneva, Switzerland: UNEP Chemicals, UNEP Publications; 2000. 
12. U.S. Environmental Protection Agency (USEPA). Reducing your child's exposure to flame retardant chemicals. Washington, DC: U.S. Environmental Protection Agency; 2016. EPA Document No. EPA/740/16/001.

13. European Chemicals Agency (ECHA). Substance information: Tris (2-chloro-1-methylethyl) phosphate. 2016. https://echa.europa.eu/substance-information/-/substanceinfo/100.033.766

14. Minegishi KI, Kurebayashi H, Nambaru S, Morimoto K, Takahashi T, Yamaha T. Comparative studies on absorption, distribution, and excretion of flame retardants halogenated alkyl phosphate in rats. Eisei Kagaku. 1988; 34(2):102-114.

http://dx.doi.org/10.1248/jhs1956.34.102

15. Van den Eede N, Maho W, Erratico C, Neels H, Covaci A. First insights in the metabolism of phosphate flame retardants and plasticizers using human liver fractions. Toxicol Lett. 2013; 223(1):9-15. http://dx.doi.org/10.1016/j.toxlet.2013.08.012

16. Kawasaki H, Murai T, Kanoh S. Studies on the toxicity of insecticides and food additives in pregnant rats. V. Fetal toxicity of tris-(chloropropyl) phosphate (TCPP) [In Japanese]. Oyo Yakuri. 1982; 24:697-702.

17. National Industrial Chemicals Notification Assessment Scheme (NICNAS). Inventory Multitiered Assessment and Prioritisation (IMAP): Human health tier II assessment for 2 propanol, 1 chloro , phosphate (3:1). Australia: Australian Government, Department of Health, National Industrial Chemicals Notification and Assessment Scheme; 2016.

https://www.nicnas.gov.au/chemical-information/imap-assessments/imap-assessmentdetails?assessment_id=1891 [Accessed: August 1, 2016]

18. Freudenthal RI, Henrich RT. A subchronic toxicity study of Fyrol PCF in Sprague-Dawley rats. Int J Toxicol. 1999; 18(3):173-176. http://dx.doi.org/10.1080/109158199225468

19. National Toxicology Program (NTP). TOX-tbd - tris(chloropropyl)phosphate (TCPP). Research Triangle Park, NC: U.S. Department of Health and Human Services, Public Health Service, National Toxicology Program, Chemical Effects in Biological Systems; 2016. http://tools.niehs.nih.gov/cebs3/views/?action=main.dataReview\&bin_id=1660 [Accessed: August 1, 2016]

20. National Toxicology Program (NTP). Nominated substances. Research Triangle Park, NC: U.S. Department of Health and Human Services, Public Health Service, National Toxicology Program; 2005. https://ntp.niehs.nih.gov/ntp/htdocs/chem_background/exsumpdf/cpscfrsnomination_supp_062 508.pdf [Accessed: November 16, 2016]

21. Chernoff N, Setzer RW, Miller DB, Rosen MB, Rogers JM. Effects of chemically induced maternal toxicity on prenatal development in the rat. Teratology. 1990; 42(6):651-658. http://dx.doi.org/10.1002/tera.1420420610

22. U.S. Environmental Protection Agency (USEPA). Guidelines for developmental toxicity risk assessment. Washington, DC: U.S. Environmental Protection Agency, Risk Assessment Forum; 1991. EPA Document No. EPA/600/FR-91/001. 
23. Tyl RW. Commentary on the role of maternal toxicity on developmental toxicity. Birth Defects Res B: Dev Reprod Toxicol. 2012; 95(3):262-266. http://dx.doi.org/10.1002/bdrb.21015

24. Organisation for Economic Co-operation and Development (OECD). OECD guideline for the testing of chemicals: Proposal for updating guideline 414. Prenatal developmental toxicity study. Paris, France: Organisation for Economic Co-operation and Development; 2001.

25. Makris SL, Solomon HM, Clark R, Shiota K, Barbellion S, Buschmann J, Ema M, Fujiwara M, Grote K, Hazelden KP. Terminology of developmental abnormalities in common laboratory mammals (version 2). Congenit Anom. 2009; 49(3):123-246. http://dx.doi.org/10.1111/j.17414520.2009.00239.x

26. National Institute of Standards and Technology (NIST). NIST/EPA/NIH mass spectral library (NIST 08) and NIST mass spectral search program (version 2.0f). Gaithersburg, MD: U.S. Department of Commerce, National Institute of Standards and Technology; 2008.

27. Suckow MA, Weisbroth SH, Franklin CL. The laboratory rat. 2nd ed. Amsterdam, Netherlands: Elsevier; 2006.

28. Hayes AW, Kruger CL. Hayes’ principles and methods of toxicology. 6th ed. Boca Raton, FL: CRC Press; 2014. p. 1670-1672.

29. Salewski E. Färbemethode zum makroskopischen nachweis von implantationsstellen am uterus der ratte. Naunyn-Schmiedeberg's Arch Pharmacol. 1964; 247(4):367. http://dx.doi.org/10.1007/BF02308461

30. Staples RE. Detection of visceral alterations in mammalian fetuses. Teratology. 1974; 9:A37A38.

31. Stuckhardt JL, Poppe SM. Fresh visceral examination of rat and rabbit fetuses used in teratogenicity testing. Teratog Carcinog Mutagen. 1984; 4(2):181-188.

http://dx.doi.org/10.1002/tcm.1770040203

32. Thompson RF. Basic neuroanatomy. Foundations of Physiological Psychology. New York, NY: Harper and Row Publishers; 1967. p. 79-82.

33. Marr MC, Price CJ, Myers CB, Morrissey RE. Developmental stages of the CD $($ (SpragueDawley) rat skeleton after maternal exposure to ethylene glycol. Teratology. 1992; 46(2):169181. http://dx.doi.org/10.1002/tera.1420460210

34. Tyl RW, Marr MC. Developmental toxicity texting - methodology. Developmental and Reproductive Toxicology. 2nd ed. New York, NY: Taylor and Francis Group; 2006. p. 201-261.

35. Dunnett CW. A multiple comparison procedure for comparing several treatments with a control. J Am Stat Assoc. 1955; 50(272):1096-1121. http://dx.doi.org/10.1080/01621459.1955.10501294

36. Williams DA. A test for differences between treatment means when several dose levels are compared with a zero dose control. Biometrics. 1971; 27:103-117.

http://dx.doi.org/10.2307/2528930 
37. Williams DA. The comparison of several dose levels with a zero dose control. Biometrics. 1972; 28:519-531. http://dx.doi.org/10.2307/2556164

38. Shirley E. A non-parametric equivalent of Williams' test for contrasting increasing dose levels of a treatment. Biometrics. 1977; 33:386-389. http://dx.doi.org/10.2307/2529789

39. Williams DA. A note on Shirley's nonparametric test for comparing several dose levels with a zero-dose control. Biometrics. 1986; 42:183-186. http://dx.doi.org/10.2307/2531254

40. Dunn OJ. Multiple comparisons using rank sums. Technometrics. 1964; 6(3):241-252. http://dx.doi.org/10.1080/00401706.1964.10490181

41. Jonckheere AR. A distribution-free k-sample test against ordered alternatives. Biometrika. 1954; 41(1/2):133-145. http://dx.doi.org/10.2307/2333011

42. Dixon WJ, Massey FJ, Jr. Introduction to statistical analysis. 2nd ed. New York, NY: McGraw-Hill Book Company, Inc; 1957. p. 276-278, 412.

43. Hsu JC. The factor analytic approach to simultaneous inference in the general linear model. J Comput Graph Stat. 1992; 1(2):151-168.

44. Armitage P. Tests for linear trends in proportions and frequencies. Biometrics. 1955; 11(3):375-386. http://dx.doi.org/10.2307/3001775

45. Gart JJ, Chu KC, Tarone RE. Statistical issues in interpretation of chronic bioassay tests for carcinogenicity. J Natl Cancer Inst. 1979; 62(4):957-974.

46. Zorrilla EP. Multiparous species present problems (and possibilities) to developmentalists. Dev Psychobiol. 1997; 30(2):141-150. http://dx.doi.org/10.1002/(SICI)10982302(199703)30:2<141::AID-DEV5>3.0.CO;2-Q

47. Pendergast JF, Gagne SJ, Lindstrom MJ. Correlated binary data. In: Encyclopedia of Biostatistics. London, UK: John Wiley \& Sons, Ltd; 2005.

http://dx.doi.org/10.1002/0470011815.b2a10018

48. Li B, Lingsma HF, Steyerberg EW, Lesaffre E. Logistic random effects regression models: A comparison of statistical packages for binary and ordinal outcomes. BMC Med Res Methodol. 2011; 11(1):77. http://dx.doi.org/10.1186/1471-2288-11-77.

49. National Toxicology Program (NTP). DART-01: Growth and clinical finding tables (I), pathology tables (PA), developmental and reproductive tables (R) from NTP developmental and reproductive toxicity studies. Research Triangle Park, NC. 2019.

http://dx.doi.org/10.22427/NTP-DATA-DART-01

50. Marklund A, Andersson B, Haglund P. Screening of organophosphorus compounds and their distribution in various indoor environments. Chemosphere. 2003; 53(9):1137-1146. http://dx.doi.org/10.1016/S0045-6535(03)00666-0

51. Slotkin TA, Levin ED, Seidler FJ. Developmental neurotoxicity of parathion: Progressive effects on serotonergic systems in adolescence and adulthood. Neurotoxicol Teratol. 2009; 31(1):11-17. http://dx.doi.org/10.1016/j.ntt.2008.08.004 
52. Slotkin TA, Seidler FJ. Developmental exposure to organophosphates triggers transcriptional changes in genes associated with Parkinson's disease in vitro and in vivo. Brain Res Bull. 2011; 86(5-6):340-347. http://dx.doi.org/10.1016/j.brainresbull.2011.09.017

53. Muñoz-Quezada MT, Lucero BA, Barr DB, Steenland K, Levy K, Ryan PB, Iglesias V, Alvarado S, Concha C, Rojas E. Neurodevelopmental effects in children associated with exposure to organophosphate pesticides: A systematic review. Neurotoxicology. 2013; 39:158168. http://dx.doi.org/10.1016/j.neuro.2013.09.003

54. Carr RL, Graves CA, Mangum LC, Nail CA, Ross MK. Low level chlorpyrifos exposure increases anandamide accumulation in juvenile rat brain in the absence of brain cholinesterase inhibition. Neurotoxicology. 2014; 43:82-89. http://dx.doi.org/10.1016/j.neuro.2013.12.009

55. Dishaw LV, Powers CM, Ryde IT, Roberts SC, Seidler FJ, Slotkin TA, Stapleton HM. Is the PentaBDE replacement, tris (1, 3-dichloro-2-propyl) phosphate (TDCPP), a developmental neurotoxicant? Studies in PC12 cells. Toxicol Appl Pharmacol. 2011; 256(3):281-289. http://dx.doi.org/10.1016/j.taap.2011.01.005

56. Behl M, Hsieh J-H, Shafer TJ, Mundy WR, Rice JR, Boyd WA, Freedman JH, Hunter Iii ES, Jarema KA, Padilla S. Use of alternative assays to identify and prioritize organophosphorus flame retardants for potential developmental and neurotoxicity. Neurotoxicol Teratol. 2015; 52:181-193. http://dx.doi.org/10.1016/j.ntt.2015.09.003

57. Dishaw LV, Hunter DL, Padnos B, Padilla S, Stapleton HM. Developmental exposure to organophosphate flame retardants elicits overt toxicity and alters behavior in early life stage zebrafish (Danio rerio). Toxicol Sci. 2014; 142(2):445-454.

http://dx.doi.org/10.1093/toxsci/kfu194

58. Oliveri AN, Bailey JM, Levin ED. Developmental exposure to organophosphate flame retardants causes behavioral effects in larval and adult zebrafish. Neurotoxicol Teratol. 2015; 52:220-227. http://dx.doi.org/10.1016/j.ntt.2015.08.008

59. Behl M, Rice JR, Smith MV, Co CA, Bridge MF, Hsieh J-H, Freedman JH, Boyd WA. Editor's highlight: Comparative toxicity of organophosphate flame retardants and polybrominated diphenyl ethers to Caenorhabditis elegans. Toxicol Sci. 2016; 154(2):241-252. http://dx.doi.org/10.1093/toxsci/kfw162

60. Xu T, Li P, Wu S, Lei L, He D. Tris (2-chloroethyl) phosphate (TCEP) and tris (2chloropropyl) phosphate (TCPP) induce locomotor deficits and dopaminergic degeneration in Caenorhabditis elegans. Toxicol Res (Camb). 2017; 6(1):63-72.

http://dx.doi.org/10.1039/C6TX00306K

61. Hall AP, Elcombe CR, Foster JR, Harada T, Kaufmann W, Knippel A, Küttler K, Malarkey DE, Maronpot RR, Nishikawa A et al. Liver hypertrophy: A review of adaptive (adverse and non-adverse) changes-conclusions from the 3rd International ESTP Expert Workshop. Toxicol Pathol. 2012; 40(7):971-994. http://dx.doi.org/10.1177/0192623312448935

62. Maronpot RR, Yoshizawa K, Nyska A, Harada T, Flake G, Mueller G, Singh B, Ward JM. Hepatic enzyme induction: Histopathology. Toxicol Pathol. 2010; 38(5):776-795. http://dx.doi.org/10.1177/0192623310373778 
63. Carmichael NG, Enzmann H, Pate I, Waechter F. The significance of mouse liver tumor formation for carcinogenic risk assessment: Results and conclusions from a survey of ten years of testing by the agrochemical industry. Environ Health Perspect. 1997; 105(11):1196-1203. http://dx.doi.org/10.1289/ehp.971051196

64. Wickramaratne GA. The post-natal fate of supernumerary ribs in rat teratogenicity studies. J Appl Toxicol. 1988; 8(2):91-94. http://dx.doi.org/10.1002/jat.2550080205

65. Foulon O, Jaussely C, Repetto M, Urtizberea M, Blacker AM. Postnatal evolution of supernumerary ribs in rats after a single administration of sodium salicylate. J Appl Toxicol. 2000; 20(3):205-209. http://dx.doi.org/10.1002/(SICI)1099-1263(200005/06)20:3<205::AIDJAT635>3.0.CO;2-G

66. Spectrum A. The Aldrich Library of Infrared Spectra. 3rd ed. Milwaukee, WI: Aldrich Chemical Company, Inc; 1981. p. 1578. 


\section{Appendix A. Chemical Characterization and Dose Formulation Studies}

\section{Table of Contents}

A.1. Procurement and Characterization ................................................................................. A-2

A.2. Preparation and Analysis of Dose Formulations ........................................................ A-3

\section{Tables}

Table A-1. Gas Chromatography Systems Used in the Gavage Studies of

Tris(chloropropyl) Phosphate ....................................................................... A-4

Table A-2. Preparation and Storage of Dose Formulations in the Gavage Studies of

Tris(chloropropyl) Phosphate .......................................................................... A-5

Table A-3. Results of Analyses of Dose Formulations Administered to Female Rats in the

Dose Range-finding Gavage Study of Tris(chloropropyl) Phosphate .................... A-6

Table A-4. Results of Analyses of Dose Formulations Administered to Female Rats in the Prenatal Developmental Toxicity Gavage Study of Tris(chloropropyl)

Phosphate

\section{Figures}

Figure A-1. Fourier Transform Infrared Absorption Spectrum of Tris(chloropropyl)

Phosphate

Figure A-2. Proton Nuclear Magnetic Resonance Spectrum of Tris(chloropropyl)

Phosphate 


\section{A.1. Procurement and Characterization}

\section{A.1.1. Tris(chloropropyl) Phosphate (TCPP)}

TCPP was obtained from Albemarle Corporation (Orangeburg, SC) in two lots (101 and 134). Lot 101 was used in the dose range-finding study, and lots 101 and 134 were blended to form lot M072911NP, which was divided into two drums and used during the prenatal developmental toxicity study. Homogeneity of the blended lot M072911NP was confirmed both within the individual drums and between the two drums. Identity, purity, and stability analyses were conducted by the analytical chemistry laboratory at MRI Global (Kansas City, MO) for the study laboratory at RTI International (Research Triangle Park, NC). Reports on analyses performed in support of the TCPP studies are on file at the National Institute of Environmental Health Sciences.

Lots 101, 134, and M072911NP of the test chemical (clear oily liquids) were identified as TCPP using proton and carbon-13 Fourier transform nuclear magnetic resonance (FT-NMR) spectroscopy. In addition, lots 101 and M072911NP were identified as TCPP using Fourier transform infrared (FT-IR) and ultraviolet/visible (UV-Vis) spectroscopy, gas chromatography (GC) with mass spectrometry (MS) detection, and measurement of density. FT-NMR, FT-IR, and UV-Vis spectra were consistent with the structure of TCPP. Because of the isomeric complexity of the test article, two-dimensional FT-NMR was performed on lot M072911NP including homonuclear correlation spectroscopy (COSY) and heteronuclear correlation (HETCOR) spectroscopy to confirm the data from the proton and carbon-13 NMR spectra. Representative FT-IR and proton NMR spectra are presented in Figure A-1 and Figure A-2, respectively. GC/MS electron ionization analyses of lots 101 and M072911NP identified one major peak and three isomers with molecular weights of 327.6. The primary isomer (Isomer 1; tris(1-chloro-2-propyl) phosphate, CASRN No. 13674-84-5) matched a literature spectrum ${ }^{26}$; the three other isomers were identified as bis (1-chloro-2-propyl) 2-chloro-1-propyl phosphate (Isomer 2, CASRN No. 76025-08-6); bis (2-chloro-1-propyl) 1-chloro-2-propyl phosphate (Isomer 3, CASRN No. 76649-15-5); and tris(2-chloro-1-propyl) phosphate (Isomer 4, CASRN No. 6145-73-9) (Table 2). The densities (at $21^{\circ} \mathrm{C}$ ) of lots 101 and M072911NP were determined to be 1.2936 and $1.2958-1.2959$, respectively.

The moisture content of lots 101 and M072911NP was determined by Karl Fischer titration. Elemental analyses for carbon, hydrogen, nitrogen, and chlorine were conducted by ICON Development Solutions (Whitesboro, NY) on lots 101 and M072911NP. The purity profiles of lots 101, 134, and M072911NP were determined using GC with flame ionization detection (FID), and octanol:water partition coefficients were determined for the two largest peaks of the profiles for lots 101 and M072911NP. Acid number and ester value were determined for lots 101 and M072911NP using titration with standardized $\sim 0.001 \mathrm{~N}$ sodium hydroxide and $\sim 0.5 \mathrm{~N}$ hydrochloric acid, respectively.

For lot 101, Karl Fischer titration indicated a water content of 0.093-0.100\%. Elemental analyses for carbon, hydrogen, nitrogen, and chlorine were consistent with the theoretical values for TCPP. GC/FID analysis by system A (Table A-1) detected four TCPP peaks with a combined area of $96.04 \%$ of the total peak area and seven reportable impurities with individual areas $\geq 0.05 \%$ of the total peak area. The largest peak in this analysis comprised $65.22 \%$ of the total peak area, and $\log \mathrm{P}$ values for the two largest peaks in this profile were determined to be 2.69 
and 2.74, respectively. The average acid number for lot 101 was determined to be $0.011 \mathrm{mg}$ potassium hydroxide $(\mathrm{KOH}) / \mathrm{g}$, and the average ester value was calculated to be $104.7 \mathrm{mg}$ $\mathrm{KOH} / \mathrm{g}$. The overall purity of lot 101 was determined to be approximately $96 \%$.

For lot 134, the GC/FID purity profile by system A detected four TCPP peaks with a combined relative area of $98.79 \%$ and three reportable impurities $\geq 0.05 \%$ of the total peak area; the largest peak comprised $71.33 \%$ of the total peak area. Coupled with the proton and carbon-13 FT-NMR identity confirmation for lot 134, these results indicated that lot 134 was suitable for blending with lot 101 to constitute lot M072911NP.

Lot M072911NP was determined to contain 0.038-0.039\% water by Karl Fischer titration. Elemental analyses for carbon, hydrogen, nitrogen, and chlorine were consistent with the theoretical values for TCPP. GC/FID by system A detected four TCPP peaks accounting for 97.04-97.43\% of the total peak area and eight minor peaks with individual areas $\geq 0.05 \%$ of the total peak area. The major peak in this analysis comprised $67.57-68.54 \%$ of the total peak area and $\log \mathrm{P}$ values for the two largest peaks in this profile were determined to be 2.59 and 2.65, respectively. Using a more polar column, GC/FID by system B detected four TCPP peaks with a combined area of $97.50-97.91 \%$ of the total peak area and six reportable impurities with individual areas $\geq 0.05 \%$ of the total peak area. The major peak in this analysis comprised 67.84 $68.85 \%$ of the total peak area. The average acid number for lot M072911NP was determined to be $0.067 \mathrm{mg} \mathrm{KOH} / \mathrm{g}$ and the average ester value was calculated to be $105.85 \mathrm{mg} \mathrm{KOH} / \mathrm{g}$. The overall purity of lot M072911NP was determined to be $97 \%$ or greater. A summary of these analyses is given in Table 2 .

Accelerated stability studies of lot 101 of the test chemical were conducted by the analytical chemistry laboratory using GC/FID by system A. Stability of the bulk chemical was confirmed for at least 2 weeks when stored in glass vials sealed with Teflon ${ }^{\circledR}$-lined crimp caps at temperatures up to $60^{\circ} \mathrm{C}$. To ensure stability, the test chemical was stored under inert gas at $\sim 25^{\circ} \mathrm{C}$, in sealed drums. Periodic analyses of lots 101 and M072911NP of the test chemical were performed prior to and during the animal studies by the analytical chemistry laboratory using FT-NMR and GC/FID; no degradation of the test chemical was detected.

\section{A.1.2. Methylcellulose}

Methylcellulose was obtained from Spectrum Quality Products (Gardena, CA) in two lots (YX0540 and 2AJ0439). Lot YX0540 was used as the vehicle in the dose range-finding study and lot 2AJ0439 was used in the prenatal developmental toxicity study. The identity of both lots was confirmed by the analytical chemistry laboratory using FT-IR spectroscopy; all spectra were consistent with the structure of methylcellulose and the literature. ${ }^{66}$ Methoxy group content, determined by Galbraith Laboratories (Knoxville, TN) using titration with standardized sodium thiosulfate solution, was $30.4 \%$ and $31.0 \%$ for lots YX0540 and 2AJ0439, respectively, both within the accepted range of $27.5-31.5 \%$.

\section{A.2. Preparation and Analysis of Dose Formulations}

The dose formulations were prepared once (dose range-finding study) or three times (prenatal developmental toxicity study) by mixing TCPP with a $0.5 \%$ methylcellulose solution to give the required concentrations (Table A-2). The dose formulations were stored at $\sim 5^{\circ} \mathrm{C}$ in sealed glass 
jars for up to 30 days (dose range-finding study) or 15 days (prenatal developmental toxicity study).

Prior to conducting the dose range-finding study, homogeneity studies of $1.56 \mathrm{mg} / \mathrm{mL}$ and $200 \mathrm{mg} / \mathrm{mL}$ formulations and stability studies of the $1.56 \mathrm{mg} / \mathrm{mL}$ formulation were performed by the analytical chemistry laboratory using GC/FID by system A (Table A-1). Homogeneity was confirmed, with the stipulation that high-dose formulations be stirred constantly during use to maintain homogeneity. Stability was confirmed for at least 7 days for dose formulations stored in sealed glass containers at $\sim 5^{\circ} \mathrm{C}$ and for 3 hours under simulated animal room conditions; at $\sim 5^{\circ} \mathrm{C}$, the $1.56 \mathrm{mg} / \mathrm{mL}$ formulation was $93.8 \%, 88 \%$, and $86.6 \%$ of the day 0 value at 7,14 , and 42 days, respectively, suggesting some loss over time. Additional stability studies were conducted at 32.5 and $130 \mathrm{mg} / \mathrm{mL}$ prior to the prenatal developmental toxicity study; stability of the $130 \mathrm{mg} / \mathrm{mL}$ formulation for up to 42 days was confirmed, while that of the $32.5 \mathrm{mg} / \mathrm{mL}$ formulation was confirmed for up to 35 days for formulations stored in sealed glass containers at $\sim 5^{\circ} \mathrm{C}$.

Periodic analyses of the dose formulations of TCPP were conducted by the analytical chemistry laboratory using GC/FID by system A. During the dose range-finding study, the dose formulations were analyzed one day after preparation and after storage at $\sim 5^{\circ} \mathrm{C}$ for 7 days; all 10 dose formulation samples were within $10 \%$ of the target concentrations (Table A-3). Animal room samples received on day 36 were also analyzed; two of six were within $10 \%$ of the target concentrations. During the prenatal developmental toxicity study, the dose formulations were prepared three times, and all nine dose formulation samples were within $10 \%$ of the target concentrations (Table A-4). Animal room samples of these dose formulations were also analyzed; six of nine were within $10 \%$ of the target concentrations.

Table A-1. Gas Chromatography Systems Used in the Gavage Studies of Tris(chloropropyl) Phosphate $^{\mathrm{a}}$

\begin{tabular}{|c|c|c|c|}
\hline Detection System & Column & Carrier Gas & $\begin{array}{c}\text { Oven Temperature } \\
\text { Program }\end{array}$ \\
\hline \multicolumn{4}{|l|}{ System A } \\
\hline Flame Ionization & $\begin{array}{l}\mathrm{DB}-5,30 \mathrm{~m} \times 0.53 \mathrm{~mm} \text {, } \\
1.5 \mu \mathrm{m} \text { film }(\mathrm{J} \& \mathrm{~W} \\
\text { Scientific, Folsom, CA })\end{array}$ & Helium at $\sim 10 \mathrm{~mL} /$ minute & $\begin{array}{l}160^{\circ} \mathrm{C} \text { for } 5 \text { minutes, then } \\
1^{\circ} \mathrm{C} / \text { minute to } 180^{\circ} \mathrm{C} \text {, held } \\
\text { for } 5,10,15 \text {, or } 25 \text { minutes }\end{array}$ \\
\hline \multicolumn{4}{|l|}{ System B } \\
\hline Flame Ionization & $\begin{array}{l}\text { DB }^{\text {TM}}-W A X, \\
30 \mathrm{~m} \times 0.53 \mathrm{~mm}, 1.0 \mu \mathrm{m} \\
\text { film (J\&W Scientific) }\end{array}$ & Helium at $\sim 10 \mathrm{~mL} /$ minute & $\begin{array}{l}200^{\circ} \mathrm{C} \text { for } 5 \text { minutes, then } \\
1^{\circ} \mathrm{C} / \text { minute to } 230^{\circ} \mathrm{C} \text {, held } \\
\text { for } 15 \text { minutes }\end{array}$ \\
\hline
\end{tabular}

aThe gas chromatographs were manufactured by Agilent Technologies, Inc. (Santa Clara, CA). 
Table A-2. Preparation and Storage of Dose Formulations in the Gavage Studies of Tris(chloropropyl) Phosphate

\section{Dose Range-finding Study}

Prenatal Developmental Toxicity Study

\section{Preparation}

The dosing vehicle was prepared by mixing methylcellulose with heated, deionized water while stirring and then diluting with water to form a $0.5 \%$ solution, which was allowed to cool. For the dose formulations, the appropriate amount of TCPP was weighed and transferred into a 2-L beaker, diluted with the vehicle, mixed using a POLYTRON ${ }^{\circledR}$ PT-10-35 homogenizer with a PTA 10TS low-foaming generator for approximately 2 minutes, and then stirred using a stir bar for approximately 5 minutes. The doses were prepared once.

\section{Chemical Lot Number}

101

M072911NP

\section{Maximum Storage Time}

30 days

Same as the 3-week dose range-finding study except that the doses were prepared three times.

\section{Storage Conditions}

Stored in glass jars with lids at $\sim 5^{\circ} \mathrm{C}$

Stored in wide-mouth clear glass jars with lids at $\sim 5^{\circ} \mathrm{C}$

\section{Study Laboratory}

RTI International (Research Triangle Park, NC)

RTI International (Research Triangle Park, NC) 
Table A-3. Results of Analyses of Dose Formulations Administered to Female Rats in the Dose Range-finding Gavage Study of Tris(chloropropyl) Phosphate

\begin{tabular}{ccccc}
\hline $\begin{array}{c}\text { Date } \\
\text { Prepared }\end{array}$ & Date Analyzed & $\begin{array}{c}\text { Target } \\
\text { Concentration } \\
(\mathbf{m g} / \mathbf{m L})\end{array}$ & $\begin{array}{c}\text { Determined } \\
\text { Concentration } \\
(\mathbf{m g} / \mathbf{m L})\end{array}$ & $\begin{array}{c}\text { Difference from } \\
\text { Target } \\
\mathbf{( \% )}\end{array}$ \\
\hline July 19, 2010 & 60 & 60.2 & 0 \\
& July 20, 2010 & 60 & 60.2 & 0 \\
& 60 & 60.4 & +1 \\
& 130 & 130.3 & 0 \\
& 200 & 207.3 & +4 \\
& July 27, 2010 & 200 & 206.5 & +3 \\
& 200 & 204.5 & +2 \\
& 60 & 59.8 & 0 \\
& August 24, & 130 & 129.7 & +3 \\
& $2010^{\mathrm{c}}$ & 200 & $75.0^{\mathrm{d}}$ & +25 \\
& 60 & $78.5^{\mathrm{d}}$ & +31 \\
& & $156.3^{\mathrm{d}}$ & +20 \\
& 60 & $143.9^{\mathrm{d}}$ & +11 \\
& 130 & 209.4 & +5 \\
& 130 & 202.6 & +1 \\
\hline
\end{tabular}

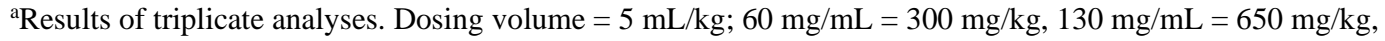

$200 \mathrm{mg} / \mathrm{mL}=1,000 \mathrm{mg} / \mathrm{kg}$.

${ }^{\mathrm{b}}$ For the 60 and $200 \mathrm{mg} / \mathrm{mL}$ dose formulations, the triplicate results are for homogeneity analyses from samples collected from the top, middle, and bottom of each vessel.

${ }^{\mathrm{c}}$ Animal room samples.

${ }^{\mathrm{d}}$ Formulation was outside the acceptable range of $\pm 10 \%$ of target concentration but determined to not affect the quality or integrity of the study. 
Table A-4. Results of Analyses of Dose Formulations Administered to Female Rats in the Prenatal Developmental Toxicity Gavage Study of Tris(chloropropyl) Phosphate

\begin{tabular}{|c|c|c|c|c|}
\hline Date Prepared & Date Analyzed & $\begin{array}{c}\text { Target } \\
\text { Concentration } \\
(\mathrm{mg} / \mathrm{mL})\end{array}$ & $\begin{array}{c}\begin{array}{c}\text { Determined } \\
\text { Concentration } \\
\text { (mg/mL) }\end{array} \\
\end{array}$ & $\begin{array}{c}\text { Difference } \\
\text { from Target } \\
(\%) \\
\end{array}$ \\
\hline \multirow[t]{6}{*}{ January 20, 2012} & January 20, 2012 & 32.5 & 32.8 & +1 \\
\hline & & 65 & 64.7 & 0 \\
\hline & & 130 & 130.9 & +1 \\
\hline & February $9,2012^{b}$ & 32.5 & 30.5 & -6 \\
\hline & & 65 & 55.2 & -15 \\
\hline & & 130 & 123.2 & -5 \\
\hline \multirow[t]{6}{*}{ February 2, 2012} & February 2, 2012 & 32.5 & 32.2. & -1 \\
\hline & & 65 & 64.2 & -1 \\
\hline & & 130 & 130.3 & 0 \\
\hline & February 16, 2012 & 32.5 & 28.7 & -12 \\
\hline & & 65 & 57.4 & -12 \\
\hline & & 130 & 126.7 & -3 \\
\hline \multirow[t]{6}{*}{ February 8, 2012} & February 8, 2012 & 32.5 & 32.9 & +1 \\
\hline & & 65 & 62.5 & -4 \\
\hline & & 130 & 125.8 & -3 \\
\hline & February 21, 2012 & 32.5 & 31.0 & -5 \\
\hline & & 65 & 61.1 & -6 \\
\hline & & 130 & 126.9 & -2 \\
\hline
\end{tabular}

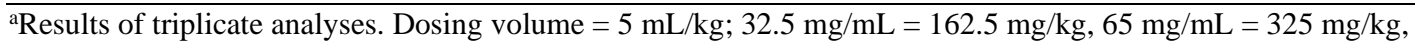
$130 \mathrm{mg} / \mathrm{mL}=650 \mathrm{mg} / \mathrm{kg}$.

bAnimal room samples. 
Tris(Chloropropyl) Phosphate, NTP DART 01

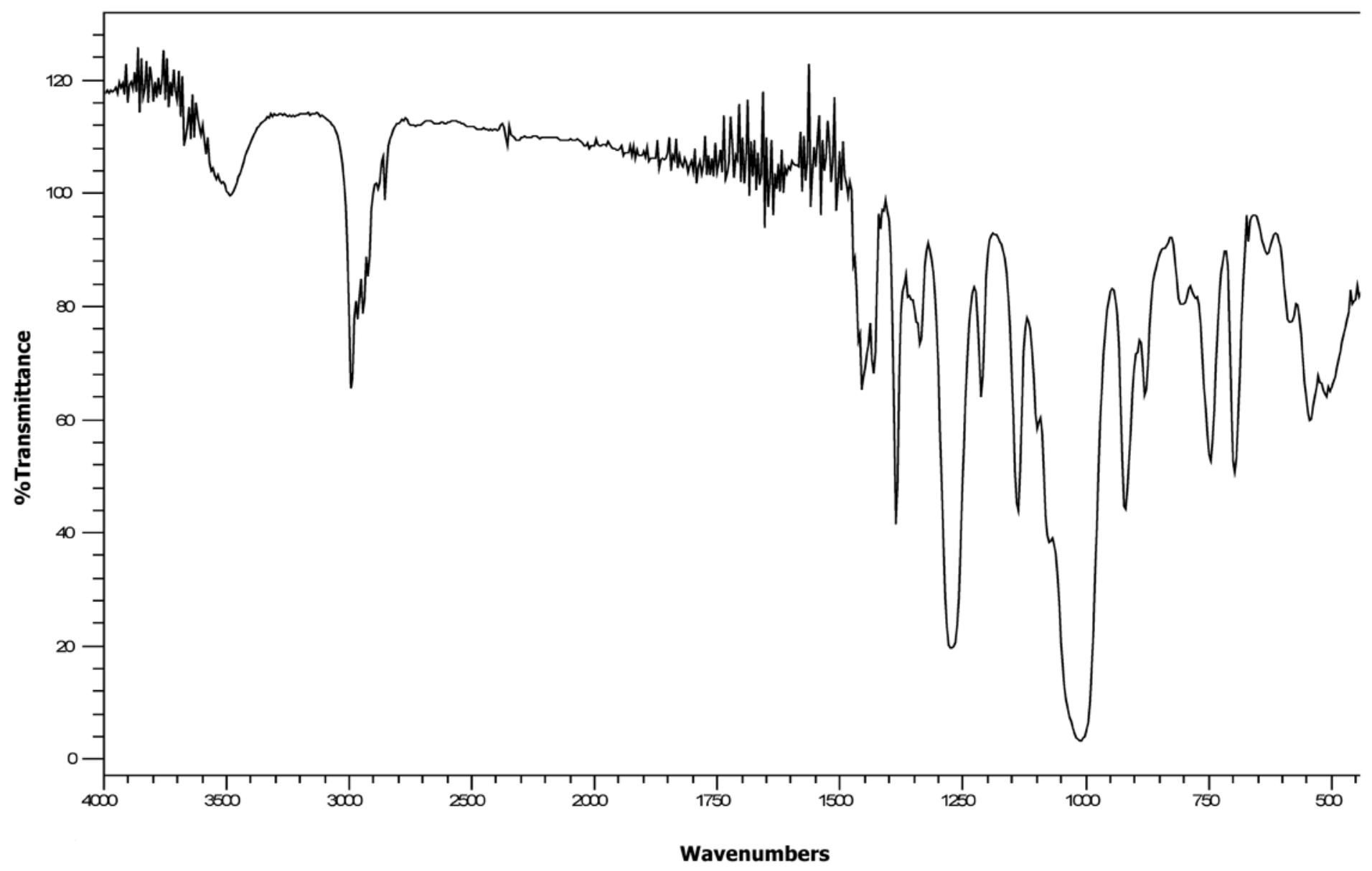

Figure A-1. Fourier Transform Infrared Absorption Spectrum of Tris(chloropropyl) Phosphate 
Tris(Chloropropyl) Phosphate, NTP DART 01

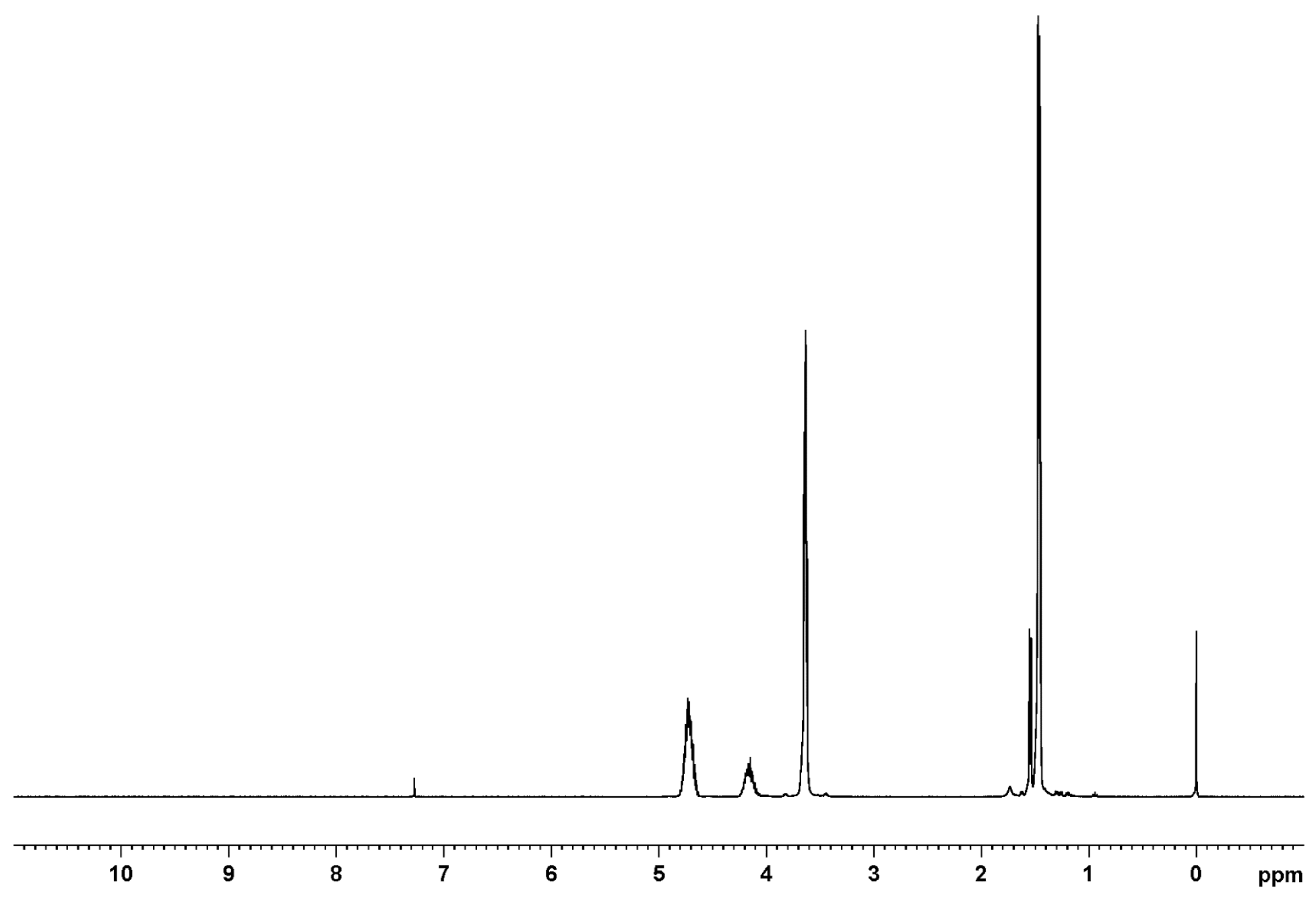

Figure A-2. Proton Nuclear Magnetic Resonance Spectrum of Tris(chloropropyl) Phosphate 


\section{Appendix B. Ingredients, Nutrient Composition, and Contaminant Levels in NIH-07 Rat and Mouse Ration}

\section{Tables}

Table B-1. Ingredients of NIH-07 Rat and Mouse Ration...................................................2

Table B-2. Vitamins and Minerals in NIH-07 Rat and Mouse Ration .....................................3

Table B-3. Nutrient Composition of NIH-07 Rat and Mouse Ration ..........................................

Table B-4. Contaminant Levels in NIH-07 Rat and Mouse Ration.............................................6 
Tris(Chloropropyl) Phosphate, NTP DART 01

Table B-1. Ingredients of NIH-07 Rat and Mouse Ration

\begin{tabular}{lc}
\hline \multicolumn{1}{c}{ Ingredients } & Percent by Weight \\
\hline Ground \#2 Yellow Shelled Corn & 24.50 \\
Ground Hard Winter Wheat & 23.00 \\
Soybean Meal (49\% Protein) & 12.0 \\
Fish Meal (60\% Protein) & 10.0 \\
Wheat Middlings & 10.0 \\
Alfalfa Meal (Dehydrated, 17\% Protein) & 4.0 \\
Soy Oil (Without Preservatives) & 2.5 \\
Dried Brewer's Yeast & 2.0 \\
Calcium Phosphate, Dibasic (USP) & 1.3 \\
Calcium Carbonate (USP) & 0.5 \\
Sodium Chloride & 0.5 \\
Premixes (Vitamin and Mineral) & 0.25 \\
Choline Chloride (70\% Choline) & 0.09 \\
\hline USP = United States Pharmacopeia. &
\end{tabular}


Tris(Chloropropyl) Phosphate, NTP DART 01

Table B-2. Vitamins and Minerals in NIH-07 Rat and Mouse Ration ${ }^{\mathrm{a}}$

\begin{tabular}{lcl}
\hline & Amount & \multicolumn{1}{c}{ Source } \\
\hline Vitamins & & \\
$\mathrm{A}$ & $6,062 \mathrm{IU}$ & Stabilized vitamin A palmitate or acetate \\
$\mathrm{D}$ & $5,070 \mathrm{IU}$ & D-activated animal sterol \\
$\mathrm{K}$ & $3.09 \mathrm{mg}$ & Menadione sodium bisulfite complex \\
$\mathrm{E}$ & $22 \mathrm{IU}$ & $\alpha$-Tocopheryl acetate \\
Niacin & $33 \mathrm{mg}$ & \\
Folic Acid & $2.4 \mathrm{mg}$ & - \\
$D$-Pantothenic Acid & $19.8 \mathrm{mg}$ & $d$-Calcium pantothenate \\
Riboflavin & $3.8 \mathrm{mg}$ & \\
Thiamin & $11 \mathrm{mg}$ & Thiamine mononitrate \\
B 12 & $50 \mathrm{Hg}$ & \\
Pyridoxine & $6.5 \mathrm{mg}$ & Pyridozine hydrochloride \\
Biotin & $0.15 \mathrm{mg}$ & $d$-Biotin \\
\hline Minerals & & \\
Iron & $132 \mathrm{mg}$ & Iron sulfate \\
Zinc & $18 \mathrm{mg}$ & Zinc oxide \\
Manganese & $66 \mathrm{mg}$ & Manganese oxide \\
Copper & $4.4 \mathrm{mg}$ & Copper sulfate \\
Iodine & $1.5 \mathrm{mg}$ & Calcium iodate \\
Cobalt & $0.44 \mathrm{mg}$ & Cobalt carbonate \\
\hline U & &
\end{tabular}

IU = international unit.

${ }^{\text {aPer }} \mathrm{kg}$ of finished product. 
Tris(Chloropropyl) Phosphate, NTP DART 01

Table B-3. Nutrient Composition of NIH-07 Rat and Mouse Ration

\begin{tabular}{|c|c|c|c|}
\hline Nutrient & Mean \pm Standard Deviation & Range & Number of Samples \\
\hline Protein (\% by Weight) & 24.7 & 24.7 & 1 \\
\hline Crude Fat (\% by Weight) & 5.6 & 5.6 & 1 \\
\hline Crude Fiber (\% by Weight) & 3.42 & 3.42 & 1 \\
\hline Ash (\% by Weight) & 7.17 & 7.17 & 1 \\
\hline \multicolumn{4}{|c|}{ Amino Acids (\% of Total Diet) } \\
\hline Arginine & $1.374 \pm 0.049$ & $1.31-1.43$ & 5 \\
\hline Cysteine & $0.325 \pm 0.029$ & $0.29-0.372$ & 5 \\
\hline Glycine & $1.120 \pm 0.041$ & $1.06-1.16$ & 5 \\
\hline Histidine & $0.504 \pm 0.008$ & $0.49-0.51$ & 5 \\
\hline Isoleucine & $0.973 \pm 0.018$ & $0.95-0.99$ & 5 \\
\hline Leucine & $1.982 \pm 0.036$ & $1.93-2.02$ & 5 \\
\hline Lysine & $1.250 \pm 0.039$ & $1.22-1.32$ & 5 \\
\hline Methionine & $0.485 \pm 0.011$ & $0.46-0.49$ & 5 \\
\hline Phenylalanine & $1.086 \pm 0.017$ & $1.07-1.11$ & 5 \\
\hline Threonine & $0.907 \pm 0.024$ & $0.88-0.94$ & 5 \\
\hline Tryptophan & $0.274 \pm 0.014$ & $0.26-0.29$ & 5 \\
\hline Tyrosine & $0.871 \pm 0.017$ & $0.85-0.89$ & 5 \\
\hline Valine & $1.120 \pm 0.022$ & $1.11-1.16$ & 5 \\
\hline \multicolumn{4}{|c|}{ Essential Fatty Acids (\% of Total Diet) } \\
\hline Linoleic & $2.23 \pm 0.223$ & $2.04-2.59$ & 5 \\
\hline Linolenic & $0.24 \pm 0.0249$ & $0.22-0.28$ & 5 \\
\hline \multicolumn{4}{|l|}{ Vitamins } \\
\hline Vitamin A (IU/kg) & 5,350 & 5,350 & 1 \\
\hline Vitamin D (IU/kg) & $1,000^{\mathrm{a}}$ & - & - \\
\hline$\alpha$-Tocopherol (ppm) & $73.72 \pm 4.40$ & $69.5-78.7$ & 5 \\
\hline Thiamine (ppm) ${ }^{\mathrm{b}}$ & 16 & 16 & 1 \\
\hline Riboflavin (ppm) & $14.42 \pm 3.64$ & $10-19.8$ & 5 \\
\hline Niacin (ppm) & $95.96 \pm 7.28$ & $87-106$ & 5 \\
\hline Pantothenic Acid (ppm) & $45.26 \pm 1.487$ & $43.2-47.4$ & 5 \\
\hline Pyridoxine (ppm) ${ }^{b}$ & $11.96 \pm 1.948$ & $9.63-14.9$ & 5 \\
\hline Folic Acid (ppm) & $2.39 \pm 0.439$ & $1.69-2.74$ & 5 \\
\hline Biotin (ppm) & $0.3 \pm 0.0463$ & $0.25-0.37$ & 5 \\
\hline Vitamin $\mathrm{B}_{12}(\mathrm{ppb})$ & $49.28 \pm 8.364$ & 41.8-61.6 & 5 \\
\hline
\end{tabular}


Tris(Chloropropyl) Phosphate, NTP DART 01

\begin{tabular}{lccc}
\hline \multicolumn{1}{c}{ Nutrient } & Mean \pm Standard Deviation & Range & Number of Samples \\
\hline Minerals & & & \\
Calcium (\%) & 1.260 & 1.260 & 1 \\
Phosphorus (\%) & 0.967 & 0.967 & 1 \\
Potassium (\%) & $0.814 \pm 0.035$ & $0.769-0.865$ & 5 \\
Chloride (\%) & $0.572 \pm 0.076$ & $0.441-0.628$ & 5 \\
Sodium (\%) & $0.344 \pm 0.018$ & $0.318-0.365$ & 5 \\
Magnesium (\%) & $0.182 \pm 0.006$ & $0.174-0.192$ & 5 \\
Iron (ppm) & $394.8 \pm 38.848$ & $348-455$ & 5 \\
Manganese (ppm) & $86.2 \pm 4.77$ & $80.7-93.2$ & 5 \\
Zinc (ppm) & $64.66 \pm 14.521$ & $52.4-89.2$ & 5 \\
Copper (ppm) & $13.12 \pm 0.949$ & $11.9-14.1$ & 5 \\
Iodine (ppm) & $1.876 \pm 0.986$ & $0.8-3.45$ & 5 \\
Chromium (ppm) & $1.304 \pm 0.225$ & $0.97-1.59$ & 5 \\
Cobalt (ppm) & $0.532 \pm 0.179$ & $0.25-0.73$ & 5 \\
\hline
\end{tabular}

$\mathrm{IU}=$ international unit.

${ }^{\mathrm{a}}$ From formulation.

${ }^{\mathrm{b}}$ As hydrochloride (thiamine and pyridoxine). 
Tris(Chloropropyl) Phosphate, NTP DART 01

Table B-4. Contaminant Levels in NIH-07 Rat and Mouse Ration ${ }^{\mathrm{a}}$

\begin{tabular}{|c|c|c|c|}
\hline & Mean \pm Standard Deviation ${ }^{b}$ & Range & Number of Samples \\
\hline \multicolumn{4}{|l|}{ Contaminants } \\
\hline Arsenic (ppm) & 0.587 & 0.587 & 1 \\
\hline Cadmium (ppm) & 0.096 & 0.096 & 1 \\
\hline Lead (ppm) & 0.106 & 0.106 & 1 \\
\hline Mercury (ppm) & 0.016 & 0.016 & 1 \\
\hline Selenium (ppm) & 0.488 & 0.488 & 1 \\
\hline Aflatoxins (ppb) & $<5.00$ & - & 1 \\
\hline Nitrate Nitrogen (ppm) ${ }^{c}$ & $<10.0$ & - & 1 \\
\hline Nitrite Nitrogen $(\mathrm{ppm})^{\mathrm{c}}$ & $<0.61$ & - & 1 \\
\hline BHA (ppm) $)^{\mathrm{d}}$ & $<1.0$ & - & 1 \\
\hline BHT (ppm) ${ }^{\mathrm{d}}$ & $<1.0$ & - & 1 \\
\hline Aerobic Plate Count (CFU/gm) & $<10$ & - & 1 \\
\hline Coliform (MPN/gm) & $<3$ & - & 1 \\
\hline Escherichia coli (MPN/gm) & $<10$ & - & 1 \\
\hline Salmonella (MPN/gm) & Negative & - & 1 \\
\hline Total Nitrosamines (ppb) ${ }^{e}$ & 8.2 & 8.2 & 1 \\
\hline$N$-Nitrosodimethylamine (ppb) & 1.1 & 1.1 & 1 \\
\hline$N$-Nitrosopyrrolidine (ppb) ${ }^{\mathrm{e}}$ & 7.1 & 7.1 & 1 \\
\hline \multicolumn{4}{|l|}{ Pesticides (ppm) } \\
\hline$\alpha-\mathrm{BHC}$ & $<0.01$ & - & 1 \\
\hline$\beta$-BHC & $<0.02$ & - & 1 \\
\hline$\gamma$-BHC & $<0.01$ & - & 1 \\
\hline$\delta$-BHC & $<0.01$ & - & 1 \\
\hline Heptachlor & $<0.01$ & - & 1 \\
\hline Aldrin & $<0.01$ & - & 1 \\
\hline Heptachlor Epoxide & $<0.01$ & - & 1 \\
\hline DDE & $<0.01$ & - & 1 \\
\hline DDD & $<0.01$ & - & 1 \\
\hline DDT & $<0.01$ & - & 1 \\
\hline НCB & $<0.01$ & - & 1 \\
\hline Mirex & $<0.01$ & - & 1 \\
\hline Methoxychlor & $<0.05$ & - & 1 \\
\hline Dieldrin & $<0.01$ & - & 1 \\
\hline Endrin & $<0.01$ & - & 1 \\
\hline Telodrin & $<0.01$ & - & 1 \\
\hline
\end{tabular}


Tris(Chloropropyl) Phosphate, NTP DART 01

\begin{tabular}{lccc}
\hline & Mean \pm Standard Deviation & Range & Number of Samples \\
\hline Chlordane & $<0.05$ & - & 1 \\
Toxaphene & $<0.10$ & - & 1 \\
Estimated PCBs & $<0.20$ & - & 1 \\
Ronnel & $<0.01$ & - & 1 \\
Ethion & $<0.02$ & - & 1 \\
Trithion & $<0.05$ & - & 1 \\
Diazinon & $<0.10$ & - & 1 \\
Methyl Chlorpyrifos & 0.0706 & - & 1 \\
Methyl Parathion & $<0.02$ & - & 1 \\
Ethyl Parathion & $<0.02$ & 0.0295 & 1 \\
Malathion & 0.0295 & - & 1 \\
Endosulfan I & $<0.01$ & - & 1 \\
Endosulfan II & $<0.01$ & - & 1 \\
Endosulfane Sulfate & $<0.03$ & 1 \\
\hline
\end{tabular}

BHA = butylated hydroxyanisole; $\mathrm{BHT}$ = butylated hydroxytoluene; CFU = colony-forming units; MPN = most probable number; BHC = hexachlorocyclohexane or benzene hexachloride; DDE = dichlorodiphenyldichloroethylene;

DDD = dichlorodiphenyldichloroethane; DDT = dichlorodiphenyltrichloroethane; HCB = hexachlorobenzene; PCB = polychlorinated biphenyl; PCB = polychlorinated biphenyl .

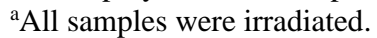

${ }^{\mathrm{b}}$ For values less than the limit of detection, the detection limit is given as the mean.

'Sources of contamination: alfalfa, grains, and fish meal.

dSources of contamination: soy oil and fish meal.

eAll values were corrected for percent recovery. 


\section{Appendix C. Sentinel Animal Program}

\section{Table of Contents}

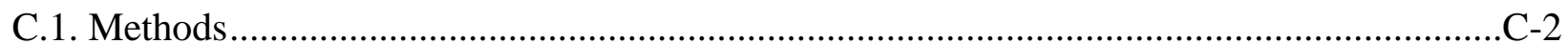

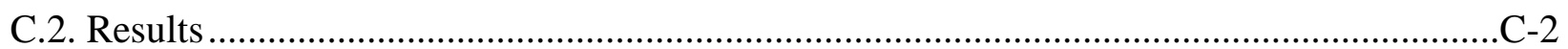

Tables

Table C-1. Laboratory Methods and Agents Tested for in the Sentinel Animal Program ..........C-2 


\section{C.1. Methods}

Rodents used in the National Toxicology Program are produced in optimally clean facilities to eliminate potential pathogens that could affect study results. The Sentinel Animal Program is part of the periodic monitoring of animal health that occurs during the toxicological evaluation of test compounds. Under this program, the disease state of the rodents is monitored via sera or feces from extra (sentinel) or dosed animals in the study rooms. The sentinel animals and the study animals are subject to identical environmental conditions. Furthermore, the sentinel animals come from the same production source and weanling groups as the animals used for the studies of test compounds.

Blood samples were collected and allowed to clot, and the serum was separated. All samples were processed appropriately and tested at the Research Animal Diagnostic Laboratory (RADIL), University of Missouri (Columbia, MO) for determination of the presence of pathogens. The laboratory methods and agents for which testing was performed are tabulated below; the times at which samples were collected during the study are also listed.

Blood was collected from five female rats per time of collection for the prenatal developmental toxicity study.

Table C-1. Laboratory Methods and Agents Tested for in the Sentinel Animal Program

\begin{tabular}{ll}
\hline \multicolumn{1}{c}{ Method and Test } & \multicolumn{1}{c}{ Time of Collection } \\
\hline Multiplex Fluorescent Immunoassay & \\
H-1 (Toolan's H-1 virus) & Arrival, study termination \\
KRV (Kilham rat virus) & Arrival, study termination \\
Mycoplasma pulmonis & Arrival, study termination \\
PVM (pneumonia virus of mice) & Arrival, study termination \\
RCV/SDA (rat coronavirus/sialodacryoadenitis virus) & Arrival, study termination \\
RMV (rat minute virus) & Arrival, study termination \\
RPV (rat parvovirus) & Arrival, study termination \\
RTV (rat theilovirus) & Arrival, study termination \\
Sendai & Arrival, study termination \\
TMEV (Theiler's murine encephalomyelitis virus) & Arrival, study termination \\
\hline
\end{tabular}

\section{C.2. Results}

All test results were negative. 


\section{Appendix D. Summary of Peer Review Panel Comments}

\section{Table of Contents}

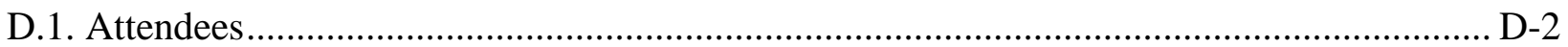

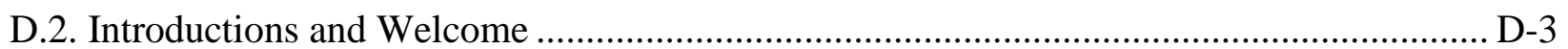

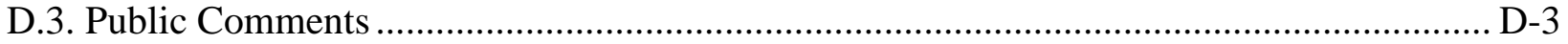

D.4. Background and Charge to the Panel..................................................................... D-3

D.5. Prenatal Developmental Toxicity Studies of Tris(chloropropyl) Phosphate .................... D-4

D.6. Prenatal Developmental Toxicity Studies of 4-Methylcyclohexanemethanol................... D-6

D.7. Prenatal Developmental Toxicity Studies of Vinpocetine ......................................... D-10

D.8. Prenatal Developmental Toxicity Studies of Dimethylaminoethanol Bitartrate ............. D-13

D.9. Closing Remarks on the Draft Reports ...................................................................... D-14

D.10. Approval of the Peer Review Report by the Chair of the Peer Review Panel.............. D-15 


\section{D.1. Attendees}

\section{Peer Review Panel}

Chair: George Daston, The Procter and Gamble Company

Cheryl Broussard, Centers for Disease Control and Prevention

Alan Hoberman, Charles River Laboratories Preclinical Services

Linda Roberts, NapaTox Consulting LLC

Mary Alice Smith, University of Georgia

Kimberley Treinen, Sunovion Pharmaceuticals Inc.

National Toxicology Program Board of Scientific Counselors Liaison

Donald Stump, Charles River Laboratories International

\section{National Institute of Environmental Health Sciences Staff}

Brian Berridge

Chad Blystone

Bradley Collins

Michelle Cora

Helen Cunny

Shawn Harris

Michelle Hooth

Angela King-Herbert

Elizabeth Maull, Designated Federal Official

Barry McIntyre

Georgia Roberts

Kristen Ryan

Sheena Scruggs

Keith Shockley

Matthew Stout

Vicki Sutherland

Nigel Walker 
AtLee Watson

Mary Wolfe

\section{Other Federal Agency Staff}

Gonçalo Gamboa, FDA

\section{Contract Support Staff}

Susan Blaine, ICF

Dave Burch, ICF

Lindsey Green, ICF

Ernie Hood, Bridport Services

Steve McCaw, Image Associates

Blake Riley, ICF

Samantha Snow, ICF

\section{D.2. Introductions and Welcome}

The National Toxicology Program (NTP) convened a peer review panel for the draft NTP Developmental and Reproductive Toxicity Technical Reports on the Prenatal Development Studies of Tris(chloropropyl) Phosphate, 4-Methylcyclohexanemethanol, Vinpocetine, and Dimethylaminoethanol Bitartrate on July 31, 2019, in Conference Room F193, Rall Building, National Institute for Environmental Health Sciences (NIEHS), Research Triangle Park, North Carolina (or via webcast).

- Dr. George Daston, panel chair, called the meeting to order at 8:30 a.m., welcomed everyone to the meeting, asked all attendees to introduce themselves, and reviewed the format for the peer review meeting for the panel and audience.

- Dr. Elizabeth Maull read the conflict of interest policy statement and briefed the attendees on meeting logistics.

- Dr. Donald Stump attended as the liaison to the NTP Board of Scientific Counselors.

\section{D.3. Public Comments}

Dr. Daston noted that no written public comments or requests for oral public comments on the draft technical reports had been received.

\section{D.4. Background and Charge to the Panel}

Dr. Chad Blystone gave a brief presentation on NTP draft technical reports, including information about the levels of evidence for developmental toxicity. He also described the 
Developmental and Reproductive Toxicity (DART) historical controls and the charge to the panel for the individual peer reviews:

- Review and evaluate the scientific and technical elements of each study and its presentation.

- Determine whether each study's experimental design, conduct, and findings support NTP's conclusions regarding the developmental toxicity of the substances tested.

\section{D.5. Prenatal Developmental Toxicity Studies of Tris(chloropropyl) Phosphate}

\section{D.5.1. Presentation and Clarifying Questions}

Dr. Kristen Ryan summarized the studies and conclusions reported in the draft NTP Developmental and Reproductive Toxicity Technical Report on the Prenatal Development Studies of Tris(chloropropyl) Phosphate (CASRN 13674-84-5) in Sprague Dawley (Hsd:Sprague Dawley ${ }^{\circledR} S D^{\circledR}$ ) Rats (Gavage Studies).

Tris(chloropropyl) phosphate (TCPP) is a flame retardant found in a variety of commercial and consumer products. It is ubiquitous but not bioaccumulative in the environment. Exposure can occur via dermal, oral, or inhalation routes. TCPP is a mixture constituted primarily of four isomers; the research focus is often on the primary isomer due to its abundance. The test article used for the NTP studies contained all four isomers. The goal of this study was to characterize the effects of TCPP exposure on pregnant rats and developing fetuses.

The dose range-finding study was conducted in 11 time-mated female rats using doses of 0,300 , 650 , and $1,000 \mathrm{mg} / \mathrm{kg} / \mathrm{day}$, administered via gavage. Adverse signs at $1,000 \mathrm{mg} / \mathrm{kg} / \mathrm{day}$ occurred throughout gestation. These results informed the use in the main study of doses of $0,162.5,325$, and $650 \mathrm{mg} / \mathrm{kg} /$ day in 25 time-mated female rats per group. An additional 25 control dams were added to this study to supplement historical control data for maternal and fetal findings. The main study findings revealed:

- No maternal treatment-related effects on mortality or body weights during gestation

o Clinical observations were of low incidence and limited to the $650 \mathrm{mg} / \mathrm{kg} /$ day group

o At $650 \mathrm{mg} / \mathrm{kg} /$ day, absolute and relative liver weights were increased approximately $26 \%$

- No treatment-related effects on uterine or litter parameters, such as implantations, litter size, live fetuses per litter, or fetal weight

- Fetal skeletal malformations of limited toxicological relevance (e.g., lumbar rudimentary ribs) or those that occurred as single or sporadic incidence

Under the conditions of this prenatal study, NTP's draft conclusion was:

- No evidence of developmental toxicity of TCPP in Hsd:Sprague Dawley rats administered $162.5,325$, or $650 \mathrm{mg} / \mathrm{kg} /$ day in the absence of overt maternal toxicity

There were no clarifying questions or comments about the presentation. 


\section{D.5.2. Peer Review Comments and Panel Discussion}

\section{D.5.2.1. First Reviewer - Dr. Cheryl Broussard}

Dr. Broussard indicated that the study was clearly described, well conducted, and the conclusions followed logically from the presented findings. She agreed with NTP's draft conclusions. Dr. Broussard then recommended adding language explaining the rationale for limiting soft tissue examination to only $50 \%$ of the heads. She also requested that NTP clarify more specifically where the audit procedures and findings were located to aid in transparency. The comments regarding soft tissue allocations and audit procedures applied to all reports. Finally, Dr. Broussard questioned why blood was not collected from the dams for clinical pathology.

- Dr. Ryan noted that the allocation for fetal exams was based on the study guidelines, with every other fetus allocated for head examination. She agreed that NTP could consider adding more information on fetal exam allocations and the use and location of the audit procedures and findings, which are archived electronically, to the reports.

- Dr. Ryan stated that blood chemistry was not typically required in this type of study. Furthermore, these endpoints were not identified in the literature as a primary concern for TCPP exposure.

\section{D.5.2.2. Second Reviewer - Dr. Alan Hoberman}

Dr. Hoberman stated that the study was well conducted, and he did not disagree with the conclusion. However, he noted that the only individual data presented in the reports were fetal data and that the public would benefit from having access to all individual animal data. This comment applied to all reports. The presence or absence of deviations should be included in the report. The historical control data lacked information on postimplantation loss percentages as well as other fetal information. The report failed to comment on an earlier study by Kawasaki (1982) that noted an increase in cervical ribs. Although Dr. Hoberman understood the use of two control groups, he noted that inclusion of group variations would have been informative. He also noted that this class of compound is known to produce enlarged livers, which may be considered an adaptive change rather than maternal toxicity. Because NTP referenced the changes in liver weights, the authors must have considered that the change in weight represented some sort of system perturbation. He recommended adding some discussion detailing why the enlarged liver was not considered as maternal toxicity.

In response to Dr. Hoberman's comments, Dr. Ryan indicated:

- NTP would consider adding language to the report specifying the location of the individual animal data.

- Deviations are listed in the good laboratory practices report. NTP would consider adding a line to the main report such as "no other deviations were noted."

- NTP is currently evaluating the historical control data and will be adding information (i.e., fetal and uterine parameters) to the database. Postimplantation loss observed in this study was limited to a single litter and was not considered an exposure-related finding.

- NTP evaluates cervical ribs as part of the fetal examinations. Although an increase in cervical ribs had been observed in the Kawasaki study, they were not seen in the NTP 
study, and, therefore, not populated in the historical control database. This information could be added.

- $\quad$ She reviewed the cross-reference data from dams to fetuses from the two control groups prior to the data being pooled and found that there were comparable findings in both control groups.

- NTP chose to report that no developmental toxicity was observed in the absence of overt maternal toxicity in this study and indicated that NTP would consider adding language to clarify the issues related to enlarged liver in the discussion.

\section{D.5.3. Vote on NTP Conclusion}

Dr. Daston called for a motion from the panel to approve the conclusion as written. Dr. Hoberman so moved and Dr. Kimberley Treinen seconded the motion. The panel voted unanimously (5 yes, 0 no, 0 abstentions) to approve the conclusion as written.

\section{D.6. Prenatal Developmental Toxicity Studies of 4-Methylcyclohexanemethanol}

\section{D.6.1. Presentation and Clarifying Questions}

Dr. AtLee Watson summarized the studies and conclusions reported in the draft NTP Developmental and Reproductive Toxicity Technical Report on the Prenatal Developmental Toxicity Studies of 4-Methylcyclohexanemethanol (CASRN 34885-03-5) in Sprague Dawley (Hsd:Sprague Dawley ${ }^{\circledR} S D^{\circledR}$ ) Rats (Gavage Studies).

4-Methylcyclohexanemethanol (MCHM) was the chemical involved in the 2014 Elk River Chemical Spill in West Virginia. An estimated 10,000 gallons of crude MCHM leaked into the river, contaminated the municipal water supply, and likely led to human exposure. This prenatal developmental toxicity study resulted from concern for women of childbearing potential and developing embryos/fetuses, and provided an opportunity to evaluate the adequacy of the 1 part per million advisory level set forth by the Centers for Disease Control and Prevention (CDC) and the Agency for Toxic Substances and Disease Registry (ATSDR) for MCHM in drinking water.

The dose range-finding study tested doses of $0,150,300,600$, and $900 \mathrm{mg} / \mathrm{kg} / \mathrm{day}$ in groups of 10 time-mated female rats each and examined maternal and fetal endpoints. In this study, exposure to 600 and $900 \mathrm{mg} / \mathrm{kg} /$ day resulted in dose-related mortality and clinical observations of toxicity. These results informed the selection of doses of $0,50,100,200$, and $400 \mathrm{mg} / \mathrm{kg} / \mathrm{day}$ for the main study in 25 time-mated female rats per group. Main study findings included:

- Reduced maternal serum total protein and globulin at doses $\geq 100 \mathrm{mg} / \mathrm{kg} /$ day

- Fetal findings at $400 \mathrm{mg} / \mathrm{kg} /$ day:

o Decreased fetal body weights (15\%) and gravid uterine weight (18\%) compared with controls

o Increased incidences of malformations of the axial skeleton

o Misshapen adrenal glands (malformation)

- No exposure-related fetal findings at doses $\leq 200 \mathrm{mg} / \mathrm{kg} / \mathrm{day}$ 
Under the conditions of this prenatal study, NTP's draft conclusion was:

- Clear evidence of developmental toxicity of MCHM in Hsd:Sprague Dawley rats at $400 \mathrm{mg} / \mathrm{kg} /$ day in the absence of overt maternal toxicity based on findings of:

o Reduced fetal weight

o Malformations of the axial skeleton

o Malformations of the adrenal glands

As a follow-up to the presentation, panelists had the following clarifying questions and discussion:

\section{Topic - Malformation of the adrenal glands}

- Dr. Linda Roberts asked for a description of the criteria for classifying the adrenal glands as misshapen.

- Dr. Hoberman asked if histopathology is routinely performed when necrotic masses are observed on adrenal glands. Although this finding appeared in three fetuses from different litters, the genealogy of the litters was unknown, which may play a role in the occurrence rate. Responding to a question posed by Dr. Roberts, Dr. Hoberman stated he could not recall ever seeing a misshapen adrenal with a necrotic mass. Dr. Sutherland agreed that it was an unusual finding.

o Dr. Watson indicated that the misshapen adrenal designation was attributed to the presence of a necrotic mass on the adrenal glands.

o Dr. Watson stated that while histopathology could inform whether the occurrence of a necrotic mass on the adrenal gland represents a permanent change or would alter postnatal or subsequent development, guideline prenatal developmental toxicity studies do not routinely call for it.

\section{Topic - Clinical chemistry endpoints}

- Dr. Daston inquired if the clinical chemistry findings on glucose, triglycerides, and blood urea nitrogen levels were also observed in other subchronic MCHM studies or if the changes in the clinical chemistry endpoints were specific to the pregnancy in the rat.

o Dr. Watson noted that there was a decrease in some of the red blood cells in the repeat dose oral gavage study that was conducted by the Eastman Chemical Company. He indicated that Eastman Chemical Company did not observe the same glucose findings.

\section{Topic - Potential MCHM review article}

- Dr. Daston noted that NTP played a significant role in quickly developing information on MCHM and wondered if there will be a larger synthesis of information based on this and other recently conducted studies. He added that there would be interest in these types of summary reports from people who were exposed and who had made health decisions based on what the scientific community conveyed to them. The current report format may be difficult for the general public to understand given the dry and science-based conclusions they contain. 
o Dr. Watson indicated that NTP's website currently has summary findings, but the development of a report summarizing all MCHM-related NTP studies would be addressed in subsequent NTP discussions.

o Dr. Blystone noted that prior communications to the stakeholders were less dry and more informal.

\section{D.6.2. Peer Review Comments and Panel Discussion}

\section{D.6.2.1. First Reviewer - Dr. Mary Alice Smith}

Dr. Smith indicated that the study was designed and conducted according to accepted DART guidelines. She stated that the findings in the study, including reduced fetal weight, adrenal malformations, and increased malformations of the axial skeleton, support the conclusion of clear evidence of developmental toxicity of MCHM in the fetuses from dams exposed to $400 \mathrm{mg} / \mathrm{kg} /$ day. Dr. Smith recommended adding historical normal pregnant rat clinical chemistry ranges (as reported for human studies) to the report, which would help interpret the exposurerelated data. Adding to this comment, Dr. Daston asked if some of the qualitative statements on clinical chemistry endpoints found in the report might be expanded on to put this type of data in context. Dr. Smith recommended that the report clearly state that the dose-related changes are significantly different from the controls based on a dose-related trend or a pairwise comparison effect and to include this type of information in the conclusion statements. Finally, she requested inclusion of a 2018 human epidemiology study investigating the possible association of adverse birth defects with exposure to crude MCHM from the spill site.

- Dr. Michelle Cora, NTP Clinical Pathologist, responding to the clinical chemistry questions, noted that currently NTP does not have historical control data for pregnant rats. She added that reporting values from the study's controls are preferred over those of historical controls due to the number of uncontrolled variables (i.e., animal diet, conditions of the study, type of machine the samples were run on) that influence historical control data. She added that the range for clinical chemistry data indicated in these reports is typically the standard error. Expansion beyond qualitative statements would not be feasible.

- Dr. Watson agreed that inclusion of dose-related response in the fetal body weight conclusion would improve the comprehension of the data but was concerned that it could overcomplicate the conclusion statement. He indicated that NTP would consider implementing this recommendation if it could be done in a concise manner.

- Dr. Watson indicated that he would incorporate the 2018 study, which found no adverse birth outcomes following the spill, in the report's discussion.

\section{D.6.2.2. Second Reviewer - Dr. Cheryl Broussard}

Dr. Broussard found the study design clearly described and well conducted, and that the conclusions followed logically from the presented findings. She agreed with the draft conclusion of clear evidence of developmental toxicity. She suggested adding the rationale for why approximately $50 \%$ of the heads were examined for soft tissue alterations, as well as being more transparent about where to find the audit procedures and findings. She wondered whether the Sentinel Animal Program described in some of the other reports was relevant here also. 
- Dr. Watson replied:

o NTP would add the rationale to the methodology section of the report.

o Given the short duration of these studies, a Sentinel Animal Program is not required. The dams received by the lab underwent a full evaluation by the staff animal veterinarian before they were cleared to be included in the study. That information is included in the report.

\section{D.6.2.3. Third Reviewer - Dr. Linda Roberts}

Dr. Roberts indicated that the studies were conducted properly and agreed, with a single caveat, with the NTP conclusion. She was not as confident with a classification of "clear evidence" versus "some or equivocal" evidence based on the absence of statistical significance in misshapen adrenal glands in the historical controls. The strongest evidence for developmental toxicity was the reduction in fetal body weight. To clarify Dr. Roberts' comments, Dr. Daston asked her to confirm that she thought there was clear evidence that MCHM causes developmental effects based on fetal weight and skeletal malformations, but not changes in adrenal malformation. Dr. Roberts confirmed that this was a correct interpretation of her thoughts.

Dr. Roberts also expressed appreciation that the fetal no-observed-effect level (NOEL) was included in the report and noted that the maternal NOEL of $50 \mathrm{mg} / \mathrm{kg} / \mathrm{day}$ was based on the clinical chemistry endpoints. She stated that although there was statistical significance in these endpoints, she was less confident that there was biological significance.

- Dr. Watson agreed that additional information discriminating between structural malformations and alterations that might affect postnatal development would be useful to help understand the significance of the effect. It was difficult to confirm whether there was a pairwise significant difference in the highest dose group for this finding due to the very low incidences. Dr. Watson noted that NTP takes litter incidence into account. The fact that the findings occurred in three single fetuses from three separate litters support the conclusion that the adrenal malformation was a treatment-related effect.

\section{D.6.2.4. Panel Discussion}

Dr. Kimberley Treinen questioned the choice of reporting NOEL for maternal toxicity rather than the no-observed-adverse-effect level (NOAEL). She mentioned that the entire call was characterized as being "in the absence of overt maternal toxicity," by which she assumes to be a NOAEL. Dr. Treinen also recommended adding a line to the summary table correcting for uterine weight. She noted that the study reported high nonpregnancy rates, along with a high rate of misshapen aortic valves. She would like to have seen a lower background rate, given concern about cardiovascular malformations in the controls. The relatively large increase in the axial skeletal malformations with limited variations in other endpoints was an unusual finding. Dr. Treinen recommended that further elaboration is needed in the report to describe the misshapen adrenal glands, perhaps by providing images, given that this is an unusual finding. Dr. Daston agreed that this issue needs more attention in the report. 
- Dr. Watson indicated that NTP avoided distinguishing between adverse and nonadverse effects. Using the NOEL designation avoided some of the close calls that would have been generated by using NOAEL.

- $\quad$ Dr. Vicki Sutherland noted:

o NTP would consider adding language to the tables as recommended.

o At the time of the study, there was a concern about successful pregnancy rates, which has since improved with increased training, suggesting this was not a strain-related effect. NTP uses the same strain across all its studies.

o NTP will consider directing the lab to follow up with histopathology in the future if this finding is present. NTP will also ascertain if this finding is specific to this strain of rat.

Dr. Daston noted that the significant decrease in dam body weight with a significant increase in food consumption was a remarkable finding that, combined with the findings on blood glucose, suggests something interesting going on beyond general maternal toxicity-something that may yield an indication of a mechanism of action. The phenomenon deserved more treatment in the report.

- Dr. Watson said that data from a MCHM toxicogenomics study suggested that fatty acid metabolism may be involved as a mechanism of action. He indicated that NTP would add a discussion to the report.

- Dr. Cora remarked that although she thought the change in blood glucose levels was real, the rats would not be considered hypoglycemic, and the mild decrease is seen with some frequency. She said the triglycerides were affected by what the dams were eating and when they had last ingested food.

\section{D.6.3. Vote on NTP Conclusion}

Dr. Daston called for a motion to accept the conclusion as written, understanding that there would be information added to the report on the adrenal malformations. Dr. Roberts said she would prefer that the reference to adrenal gland malformations be removed from the conclusion. Dr. Smith moved to accept the conclusion as written and Dr. Broussard seconded. The panel passed the motion (4 yes, 1 no, 0 abstentions). Dr. Roberts voted no, citing her discomfort with including the adrenal malformations as the reason for her vote.

\section{D.7. Prenatal Developmental Toxicity Studies of Vinpocetine}

\section{D.7.1. Presentation and Clarifying Questions}

Dr. Sutherland summarized the studies and conclusions reported in the draft NTP Developmental and Reproductive Toxicity Technical Report on the Prenatal Developmental Toxicity Studies of Vinpocetine (CASRN 42971-09-5) in Sprague Dawley (Hsd:Sprague Dawley ${ }^{\circledR} S D^{\circledR}$ ) Rats and New Zealand White (Hra:NZW SPF) Rabbits (Gavage Studies).

Vinpocetine is marketed as a dietary supplement for cognitive enhancement. It is also a semisynthetic/synthetic pharmaceutical agent for treatment of cerebrovascular and cognitive disorders. NTP chose to study vinpocetine due to concerns of consumer exposure through dietary 
supplement use, signals of developmental toxicity in the literature, and lack of adequate toxicity data.

The rat dose range-finding study used doses of $0,20,40,80,160$, or $320 \mathrm{mg} / \mathrm{kg} /$ day via gavage, with 10 time-mated female rats per group. A dose-related decrease in maternal body weight correlated with fetal loss at the higher two doses in this study. These results informed the selection of doses of $0,5,20$, and $60 \mathrm{mg} / \mathrm{kg} /$ day for the main study in 25 time-mated female rats per group. Findings from the main study included:

- Dose-related increase in the incidence of vaginal discharge (20 and $60 \mathrm{mg} / \mathrm{kg} /$ day)

- Decreased maternal body weight

- Exposure-related increases in postimplantation loss (83\% at $60 \mathrm{mg} / \mathrm{kg} /$ day)

- Fetal examination findings such as:

o Increased incidences of fetuses with ventral septal defect (malformation)

o Increased incidences of incomplete ossification of the thoracic centra (variation) and full thoracolumbar ribs (malformation)

The above findings provided sufficient concern to examine the effects of vinpocetine in a second species, the rabbit. The dosages chosen for the rabbit study were $0,25,75,150$, and $300 \mathrm{mg} / \mathrm{kg} / \mathrm{day}$, administered via gavage to eight time-mated female animals per group. The main rabbit study findings revealed:

- Decreased maternal body weight gains at 150 and $300 \mathrm{mg} / \mathrm{kg} / \mathrm{day}$

- Exposure-related effect on embryo-fetal survival at $300 \mathrm{mg} / \mathrm{kg} / \mathrm{day}$

Data from the rabbit study supported the findings observed in the rat dose range-finding study and rat prenatal developmental toxicity studies.

Under the conditions of the rat prenatal study, NTP's draft conclusion was:

- Clear evidence of developmental toxicity of vinpocetine in Hsd:Sprague Dawley rats in the absence of overt maternal toxicity based on findings of:

o Increased postimplantation loss

o Increased incidences of ventricular septum defects

o Increased incidences of thoracolumbar ribs (full)

o Increased incidences of incomplete ossification of the thoracic centrum

As a follow-up to the presentation, participants had the following clarifying question and discussion:

Topic - No-observed-effect levels

- Dr. Roberts noted that the study did not include NOEL values and asked whether that was intentional.

o Dr. Sutherland responded that NTP had internal discussion about the language; if the panel feels that NOELs should be included in all the reports, the team will consider modifying the text. 


\section{D.7.2. Peer Review Comments and Panel Discussion}

\section{D.7.2.1. First Reviewer - Dr. Alan Hoberman}

Dr. Hoberman expressed appreciation to NTP for completing the study of this dietary supplement, approved performing the studies in both the rat and rabbit, and overall agreed with the conclusion. He recommended that individual animal data be made available for this report and all other studies and thought that including the onset and duration for clinical signs, such as vaginal discharge, could be informative. Recognizing that the studies were hazard assessments and not risk assessments, Dr. Hoberman also thought it would be beneficial to report how the animal doses in the study compared with human doses.

Dr. Sutherland responded:

- The individual data are available online and indicated that NTP would consider how to make access more apparent in the reports.

- The vaginal discharge data did not directly correlate with embryonic loss.

- NTP considered risk assessment information outside the scope of this report.

\section{D.7.2.2. Second Reviewer - Dr. Linda Roberts}

Dr. Roberts commented that the study was well conducted and appreciated that a second species was included. She said that the body weight gain seen did not meet the criteria for overt maternal toxicity. She agreed with the clear evidence conclusion as written.

\section{D.7.2.3. Third Reviewer - Dr. Kimberley Treinen}

Dr. Treinen recommended that an additional line be added to the summary table with corrected numbers for maternal body weight. She noted that there was a comment made in the rabbit study that food consumption might have contributed to the body weight decrement, but it appeared that it was more attributable to the decrease in implants.

In response to Dr. Treinen's comments, Dr. Sutherland indicated:

- NTP would consider adding corrected body weight in the text and tables if that would add clarity.

- The food consumption was not directly correlated to embryonic loss.

\section{D.7.2.4. Other Comments}

Dr. Gonçalo Gamboa, FDA, thanked NTP for keeping the FDA apprised as to the results. He noted that FDA released a statement cautioning women of childbearing ages from consuming this chemical. He appreciated the good communication.

\section{D.7.3. Vote on NTP Conclusion}

Dr. Daston asked for a motion and second from the panel to approve the conclusion as written. Dr. Roberts so moved and Dr. Hoberman seconded the motion. The panel voted unanimously (5 yes, 0 no, 0 abstentions) to approve the conclusion as written. 


\section{D.8. Prenatal Developmental Toxicity Studies of Dimethylaminoethanol Bitartrate}

\section{D.8.1. Presentation and Clarifying Questions}

Dr. Sutherland summarized the studies and conclusions reported in the draft NTP Developmental and Reproductive Toxicity Technical Report on the Prenatal Developmental Toxicity Studies of Dimethylaminoethanol Bitartrate (CASRN 5988-51-2) in Sprague Dawley (Hsd:Sprague Dawley ${ }^{\circledR} S{ }^{\circledR}$ ) Rats (Gavage Studies).

Dimethylaminoethanol bitartrate (DMAE) is a close structural analog of the essential nutrient choline. It is marketed as a dietary supplement to improve memory and general cognitive function. NTP chose to study DMAE because of its potential for widespread human exposure through its use in industrial and consumer products and limited evidence from the literature that it may be a teratogen and reproductive toxicant.

The dose range-finding study used doses of $0,250,500$, and $1,000 \mathrm{mg} / \mathrm{kg} /$ day via gavage, with 10 time-mated female rats per group. No maternal or fetal toxicity were present at the doses used in the range-finding study. The same doses were employed in the main study, which used 25 time-mated female rats per group. Findings from the main study revealed:

- No treatment-related effects on mortality, body weights, or feed consumption o Effects were sporadic or without a dose response

- No effects on uterine or litter parameters such as implantations, litter size, live fetuses per litter, or fetal weight

- Fetal examination findings of:

o Increased incidence of short thoracolumbar ribs (a variation) at the $1,000 \mathrm{mg} / \mathrm{kg} /$ day dose

o Increased incidence in the number of supernumerary sites, or ossification sites, in the skull at the $1,000 \mathrm{mg} / \mathrm{kg} / \mathrm{day}$ dose

Under the conditions of this prenatal study, NTP's draft conclusion was:

- Equivocal evidence of developmental toxicity of DMAE in Hsd:Sprague Dawley rats in the absence of overt maternal toxicity based on increased incidences of:

o Short thoracolumbar ribs

o Supernumerary sites in the skull

There were no clarifying questions or comments about the presentation.

\section{D.8.2. Peer Review Comments and Panel Discussion}

\section{D.8.2.1. First Reviewer - Dr. Kimberley Treinen}

Dr. Treinen commented that the study was well conducted and met the standard for this type of study. She wondered why the absent innominate artery in the high-dose group was not considered a finding, even though it was statistically different from controls and was present across multiple litters. When combined with short innominate arteries, it potentially looked like a 
dose-related effect. Dr. Hoberman commented that the absent innominate artery is a very common variation. However, he added that it and other similar variations do seem to indicate a perturbation in the system and should be investigated.

Dr. Treinen recommended breaking down the historical controls rather than lumping them together.

Dr. Sutherland noted that the absent innominate artery is an extremely common finding and therefore was not included as a potential toxicity endpoint.

\section{D.8.2.2. Second Reviewer - Dr. Mary Alice Smith}

Dr. Smith thought that the maternal death in the $1,000 \mathrm{mg} / \mathrm{kg} /$ day dose group raised a question and recommended adding more historical control data in the report. She remarked that there was not a lot of evidence for dose-related outcomes in this study. In addition, Dr. Smith cautioned against concluding that there were no brain effects and recommended qualifying the statement by indicating that there were no lesions noted in the brain because functional outcomes were not evaluated. Dr. Smith said that it should be made clear that there were no structural changes in the brain.

Dr. Sutherland responded to Dr. Smith:

- More historical control data would be helpful.

- NTP only looked for structural changes in the brain. NTP will ensure that it is clear that there were no structural changes in the brain in the revised report.

- Individual data tables were available, but NTP needs to consider how to make them easier to access.

- The primary report focused on bringing forward positive findings; therefore, negative findings were not highlighted. She mentioned that this distinction would be clarified in the report.

\section{D.8.2.3. Panel Discussion}

Dr. Roberts indicated that the innominate artery finding should have received more attention in the report. Dr. Sutherland asked if she was suggesting more detail in the discussion or an addition to the conclusion. Dr. Roberts responded both.

\section{D.8.3. Vote on NTP Conclusion}

Dr. Daston proposed adding a third bullet to the draft NTP conclusion to read "increased incidence of absent innominate artery." He called for a motion to add the bullet to the NTP conclusion. Dr. Treinen so moved and Dr. Smith seconded. Dr. Daston called for a vote on the conclusion, including the addition. The panel voted unanimously (5 yes, 0 no, 0 abstentions) to approve the conclusion with the addition.

\section{D.9. Closing Remarks on the Draft Reports}

Dr. Daston welcomed additional panel comments on the overall organization of the reports. Dr. Hoberman suggested clarifying the definition of the term "natural death" used throughout the reports. 
Dr. Sutherland noted that they would revise the term to "found dead" in the reports.

Dr. Treinen recommended that litter data, as well as individual data, be added to the reports or compiled as a stand-alone report to assist with understanding the rate of resorptions and other important fetal findings. Dr. Hoberman added that it was standard to have that type of information in a toxicology report.

Dr. Blystone remarked that NTP could explore adding some of the selected endpoints in an appendix.

Dr. Roberts appreciated having the pharmacokinetic information in the report along with its relevance to humans. She added that the value of including the NOEL eliminates the possibility of other researchers calculating their own NOEL based on the data in the report.

Closing the meeting, Dr. Maull thanked all the peer review panelists.

Dr. Daston added his thanks to NTP staff and the panel members for their efforts.

Dr. Daston adjourned the meeting at 11:22 a.m. EDT on July 31, 2019.

\section{D.10. Approval of the Peer Review Report by the Chair of the Peer Review Panel}

This peer review report has been read and approved by the chair of the July 31, 2019, Peer Review of the draft NTP Developmental and Reproductive Toxicity Technical Reports on the Prenatal Development Studies of Tris(chloropropyl) Phosphate, 4-Methylcyclohexanemethanol, Vinpocetine, and Dimethylaminoethanol Bitartrate.

George Daston, Ph.D.

Peer Review Panel Chair

Date: July 31, 2019 


\section{Appendix E. Supplemental Files}

The following supplemental data files are available at http://dx.doi.org/10.22427/NTP-DATADART-01.

\section{E.1. Prenatal Developmental Toxicity Dose Range-finding Study - Rats}

I01 - Animal Removal Summary

I03 - Growth Curve

I04 - Mean Body Weights and Survival

I04G - Mean Body Weight Gain

I05 - Clinical Observations Summary

I06 - Mean Feed Consumption

PA46 - Gross Pathology Summary

R09 - Uterine Content Summary

R10 - Fetal Defects

R11 - Fetal Defect Summary

R13 - Fetal Defect Cross Reference Summary

\section{E.2. Prenatal Developmental Toxicity Dose Range-finding Individual Animal Data - Rats}

Individual Animal Body Weight Data

Individual Animal Clinical Observations Data

Individual Animal Consumption Data

Individual Animal Gross Pathology Data

Individual Animal Removal Reasons

Individual Animal Teratology Dam Data

Individual Animal Teratology Implant Data

\section{E.3. Prenatal Developmental Toxicity Study - Rats}

I01 - Animal Removal Summary 


\author{
I03 - Growth Curve \\ I04 - Mean Body Weights and Survival \\ I04G - Mean Body Weight Gain \\ I05 - Clinical Observations Summary \\ I06 - Mean Feed Consumption \\ PA06 - Organ Weights Summary \\ PA46 - Gross Pathology Summary \\ R09 - Uterine Content Summary \\ R10 - Fetal Defects \\ R11 - Fetal Defect Summary \\ R13 - Fetal Defect Cross Reference Summary
}

\title{
E.4. Prenatal Developmental Toxicity Individual Animal Data - Rats
}

Individual Animal Body Weight Data

Individual Animal Clinical Observations Data

Individual Animal Consumption Data

Individual Animal Gross Pathology Data

Individual Animal Organ Weight Data

Individual Animal Removal Reasons

Individual Animal Teratology Dam Data

Individual Animal Teratology Implant Data 


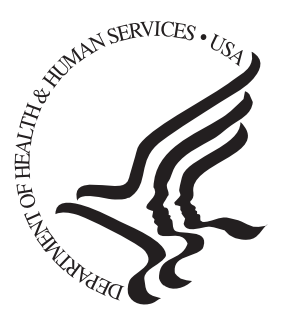

\section{National Toxicology Program}

NTP Central Data Management, MD EC-03

National Institute of Environmental Health Sciences

P.O. Box 12233

Research Triangle Park, NC 27709

http://ntp.niehs.nih.gov 